\title{
Catalysis with Phosphine Containing Amino Acids in Various Turn Motifs
}

Anton Agarkov ${ }^{\mathrm{a}}$, Scott J. Greenfield ${ }^{\mathrm{a}}$, Takahiro Ohishi ${ }^{\mathrm{a}}$, Scott E. Collibee ${ }^{\mathrm{a}}$ and Scott R. Gilbertson $^{\mathrm{b} *}$

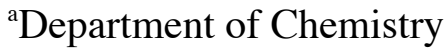

Washington University

One Brookings Drive

Saint Louis Missouri, 63130-4899

${ }^{\mathrm{b}}$ Chemical Biology Program

Pharmacology and Toxicology

The University of Texas Medical Branch

301 University Blvd.

Galveston Texas, 77555-0650

\section{Supplementary Material;}

General procedures. ${ }^{1} \mathrm{H},{ }^{13} \mathrm{C},{ }^{31} \mathrm{P}$ and ${ }^{29} \mathrm{Si}$ NMR spectra were recorded on either a Varian Unity 300 or Unity 600 at ambient temperature. Infrared spectra were obtained using a Perkin Elmer Spectrum BX FT-IR System spectrophotometer; infrared spectra of solid samples were obtained by the diffuse reflectance technique using $\mathrm{KBr}$ powder or an abrasive pad. Flash chromatography was performed on ICN silica gel $60 \AA$ (32-63 D). Thin layer chromatography (TLC) was carried out on Whatman polyester plates coated with $0.25 \mathrm{~mm}$ of silica gel 60 Fluorescence $\mathrm{UV}_{254}$. Mass spectra (MS) were obtained from the Mass Spectrometry Center of Washington University.

Materials and reagents. All reagents were used directly as obtained commercially unless otherwise stated. Tetrahydrofuran (THF) and ethylene glycol dimethyl ether (DME) were distilled from sodium benzophenone ketyl. Dichloromethane and acetonitrile were distilled from calcium hydride. Toluene was distilled from sodium. Dimethyl formamide (DMF) and 1-methyl-2-pyrrolidinone (NMP) were treated with 
DOWEX 50WX8-200 ion-exchange resin and stored over 4 $\mathrm{A}$ molecular sieves. L-4-cisHydroxyproline ${ }^{1}$, diphenylphosphine sulfide ${ }^{2}$, Fmoc- $N-\operatorname{Pps}(P S)-\mathrm{OH}^{3,4}$, ditolylchloro phosphine $^{5}$, difurylchlorophosphine ${ }^{6}$, dibenzophosphole chloride ${ }^{7}$ were prepared according to published literature procedures.

General procedure for solid phase peptide library synthesis. The peptides were synthesized simultaneously on SynPhase ${ }^{\mathrm{TM}}$ crowns. The support consists of a methacrylic acid/dimethylacrylamide copolymer on a polyethylene crown. The surface of each crown was loaded with $\sim 7.0 \square \mathrm{mol}$ of a Fmoc-protected Rink amide handle. The crowns were attached to stems and inserted into a 96-unit pin holder. Before each coupling step, the crowns were submerged for 30 min in $20 \%$ solution of piperidine in DMF. After Fmoc deprotection, the crowns were washed for $5 \mathrm{~min}$ in $\mathrm{DMF}, \mathrm{MeOH}, \mathrm{CH}_{2} \mathrm{Cl}_{2}, \mathrm{MeOH}$, DMF (total washing time $25 \mathrm{~min}$ ). Next, the wells of $96-$ well microtiter plate were loaded with a solution of amino acid (5 eq.), HOBt (5 eq.), DIC (5 eq.) in $0.45 \mathrm{~mL}$ of DMF. The crowns attached to the holder were inserted into the microtiter plate. Each well of the plate contained the appropriate reagents and acted as individual reaction vessel. The time for each coupling step was $3 \mathrm{~h}$. After coupling, the crowns were washed briefly with DMF, $\mathrm{MeOH}, \mathrm{CH}_{2} \mathrm{Cl}_{2}$, and Fmoc-deprotection was initiated again. After the elongation of the peptide was completed, terminal acetylation was performed by treating the crowns with freshly prepared 5\% solution of acetic anhydride in DMF for 15 min.

\section{General procedure for the phosphine reduction and preparation of the palladium}

catalyst. The peptide containing crown (capacity $\sim 7.0 \square \mathrm{mol} /$ crown) was placed in a standard $20 \mathrm{~mL}$ scintillation vial. A septum was fitted over the top of the vial and was secured with copper wire and parafilm ${ }^{\circledR}$. A $18 \mathrm{G}$ needle was inserted into each vial, and 
all vials were placed into a vacuum desiccator. The desiccator was evacuated and filled with nitrogen. The desiccator was opened, and the needles were quickly removed from all vials. A solution of methyl triflate (5.0 $\square \mathrm{L}, 5.0$ eq.) in $2.5 \mathrm{~mL}$ of $\mathrm{CH}_{2} \mathrm{Cl}_{2}$ was added in each vial. The vials were placed on an orbital shaker and shaken overnight at $150 \mathrm{rpm}$. Next day the crowns were washed with $\mathrm{CH}_{2} \mathrm{Cl}_{2}(2 \times 3.0 \mathrm{~mL})$ and THF $(2 \times 3.0 \mathrm{~mL})$, and then treated with a solution of HMPT (10.0 $\square \mathrm{L}, 5.0 \mathrm{eq})$ in $2.0 \mathrm{ml}$ of THF for $2 \mathrm{~h}$. The crowns were washed with THF $(2 \times 3.0 \mathrm{~mL})$ and $\mathrm{CH}_{3} \mathrm{CN}(2 \times 3.0 \mathrm{~mL})$, and then treated with $1.0 \mathrm{~mL}$ (1.0 eq.) of a freshly made $0.0035 \mathrm{M}$ solution of $[\mathrm{Pd}(\mathrm{allyl}) \mathrm{Cl}]_{2}$ in $\mathrm{CH}_{3} \mathrm{CN}$ for 15 min. After this time the crown turned yellow.

General method for solution phase peptide synthesis and phosphine deprotection. To a Boc-protected amino acid in DCM was added 1.5 equiv. of PyBOP and an ammonium salt of an amino ester. 3 equiv. of DIPEA were added and the reaction was allowed to stir for 30 minutes. The reaction mixture was then washed with $3 \mathrm{~N} \mathrm{HCl}$, sat. sodium bicarb., and brine. The DCM solution was dried with $\mathrm{Na}_{2} \mathrm{SO}_{4}$, filtered, concentrated and chromatographed on silica gel. The Boc-methyl ester protected dipeptide was then treated with a 50\% solution of TFA in DCM until complete removal of the Boc group as judged by TLC. The reaction mixture was then concentrated, dissolved in toluene and concentrated, dissolved in chloroform and concentrated and finally dissolved in DCM and concentrated before drying in-vacuo for 30 minutes. This coupling/deprotection sequence was repeated until the desired peptide was attached.

General method for the desulfurization of the phosphine sulfides in solution. 10 $\square \mathrm{mol}$ of the bis-phosphine ligands were treated with $400 \mathrm{mg}$ of Raney-Ni* in $\mathrm{MeCN}$ 
(under $\mathrm{N}_{2}$ ) for 2 hours (6-membered ring) or until complete by TLC (5-membered ring). The Raney-Ni was allowed to settle and the solution was syringe filtered into a schlenk tube. The Raney-Ni was washed with MeCN 3 X $3 \mathrm{~mL}$ and syringe filtered into the schlenk tube and concentrated in-vacuo.

"Prior to deprotection, the Raney-Ni slurry was washed with $\mathrm{MeOH}$ until the $\mathrm{MeOH}$ was clear and then washed with $\mathrm{MeCN} 3 \mathrm{X}$.

General procedure for the allylic alkylation reaction. In a Schlenk tube a solution of the nucleophile was prepared by mixing dimethyl malonate $(57.2 \square \mathrm{L})$ and BSA (123.6 $\square \mathrm{L}$ ) in $2.0 \mathrm{~mL}$ of $\mathrm{CH}_{3} \mathrm{CN}$ followed by addition of $0.5 \mathrm{~mL}$ TBAF (1M solution in THF). After the TBAF addition, a slightly exothermic reaction occurs, so the mixture was allowed to cool to room temperature. Cyclopentenyl acetate $(20 \square \mathrm{L})$ was added to a vial containing the crown and $[\mathrm{Pd}(\text { allyl }) \mathrm{Cl}]_{2}$ solution. After $2-3 \mathrm{~min}$. $2.0 \mathrm{~mL}$ of the nucleophile solution was added, and the vial was shaken overnight at room temperature. The next day the reaction was checked by $\mathrm{TLC}\left(\mathrm{Et}_{2} \mathrm{O} /\right.$ pentane $\left.=1: 10\right)$. The septum was removed, and $2.0 \mathrm{~mL}$ of $2 \mathrm{M}$ aqueous $\mathrm{NH}_{4} \mathrm{Cl}$ was added. The reaction was extracted with $\mathrm{CH}_{2} \mathrm{Cl}_{2}(3 \times 3.0 \mathrm{ml})$. The combined organic extracts were dried over $\mathrm{Na}_{2} \mathrm{SO}_{4}$ and concentrated under reduced pressure. If the TLC showed the presence of the starting material, $\mathrm{CDCl}_{3}$ was added, conversions were determined by ${ }^{1} \mathrm{H} \mathrm{NMR}$, and the mixture was concentrated again. If no starting material was detected by TLC, a conversion greater than $95 \%$ was assumed. The crude product was purified by flash chromatography using a pipet filled with silica gel. After purification, solvents were removed and enantiomeric excess was determined. 
Procedure for determination of $e \boldsymbol{e}$ by ${ }^{1} \mathbf{H}$ NMR. The purified product was dissolved in $0.7 \mathrm{~mL}$ of $\mathrm{C}_{6} \mathrm{D}_{6}(99.5 \%)$, and ${ }^{1} \mathrm{H}$ NMR was recorded. From the obtained spectrum using residual protons of $\mathrm{C}_{6} \mathrm{D}_{6}$, approximate concentration of the product in the NMR sample was calculated, and if necessarily, the sample was diluted so that signals from the product's methyl groups were $\sim 20 \%$ compared to $\mathrm{C}_{6} \mathrm{H}_{6}$ signal. $100 \square \mathrm{L}$ of a saturated solution of $\mathrm{Eu}(\mathrm{hfc})_{3}$ in $\mathrm{C}_{6} \mathrm{D}_{6}$ was added to the sample, and the enantiomeric excess was determined by integration of signals from the methyl groups.

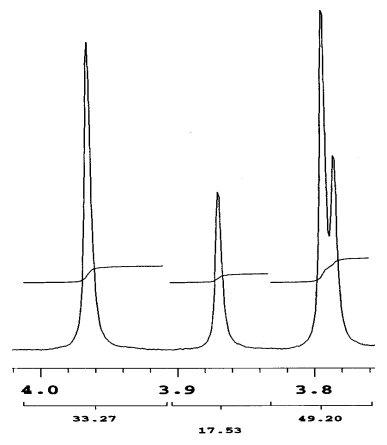

The results for both libraries reported in this paper are presented below.

Library 1; Members and results for Figure 3

\begin{tabular}{|l|c|c|c|c|c|c|c|c|}
\hline A01 & D-Ala & Pps & Pro & D-Ala & Pps & Gly & 75 & 99 \\
\hline A02 & D-Met & Pps & Pro & D-Ala & Pps & Gly & 58 & 83 \\
\hline A03 & D-Phg & Pps & Pro & D-Ala & Pps & Gly & 66 & 99 \\
\hline A04 & D-Val & Pps & Pro & D-Ala & Pps & Gly & 64 & 99 \\
\hline A05 & D-Phe & Pps & Pro & D-Ala & Pps & Gly & 62 & 99 \\
\hline A06 & Tyr & Pps & Pro & D-Ala & Pps & Gly & 68 & 99 \\
\hline A07 & Ala & Pps & Pro & D-Ala & Pps & Gly & 70 & 99 \\
\hline A08 & Ile & Pps & Pro & D-Ala & Pps & Gly & 56 & 99 \\
\hline A09 & Glu(gOBn) & Pps & Pro & D-Ala & Pps & Gly & 68 & 99 \\
\hline A10 & Tyr(gOtBu) & Pps & Pro & D-Ala & Pps & Gly & 68 & 99 \\
\hline A11 & Tyr & Pps & Pro & D-Ala & Pps & Gly & 68 & 77 \\
\hline A12 & Glu(gOtBu) & Pps & Pro & D-Ala & Pps & Gly & 66 & 99 \\
\hline B01 & BocCys(SBn) & Pps & Pro & D-Ala & Pps & Gly & 52 & 66 \\
\hline B02 & eBOC-Lys & Pps & Pro & D-Ala & Pps & Gly & 62 & 99 \\
\hline B03 & BocCys(SBn) & Pps & Pro & D-Ala & Pps & Gly & 64 & 99 \\
\hline B04 & Ser(OtBu) & Pps & Pro & D-Ala & Pps & Gly & 58 & 77 \\
\hline
\end{tabular}




\begin{tabular}{|c|c|c|c|c|c|c|c|c|}
\hline B05 & Trp(inBOC) & Pps & Pro & D-Ala & Pps & Gly & 66 & 99 \\
\hline B06 & Trp(inAc) & Pps & Pro & D-Ala & Pps & Gly & 67 & 99 \\
\hline \begin{tabular}{|l|} 
B07 \\
\end{tabular} & Gly & Pps & Pro & D-Ala & Pps & D-Ala & 68 & 99 \\
\hline B08 & Gly & Pps & Pro & D-Ala & Pps & D-Met & 38 & 99 \\
\hline B09 & Gly & Pps & Pro & D-Ala & Pps & D-Phe & 72 & 99 \\
\hline B10 & Gly & Pps & Pro & D-Ala & Pps & D-Val & 68 & 42 \\
\hline B11 & Gly & Pps & Pro & D-Ala & Pps & D-Phg & 74 & 96 \\
\hline B12 & Gly & Pps & Pro & D-Ala & Pps & D-Leu & 66 & 99 \\
\hline C01 & Gly & Pps & Pro & D-Ala & Pps & Ala & 64 & 88 \\
\hline C02 & Gly & Pps & Pro & D-Ala & Pps & Phe & 64 & 99 \\
\hline C03 & Gly & Pps & Pro & D-Ala & Pps & Ser(OtBu) & 72 & 99 \\
\hline C04 & Gly & Pps & Pro & D-Ala & Pps & Cys(StBu) & 34 & 67 \\
\hline \begin{tabular}{|l|}
$\mathrm{CO5}$ \\
\end{tabular} & Gly & Pps & Pro & D-Ala & Pps & Tyr(OtBu) & 63 & 99 \\
\hline C06 & Gly & Pps & Pro & D-Ala & Pps & Lys(eBOC) & 66 & 85 \\
\hline $\mathrm{CO7}$ & Gly & Pps & Pro & D-Ala & Pps & $\mathrm{Glu}(\mathrm{gOBn})$ & 50 & 99 \\
\hline C08 & Gly & Pps & Pro & D-Ala & Pps & Glu(gOtBu) & 67 & 99 \\
\hline C09 & D-Val & Pps & Pro & D-Ala & Pps & Phe & 66 & 99 \\
\hline C10 & D-Met & Pps & Pro & D-Ala & Pps & Ala & 67 & 99 \\
\hline C11 & D-Phg & Pps & Pro & D-Ala & Pps & D-Leu & 80 & 99 \\
\hline \begin{tabular}{|l|} 
C12 \\
\end{tabular} & Phg & Pps & Pro & D-Ala & Pps & $\mathrm{Ile}$ & 67 & 99 \\
\hline \begin{tabular}{|l|} 
D01 \\
\end{tabular} & Phe & Pps & Pro & D-Ala & Pps & Ile & 74 & 99 \\
\hline D02 & Tyr & Pps & Pro & D-Ala & Pps & Ala & 76 & 99 \\
\hline D03 & Cys(SBn) & Pps & Pro & D-Ala & Pps & Tyr & 74 & 99 \\
\hline \begin{tabular}{|l|} 
D04 \\
\end{tabular} & Cys(SBn) & Pps & Pro & D-Ala & Pps & D-Ala & 66 & 99 \\
\hline D05 & Phe & Pps & Pro & D-Ala & Pps & D-Phg & 70 & 99 \\
\hline D06 & Phg & Pps & Pro & D-Ala & Pps & Phe & 71 & 99 \\
\hline \begin{tabular}{|l|} 
D07 \\
\end{tabular} & Phg & Pps & Pro & D-Ala & Pps & D-Phe & 66 & 99 \\
\hline \begin{tabular}{|l|} 
D08 \\
\end{tabular} & Ser(OtBu) & Pps & Pro & D-Ala & Pps & Ser(OtBu) & 76 & 89 \\
\hline D09 & D-Val & Pps & Pro & D-Ala & Pps & Ile & 66 & 99 \\
\hline D10 & Lys(eBOC) & Pps & Pro & D-Ala & Pps & Tyr & 72 & 99 \\
\hline \begin{tabular}{|l|} 
D11 \\
\end{tabular} & Tyr & Pps & Pro & D-Ala & Pps & Cys(SBn) & 56 & 79 \\
\hline \begin{tabular}{|l|} 
D12 \\
\end{tabular} & Cys(SBn) & Pps & Pro & D-Ala & Pps & Cys(SBn) & 54 & 57 \\
\hline E01 & Tyr & Pps & Pro & D-Ala & Pps & Lys(eBOC) & 60 & 99 \\
\hline E02 & His(Mtt) & Pps & Pro & D-Ala & Pps & Tyr & 56 & 99 \\
\hline E03 & Cys(SBn) & Pps & Pro & D-Ala & Pps & Tyr & 71 & 99 \\
\hline E04 & Glu(gOBn) & Pps & Pro & D-Ala & Pps & Tyr & 66 & 89 \\
\hline E05 & Glu(gOtBu) & Pps & Pro & D-Ala & Pps & Tyr & 70 & 99 \\
\hline \begin{tabular}{|l|} 
E06 \\
\end{tabular} & $\operatorname{Trp}(\mathrm{Ac})$ & Pps & Pro & D-Ala & Pps & Tyr & 66 & 99 \\
\hline E07 & D-Ala & Pps & Pro & D-Ala & Pps & D-Ala & 72 & 99 \\
\hline E08 & D-Ala & Pps & Pro & D-Phe & Pps & D-Ala & 66 & 99 \\
\hline \begin{tabular}{|l|} 
E09 \\
\end{tabular} & D-Ala & Pps & Pro & D-Val & Pps & D-Ala & 76 & 99 \\
\hline E10 & D-Ala & Pps & Pro & D-Leu & Pps & D-Ala & 72 & 99 \\
\hline E11 & D-Ala & Pps & Pro & D-Met & Pps & D-Ala & 70 & 99 \\
\hline E12 & D-Ala & Pps & Pro & D-Phg & Pps & D-Ala & 60 & 99 \\
\hline \begin{tabular}{|l|} 
F01 \\
\end{tabular} & D-Ala & Pps & Pro & Gly & Pps & D-Ala & 61 & 99 \\
\hline \begin{tabular}{|l|} 
F02 \\
\end{tabular} & D-Ala & Pps & Pro & D-Ala & Pps & D-Ala & 65 & 99 \\
\hline F03 & D-Ala & Pps & Pro & D-Ala & Pps & Ala & 64 & 99 \\
\hline
\end{tabular}




\begin{tabular}{|c|c|c|c|c|c|c|c|c|}
\hline F04 & D-Met & Pps & Pro & D-Phg & Pps & Ala & 69 & 99 \\
\hline F05 & D-Val & Pps & Pro & D-Phg & Pps & Ala & 71 & 99 \\
\hline F06 & D-Phe & Pps & Pro & D-Phg & Pps & Ala & 66 & 65 \\
\hline F07 & Phe & Pps & Pro & D-Phg & Pps & Ala & 67 & 99 \\
\hline F08 & D-Leu & Pps & Pro & D-Phg & Pps & Ala & 64 & 49 \\
\hline F09 & Tyr & Pps & Pro & D-Phg & Pps & Ala & 67 & 83 \\
\hline F10 & Tyr(gOtBu) & Pps & Pro & D-Phg & Pps & Ala & 54 & 34 \\
\hline F11 & Glu(gOtBu) & Pps & Pro & D-Phg & Pps & Ala & 70 & 79 \\
\hline F12 & BocCys(SBn) & Pps & Pro & D-Phg & Pps & Ala & 57 & 43 \\
\hline G01 & D-Val & Pps & Pro & D-Leu & Pps & Phe & 66 & 99 \\
\hline G02 & D-Met & Pps & Pro & D-Leu & Pps & Ala & 60 & 36 \\
\hline G03 & D-Phg & Pps & Pro & D-Leu & Pps & D-Leu & 61 & 35 \\
\hline G04 & D-Phg & Pps & Pro & D-Leu & Pps & Ile & 70 & 89 \\
\hline G05 & Ser(OBn) & Pps & Pro & D-Leu & Pps & Ile & 60 & 99 \\
\hline G06 & Tyr & Pps & Pro & D-Leu & Pps & Tyr & 61 & 31 \\
\hline G07 & BocCys(SBn) & Pps & Pro & D-Leu & Pps & Ala & 66 & 27 \\
\hline G08 & BocCys(SBn) & Pps & Pro & D-Leu & Pps & D-Ala & 69 & 91 \\
\hline G09 & Phe & Pps & Pro & D-Leu & Pps & D-Met & 71 & 99 \\
\hline G10 & D-Met & Pps & Pro & D-Leu & Pps & Phe & 58 & 72 \\
\hline G11 & D-Met & Pps & Pro & D-Leu & Pps & D-Phe & 57 & 38 \\
\hline G12 & Ser(OtBu) & Pps & Pro & D-Leu & Pps & Ser(OtBu) & 68 & 75 \\
\hline $\mathrm{H} 01$ & D-Val & Pps & Pro & D-Leu & Pps & Ile & 70 & 99 \\
\hline $\mathrm{H} 02$ & Lys(eBOC) & Pps & Pro & D-Leu & Pps & Tyr & 70 & 99 \\
\hline $\mathrm{HO3}$ & Tyr & Pps & Pro & D-Leu & Pps & Cys(SBn) & & 36 \\
\hline \begin{tabular}{|l|}
$\mathrm{H} 04$ \\
\end{tabular} & Cys(SBn) & Pps & Pro & D-Leu & Pps & Cys(SBn) & 64 & 22 \\
\hline $\mathrm{H05}$ & Tyr & Pps & Pro & D-Leu & Pps & Lys(BOC) & 53 & 99 \\
\hline $\mathrm{H} 06$ & Gly & Pps & Pro & D-Ala & Pps & Gly & 70 & 99 \\
\hline $\mathrm{HO}$ & Gly & Pps & Pro & D-Phe & Pps & Gly & 69 & 99 \\
\hline $\mathrm{H} 08$ & Gly & Pps & Pro & D-Leu & Pps & Gly & 69 & 99 \\
\hline \begin{tabular}{|l|}
$\mathrm{H} 09$ \\
\end{tabular} & Gly & Pps & Pro & D-Met & Pps & Gly & 70 & 99 \\
\hline \begin{tabular}{|l|}
$\mathrm{H} 10$ \\
\end{tabular} & Gly & Pps & Pro & D-Val & Pps & Gly & 71 & 85 \\
\hline $\mathrm{H} 11$ & Gly & Pps & Pro & D-Phg & Pps & Gly & 51 & 67 \\
\hline \begin{tabular}{|l|}
$\mathrm{H} 12$ \\
\end{tabular} & Gly & Pps & Pro & Gly & Pps & Gly & 56 & 99 \\
\hline
\end{tabular}

Unless noted the isomer that was obtained has the $R$ configuration.

Library 2; Members and results for Figure 4

\begin{tabular}{|c|c|c|c|c|c|c|c|c|c|c|c|}
\multicolumn{10}{|c|}{ ee conversion } \\
\hline A1 & Ac & Gly & & Pps & Pro & D-Ala & Pps & Gly & & 74 & $>96$ \\
\hline A2 & NH2 & Gly & & Pps & Pro & D-Ala & Pps & Gly & & 75 & $>96$ \\
\hline A3 & Fmoc & Gly & & Pps & Pro & D-Ala & Pps & Gly & & 74 & $>96$ \\
\hline A4 & Boc? & Gly & & Pps & Pro & D-Ala & Pps & Gly & & 74 & $>96$ \\
\hline A5 & Ac & Gly & & Pps & & & Pps & Gly & & 3 & 45 \\
\hline A6 & Ac & Gly & & Pps & & D-Ala & Pps & Gly & $43($ S) & 31 \\
\hline A7 & Ac & Gly & Pps & Ala & Pro & D-Ala & Pps & Gly & 18 & 34 \\
\hline A8 & Ac & Gly & Pps & Pro & D-Ala & Ala & Pps & Gly & & 6 & 47 \\
\hline
\end{tabular}




\begin{tabular}{|c|c|c|c|c|c|c|c|c|c|c|c|}
\hline B1 & $A c$ & Gly & Pps & Pro & D-Ala & Gly & Pps & Gly & & 11 & 26 \\
\hline B2 & $A C$ & Gly & Pps & Pro & D-Pro & Gly & Pps & Gly & & 3 & 35 \\
\hline B3 & $A c$ & Gly & Pps & Pro & & Pro & Pps & Gly & & 1 & 21 \\
\hline B4 & $A C$ & Gly & Pps & Pro & & Tyr(t) & Pps & Gly & & 4 & 28 \\
\hline B5 & $A c$ & Gly & Pps & Pro & & $\operatorname{Ser}(t)$ & Pps & Gly & & $1(\mathrm{~S})$ & 43 \\
\hline B6 & $A c$ & Gly & Pps & D-Ala & Pro & Gly & Pps & Gly & & $3(S)$ & 55 \\
\hline B7 & $A c$ & Gly & Pps & Pro & Gly & D-Ala & Pps & Gly & & $2(S)$ & 37 \\
\hline B8 & $A c$ & Gly & & Pps & Pro & D-Ala & & Gly & & $1(S)$ & 3 \\
\hline C1 & $A C$ & Gly & & & Pro & D-Ala & Pps & Gly & & 31 & 34 \\
\hline C2 & $A c$ & & & Pps & Pro & D-Ala & Pps & Gly & & 74 & $>96$ \\
\hline C3 & $A C$ & D-Ala & & Pps & Pro & D-Ala & Pps & Gly & Gly & 75 & $>96$ \\
\hline C4 & $A c$ & D-Ala & D-Ala & Pps & Pro & D-Ala & Pps & Gly & & 67 & $>96$ \\
\hline C5 & $A c$ & Gly & & Pps & Pro & D-Ala & Pps & & & 71 & $>96$ \\
\hline C6 & $A c$ & Gly & & Pps & Pro & D-Ala & Pps & Gly & & 73 & $>96$ \\
\hline $\mathrm{C7}$ & $A c$ & Gly & & Pps & Pro & D-Ala & Pps & Gly & & 74 & 52 \\
\hline C8 & $A C$ & D-Phg & & Pps & Pro & D-Ala & Pps & D-Leu & & 74 & $>96$ \\
\hline D1 & $A c$ & Tyr & & Pps & Pro & D-Ala & Pps & Ala & & 71 & $>96$ \\
\hline D2 & Ac & D-Ala & & Pps & Pro & D-Val & Pps & D-Val & & 74 & $>96$ \\
\hline D3 & $A c$ & $\operatorname{Ser}(t)$ & & Pps & Pro & D-Ala & Pps & $\operatorname{Ser}(\mathrm{t})$ & & 72 & $>96$ \\
\hline D4 & $A c$ & D-Ala & & Pps & Pro & D-Ala & Pps & Gly & & 74 & $>96$ \\
\hline D5 & $A c$ & Phe & & Pps & Pro & D-Ala & Pps & Ile & & 74 & 81 \\
\hline D6 & $A c$ & Cys(Bn & & Pps & Pro & D-Ala & Pps & Tyr (t) & & 70 & $>96$ \\
\hline D7 & $A C$ & Gly & & Pps & Pro & D-Ala & Pps & D-Phg & & 71 & 76 \\
\hline D8 & $A c$ & Gly & & Pps & Pro & D-Phg & Pps & Gly & & 66 & 64 \\
\hline E1 & $A c$ & D-Ala & & Pps & Pro & D-Ala & Pps & D-Ala & & 74 & $>96$ \\
\hline E2 & $A c$ & D-Phg & & Pps & Pro & D-Val & Pps & D-Leu & & 80 & $>96$ \\
\hline E3 & $A c$ & Tyr (t) & & Pps & Pro & D-Ala & Pps & D-Ala & & 71 & 90 \\
\hline E4 & $A c$ & D-Val & & Pps & Pro & D-Val & Pps & D-Ala & & 76 & $>96$ \\
\hline E5 & $A c$ & $\operatorname{Ser}(\mathrm{t})$ & & Pps & Pro & D-Val & Pps & D-Leu & & 78 & $>96$ \\
\hline E6 & $A C$ & D-Val & & Pps & Pro & D-Val & Pps & D-Leu & & 74 & $>96$ \\
\hline E8 & $A c$ & Tyr (t) & & Pps & Pro & D-Ala & Pps & D-Leu & & 74 & $>96$ \\
\hline F1 & $A c$ & D-Phg & & Pps & Pro & D-Met & Pps & D-Leu & & 70 & $>96$ \\
\hline
\end{tabular}

\section{TsOH:H ${ }_{2} N-{ }^{t} \mathrm{Hyp}-\mathrm{OBn}(\mathbf{S 1})$}

$\mathrm{HO}$,<smiles>O=C(OCc1ccccc1)C1CCCN1[PH2+]</smiles>

A dry 250-mL flask equipped with a large magnetic stir bar and Dean-Stark receiver was charged with trans-L-hydroxyproline (10.00 g, $76.30 \mathrm{mmol}), \mathrm{TsOH}^{\mathrm{H}} \mathrm{H}_{2} \mathrm{O}(14.79 \mathrm{~g}, 77.50$ mmol), benzyl alcohol $(60.0 \mathrm{~mL})$ and benzene $(60 \mathrm{~mL})$. The mixture was heated at reflux for $17 \mathrm{~h}$, resulting in a brown, homogeneous solution. The reaction was cooled to room 
temperature and poured into cold diethyl ether $(800 \mathrm{~mL})$. After $\sim 30 \mathrm{~min}$ the initial oil became a white precipitate. The solid was collected by filtration, washed with ether $(250$ $\mathrm{mL})$ and dried in vacuo to give the desired salt $(28.85 \mathrm{~g}, 96.1 \%$ yield) as a white crystalline solid: ${ }^{1} \mathrm{H}$ NMR $\left(300 \mathrm{MHz}, \mathrm{CD}_{3} \mathrm{OD}\right) \square 7.69(\mathrm{~d}, J=8.2 \mathrm{~Hz}, 2 \mathrm{H}), 7.44-7.26$ (m, $5 \mathrm{H}), 7.19(\mathrm{~d}, J=8.2 \mathrm{~Hz}, 2 \mathrm{H}), 5.27(\mathrm{~d}, J=12.1 \mathrm{~Hz}, 1 \mathrm{H}), 5.20(\mathrm{~d}, J=12.1 \mathrm{~Hz}, 1 \mathrm{H}), 4.87$ (s, 2H), $4.61(\mathrm{dd}, J=10.7,7.7 \mathrm{~Hz}, 1 \mathrm{H}), 4.58-4.53(\mathrm{~m}, 1 \mathrm{H}), 3.42(\mathrm{dd}, J=12.1,3.6 \mathrm{~Hz}$, $1 \mathrm{H}), 3.35-3.22(\mathrm{~m}, 1 \mathrm{H}), 2.45-2.30(\mathrm{~m}, 1 \mathrm{H}), 2.32(\mathrm{~s}, 3 \mathrm{H}), 2.13(\mathrm{ddd}, J=13.8,10.7,4.1$ $\mathrm{Hz}, 1 \mathrm{H}) ;{ }^{13} \mathrm{C}\{\mathrm{H}\} \mathrm{NMR}\left(75 \mathrm{MHz}, \mathrm{CD}_{3} \mathrm{OD}\right) \square 169.94,143.30,141.71,136.26,129.82$, $129.69,129.65,129.59,126.91,70.64,69.40,59.58,55.12,38.63,21.50$ पD厂; FT-IR (KBr) 3391, 3033, 2774, 2476, 1747, 1598, 1497, 1456, 1424, 1343, 1239, 1210, 1124, $1031,1008,823,740,684,568,473,452,419 \mathrm{~cm}^{-1}$; HRFAB calcd. for $\mathrm{C}_{12} \mathrm{H}_{16} \mathrm{NO}_{3}(\mathrm{M}-$ OTs $)^{+} 222.1130$, found 222.1135 .

\section{Cbz- $N$ - ${ }^{t} \mathrm{Hyp}-\mathrm{OBn}(\mathbf{S 2})$}<smiles>O=C(OCc1ccccc1)C1C[C@@H](O)CN1C(=O)[O-]</smiles>

4-trans-L-Hydroxyproline benzyl ester tosylate salt (3.934 g, $10.00 \mathrm{mmol})$ and $\mathrm{NaHCO}_{3}$ $(2.100 \mathrm{~g}, 25.00 \mathrm{mmol})$ were dissolved in water $(15.0 \mathrm{~mL})$ and 5 min later acetone $(15.0$ $\mathrm{mL})$ was added followed by CbzOSu (2.492 $\mathrm{g}, 10.00 \mathrm{mmol})$. The resulting slurry was stirred overnight at room temperature. The reaction mixture was quenched by the addition of $4 \% \mathrm{HCl}(250 \mathrm{~mL})$ and was extracted with ethyl acetate $(2 \times 150 \mathrm{~mL})$. The combined organic extracts were washed with $5 \%$ aqueous $\mathrm{NaHCO}_{3}(150 \mathrm{~mL})$ and $5 \%$ aqueous $\mathrm{NaCl}(100 \mathrm{~mL})$, dried over $\mathrm{Na}_{2} \mathrm{SO}_{4}$, filtered, and concentrated on a rotary 
evaporator. The residue was purified by flash chromatography (1:1 ethyl acetate-hexane) to give the title compound $(2.896 \mathrm{~g}, 81.5 \%$ yield $)$ as a clear and colorless oil. The NMR spectra are reported for a mixture of two rotamers: ${ }^{1} \mathrm{H} \mathrm{NMR}\left(300 \mathrm{MHz}, \mathrm{CDCl}_{3}\right) \square 7.42-$ $7.12(\mathrm{~m}, 10 \mathrm{H}), 5.23(\mathrm{~d}, J=12.4 \mathrm{~Hz}, 0.5 \mathrm{H}), 5.16(\mathrm{~d}, J=12.6 \mathrm{~Hz}, 0.5 \mathrm{H}), 5.15(\mathrm{~d}, J=12.4$ $\mathrm{Hz}, 0.5 \mathrm{H}), 5.12(\mathrm{~d}, J=12.4 \mathrm{~Hz}, 0.5 \mathrm{H}), 4.63-4.41(\mathrm{~m}, 2 \mathrm{H}), 3.75-3.45(\mathrm{~m}, 2 \mathrm{H}), 2.40-2.20$ (m, 1H), 2.20-2.00 (m, 2H) ${ }^{13} \mathrm{C}\{\mathrm{H}\} \mathrm{NMR}\left(75 \mathrm{MHz}, \mathrm{CDCl}_{3}\right) \square$ 172.53, 172.32, 155.00, 154. $52,136.20,135.51,135.29,128.53,128.46,128.40,128.35,128.26,128.13,128.08$, $128.02,127.97,127.88,127.80,70.10,69.37,67.23,66.95,66.81,57.98,57.76,55.20$, 54.60, 39.14, 38.34; FT-IR (thin film) 3444, 3065, 3033, 2950, 2885, 1748, 1706, 1498, $1455,1422,1357,1274,1190,1167,1123,1085,1003,916,753,698,607,563,488,456$ $\mathrm{cm}^{-1} ; \mathrm{R}_{f}\left(1: 1\right.$ ethyl acetate-hexane) 0.37 ; HRFAB calcd. for $\mathrm{C}_{20} \mathrm{H}_{21} \mathrm{NO}_{5} \mathrm{Li}(\mathrm{M}+\mathrm{Li})^{+}$ 362.1580 , found 362.1577 .

\section{Cbz- $N-{ }^{t} \mathrm{Hyp}(O \mathrm{MOM})-\mathrm{OBn}(\mathbf{S 3})$}<smiles>COCOC1CC(C(=O)OCc2ccccc2)N(C)C1</smiles>

A mixture of sodium iodide $(2.998 \mathrm{~g}, 20.00 \mathrm{mmol})$ and chloromethyl ether $(1.899 \mathrm{~mL}$, $25.00 \mathrm{mmol})$ in DME $(10.0 \mathrm{~mL})$ was stirred for $10 \mathrm{~min}$ at room temperature producing a thick precipitate. Then a solution of the amino acid S2 $(5.000 \mathrm{mmol})$ and diisopropylethylamine $(5.226 \mathrm{~mL}, 30.00 \mathrm{mmol})$ in DME $(20.0 \mathrm{~mL})$ was added. The reaction was stirred $1 \mathrm{~h}$ at room temperature (slightly exothermic!) and for an additional 1 $\mathrm{h}$ under reflux. The orange reaction mixture was poured into EtOAc/5\% $\mathrm{NaCl}(250 / 150$ $\mathrm{mL})$. The organic layer was separated, washed $5 \% \mathrm{NaCl}$ solution $(100 \mathrm{~mL})$, dried over 
$\mathrm{Na}_{2} \mathrm{SO}_{4}$ and concentrated in vacuo. The residue was chromatographed over silica gel with ethyl acetate : hexane (1:2) to give $1.170 \mathrm{~g}(58.6 \%$ yield) of the desired product as an oil. The NMR spectra are reported for a mixture of two rotamers: ${ }^{1} \mathrm{H}$ NMR $(300 \mathrm{MHz}$, $\left.\mathrm{CDCl}_{3}\right) \square 7.15-7.40(\mathrm{~m}, 10 \mathrm{H}), 5.24(\mathrm{~d}, J=12.4 \mathrm{~Hz}, 0.5 \mathrm{H}), 5.20(\mathrm{~d}, J=10.0 \mathrm{~Hz}, 0.5 \mathrm{H})$, $5.16(\mathrm{~d}, J=12.4 \mathrm{~Hz}, 0.5 \mathrm{H}), 5.13(\mathrm{~d}, J=10.0 \mathrm{~Hz}, 0.5 \mathrm{H}), 4.70-4.58(\mathrm{~m}, 2 \mathrm{H}), 4.58-4.40(\mathrm{~m}$, $1 \mathrm{H}), 4.40-4.25(\mathrm{~m}, 1 \mathrm{H}), 3.78-3.57(\mathrm{~m}, 2 \mathrm{H}), 3.34(\mathrm{~s}, 1.5 \mathrm{H}), 3.32(\mathrm{~s}, 1.5 \mathrm{H}), 2.45-2.25(\mathrm{~m}$, 1H), 2.20-2.00 (m, $1 \mathrm{H}) ;{ }^{13} \mathrm{C}\{\mathrm{H}\}$ NMR $\left(75 \mathrm{MHz}, \mathrm{CDCl}_{3}\right) \square$ 172.39, 172.19, 154.82, $154.22,136.41,136.26,135.49,135.27,128.50,128.40,128.34,128.30,128.21,128.10$, $128.03,127.96,127.89,127.86,127.77,95.43,95.27,74.87,73.88,67.14,67.09,66.90$, $66.77,57.99,57.77,55.51,52.49,52.16,36.98,35.97$; FT-IR (thin film) 3509, 3090, $3065,3033,2949,2891,2824,1957,1748,1710,1498,1455,1417,1355,1266,1188$, $1165,1116,1034,992,918,769,753,699,600 \mathrm{~cm}^{-1} ; \mathrm{R}_{f}(1: 2$ ethyl acetate-hexane) 0.25 ; HRFAB calcd. for $\mathrm{C}_{22} \mathrm{H}_{25} \mathrm{NO}_{6} \mathrm{Li}(\mathrm{M}+\mathrm{Li})^{+}$406.1842, found 406.1847.

\section{${ }^{t} \mathrm{Hyp}(\mathrm{OMOM})-\mathrm{OH}(\mathbf{S 4})$}

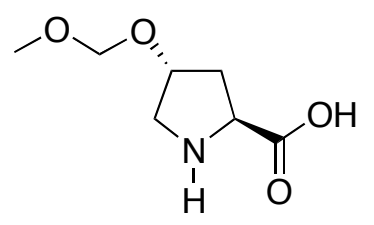

To a solution of Cbz- $N-{ }^{t} \mathrm{Hyp}(O \mathrm{MOM})-\mathrm{OBn}(\mathbf{S 3})(437.6 \mathrm{mg}, 1.095 \mathrm{mmol})$ in methyl alcohol (10 mL) palladium on activated carbon $(207.6 \mathrm{mg}, 10 \mathrm{wt}$. \%, water $\sim 50 \%)$ was added. The reaction was stirred under an atmosphere of hydrogen for $30 \mathrm{~min}$. The reaction contents were then filtered through Celite, and the filtrate was concentrated in vacuo leaving a pale oily solid (190.8 mg, $99.5 \%$ yield): ${ }^{1} \mathrm{H}$ NMR (300 MHz, $\left.\mathrm{CD}_{3} \mathrm{OD}\right)$ $4.99(\mathrm{~s}, 2 \mathrm{H}), 4.69(\mathrm{~s}, 2 \mathrm{H}), 4.52-4.45(\mathrm{~m}, 1 \mathrm{H}), 4.20-4.10(\mathrm{dd}, J=10.1,8.0 \mathrm{~Hz}, 1 \mathrm{H}), 3.51-$ 
$3.34(\mathrm{~m}, 1 \mathrm{H}), 3.38(\mathrm{~s}, 3 \mathrm{H}), 2.60-2.48(\mathrm{~m}, 1 \mathrm{H}), 2.20-2.05(\mathrm{~m}, 1 \mathrm{H}) ;{ }^{13} \mathrm{C}\{\mathrm{H}\}$ NMR $(75$ $\left.\mathrm{MHz}, \mathrm{CD}_{3} \mathrm{OD}\right) \square 174.00,96.63,77.16,61.60,56.13,52.50,37.21$; FT-IR (abrasive pad) 3404, 2951, 1638, 1400, 1221, 1151, 1103, 1046, 918, 848, 782, 698, $478 \mathrm{~cm}^{-1}$; HRFAB calcd. for $\mathrm{C}_{7} \mathrm{H}_{12} \mathrm{NO}_{4} \mathrm{Li}_{2}(\mathrm{M}+2 \mathrm{Li}-\mathrm{H})^{+} 188.1086$, found 188.1081.

Fmoc- $N-{ }^{t} \mathrm{Hyp}(O \mathrm{MOM})-\mathrm{OH}(\mathbf{S 5})$<smiles>COCOC1CC(C(=O)O)N(P)C1</smiles>

A solution of $\mathrm{NaHCO}_{3}(95.90 \mathrm{mg}, 1.142 \mathrm{mmol})$ in water $(4.0 \mathrm{~mL})$ was added to a stirred solution of ${ }^{t} \mathrm{Hyp}(O \mathrm{MOM})-\mathrm{OH}(\mathbf{S 4})(200.0 \mathrm{mg}, 1.142 \mathrm{mmol})$ in acetone $(4.0 \mathrm{~mL})$ followed by addition of FmocOSu (385.0 mg, $1.142 \mathrm{mmol})$. The reaction was stirred overnight and was stopped by addition of $4 \% \mathrm{HCl}(100 \mathrm{~mL})$ and ethyl acetate $(100 \mathrm{~mL})$. The organic layer was separated, washed with $5 \% \mathrm{NaCl}(100 \mathrm{~mL})$ and dried over $\mathrm{Na}_{2} \mathrm{SO}_{4}$. After removing of solvent the residue was purified by flash chromatography (using eluent gradient 1:99 methyl alcohol-chloroform to 5:95 methyl alcohol-chloroform) to give $277.6 \mathrm{mg}$ (61.2\% yield) of the title compound as an oily solid. The NMR spectra are reported for a mixture of two rotamers: ${ }^{1} \mathrm{H} \mathrm{NMR}\left(300 \mathrm{MHz}, \mathrm{CDCl}_{3}\right) \square 9.57(\mathrm{~s}, 1 \mathrm{H}), 7.78$ $(\mathrm{d}, J=7.6 \mathrm{~Hz}, 1.4 \mathrm{H}), 7.72(\mathrm{~d}, J=7.3 \mathrm{~Hz}, 0.6 \mathrm{H}), 7.50-7.20(\mathrm{~m}, 4 \mathrm{H}), 4.75-4.60(\mathrm{~m}, 2 \mathrm{H})$, 4.60-4.10 (m, 5H), 3.77-3.60 (m, 2H), $3.38(\mathrm{~s}, 2 \mathrm{H}), 3.38(\mathrm{~s}, 1 \mathrm{H}), 2.52-2.34(\mathrm{~m}, 1 \mathrm{H}), 2.34-$ $2.15(\mathrm{~m}, 1 \mathrm{H}) ;{ }^{13} \mathrm{C}\{\mathrm{H}\} \mathrm{NMR}\left(75 \mathrm{MHz}, \mathrm{CDCl}_{3}\right) \square 177.25,175.99,155.57,154.52,143.90$, $143.76,143.62,141.22,127.67,127.56,127.01,125.02,124.97,124.84,119.92,119.83$, $95.46,95.31,74.75,73.78,67.84,57.95,57.37,55.52,52.42,52.13,47.04,37.06,35.62$; FT-IR (abrasive pad) 2949, 1704, 1422, 1353, 1149, 1116, 1031, 916, 758, $738 \mathrm{~cm}^{-1} ; \mathrm{R}_{f}$ 
(5:95 methyl alcohol-methelene chloride) 0.21; (HRFAB calcd. for $\mathrm{C}_{22} \mathrm{H}_{22} \mathrm{NO}_{6} \mathrm{Li}_{2}$ $(\mathrm{M}+2 \mathrm{Li}-\mathrm{H})^{+} 410.1767$, found 410.1785 .

\section{$\mathrm{TsOH} \cdot \mathrm{H}_{2} \mathrm{~N}^{-}{ }^{c} \mathrm{Hyp}-\mathrm{OBn}(\mathbf{S 6})$}

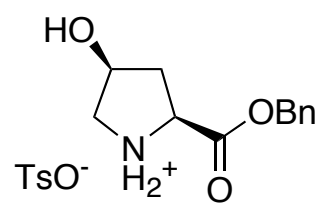

The procedure used was identical with that used for the preparation of S1. Yield 94.7\% as a white solid: ${ }^{1} \mathrm{H}$ NMR $\left(300 \mathrm{MHz}, \mathrm{CD}_{3} \mathrm{OD}\right) \square 7.70(\mathrm{~d}, J=8.5 \mathrm{~Hz}, 2 \mathrm{H}), 7.46-7.28(\mathrm{~m}$, $5 \mathrm{H}), 7.23(\mathrm{~d}, J=7.8 \mathrm{~Hz}, 2 \mathrm{H}), 5.31(\mathrm{~d}, J=12.1 \mathrm{~Hz}, 1 \mathrm{H}), 5.25(\mathrm{~d}, J=12.1 \mathrm{~Hz}, 1 \mathrm{H}), 4.90$ (s, 2H), 4.62-4.55 (m, 1H), 4.55-4.45 (m, 1H), 3.42-3.27 (m, 2H), 2.51-2.40 (m, 2H), $2.36(\mathrm{~s}, 3 \mathrm{H}) ;{ }^{13} \mathrm{C}\{\mathrm{H}\}$ NMR $\left(75 \mathrm{MHz}, \mathrm{CD}_{3} \mathrm{OD}\right) \square 170.24,143.25,141.79,129.87,129.62$, 129.52, 126.90, 70.13, 69.46, 59.80, 55.10, 38.46, 21.51; FT-IR (KBr) 3346, 2965, 2769, 2682, 2570, 2486, 1751, 1595, 1500, 1457, 1437, 1334, 1174, 1125, 1094, 1037, 1012, $960,818,744,699,685,618,566,456,416,407 \mathrm{~cm}^{-1}$; HRFAB calcd. for $\mathrm{C}_{12} \mathrm{H}_{16} \mathrm{NO}_{3}(\mathrm{M}-$ OTs) ${ }^{+} 222.1130$, found 222.1135 .

\section{Cbz- $N-{ }^{c} \mathrm{Hyp}-\mathrm{OBn}(\mathbf{S 7})$}

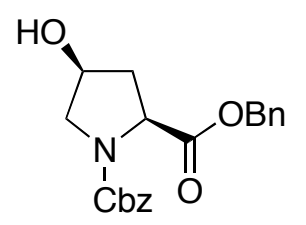

The procedure used was identical with that used for the preparation of S2. Yield 92.8\% as a clear oil. The NMR spectra are reported for a mixture of two rotamers: ${ }^{1} \mathrm{H}$ NMR (300 $\left.\mathrm{MHz}, \mathrm{CDCl}_{3}\right) \square 7.50-7.15(\mathrm{~m}, 10 \mathrm{H}), 5.40-4.98(\mathrm{~m}, 4 \mathrm{H}), 4.50(\mathrm{~d}, J=9.6 \mathrm{~Hz}, 0.5 \mathrm{H}), 4.44$ 
$(\mathrm{d}, J=9.6 \mathrm{~Hz}, 0.5 \mathrm{H}), 4.38(\mathrm{~s}, 1 \mathrm{H}), 3.81-3.57(\mathrm{~m}, 2 \mathrm{H}), 3.41(\mathrm{~s}, 1 \mathrm{H}), 2.42-2.23(\mathrm{~m}, 1 \mathrm{H})$, 2.23-2.04 (m, 1H); ${ }^{13} \mathrm{C}\{\mathrm{H}\}$ NMR $\left(75 \mathrm{MHz}, \mathrm{CDCl}_{3}\right) \square 173.87,173.80,154.86,154.21$, $136.24,136.13,135.13,134.95,128.44,128.35,128.31,128.22,128.12,128.01,127.95$, $127.77,127.71,70.74,69.79,67.28,67.21,67.13,58.17,57.74,55.71,55.36,38.54$, 37.66; FT-IR (thin film) 3453, 3065, 3033, 2951, 2887, 1705, 1498, 1455, 1418, 1352, 1193, 1166, 1120, 1087, 1004, 967, 752, 698, 609, 567, 494, $460 \mathrm{~cm}^{-1} ; \mathrm{R}_{f}(1: 1$ ethyl acetate-hexane) 0.40; HRFAB calcd. for $\mathrm{C}_{20} \mathrm{H}_{21} \mathrm{NO}_{5} \mathrm{Li}(\mathrm{M}+\mathrm{Li})^{+} 362.1580$, found 362.1570.

$\mathrm{Cbz}-\mathrm{N}-{ }^{\mathrm{c}} \mathrm{Hyp}(\mathrm{OMOM})-\mathrm{OBn}(\mathbf{S 8})$<smiles>COCOC1CC(C(=O)OCc2ccccc2)N(C(=O)OCc2ccccc2)C1</smiles>

The procedure used was identical with that used for the preparation of $\mathbf{S 3}$. Yield $84.9 \%$ as a clear oil. The NMR spectra are reported for a mixture of two rotamers: ${ }^{1} \mathrm{H}$ NMR (300 $\left.\mathrm{MHz}, \mathrm{CDCl}_{3}\right) \square 7.40-7.20(\mathrm{~m}, 10 \mathrm{H}), 5.25(\mathrm{~d}, J=12.4 \mathrm{~Hz}, 0.5 \mathrm{H}), 5.14(\mathrm{~d}, J=12.4 \mathrm{~Hz}$, 0.5H), 5.20-5.00 (m, 3H), 4.63-4.38 (m, 3H), 4.30-4.17 (m, 1H), 3.80-3.54 (m, 2H), 3.27 (s, 1.5H), $3.24(\mathrm{~s}, 1.5 \mathrm{H}), 2.41-2.22(\mathrm{~m}, 2 \mathrm{H}) ;{ }^{13} \mathrm{C}\{\mathrm{H}\} \mathrm{NMR}\left(75 \mathrm{MHz}, \mathrm{CDCl}_{3}\right) \square$ 171.60, $171.28,154.69,154.23,136.44,136.36,135.70,135.51,128.35,128.29,128.09,128.02$, $127.89,127.81,127.73,94.92,94.79,74.46,73.61,67.00,66.95,66.68,66.59,57.77$, 57.55, 55.36, 52.42, 52.16, 36.60, 35.52; FT-IR (thin film) 3090, 3065, 3033, 2950, 2890, 2824, 1754, 1710, 1498, 1455, 1417, 1356, 1308, 1211, 1189, 1165, 1101, 1038, 991, $918,769,752,699,610,463 \mathrm{~cm}^{-1} ; \mathrm{R}_{f}$ (1:2 ethyl acetate-hexane) 0.20 ; HRFAB calcd. for $\mathrm{C}_{22} \mathrm{H}_{25} \mathrm{NO}_{6} \mathrm{Li}(\mathrm{M}+\mathrm{Li})^{+} 406.1842$, found 406.1839 . 
${ }^{c} \mathrm{Hyp}(O \mathrm{MOM})-\mathrm{OH}(\mathbf{S 9})$<smiles>COCO[C@H]1CNC(C(=O)OCc2ccccc2)C1</smiles>

The procedure used was identical with that used for the preparation of $\mathbf{S 4}$. Yield $92.8 \%$ as a white solid: ${ }^{1} \mathrm{H}$ NMR (300 MHz, $\left.\mathrm{CD}_{3} \mathrm{OD}\right) \square 4.93(\mathrm{~s}, 2 \mathrm{H}), 4.63$ (d, $\left.J=6.9 \mathrm{~Hz}\right), 4.61$ (d, $J$ $=6.9 \mathrm{~Hz}), 4.42-4.37(\mathrm{~m}, 1 \mathrm{H}), 4.05(\mathrm{t}, J=7.2 \mathrm{~Hz}), 3.59-3.43(\mathrm{~m}, 1 \mathrm{H}), 3.36-3.27(\mathrm{~m}, 1 \mathrm{H})$, $3.34(\mathrm{~s}, 3 \mathrm{H}), 2.46-2.38(\mathrm{~m}, 2 \mathrm{H}) ;{ }^{13} \mathrm{C}\{\mathrm{H}\} \mathrm{NMR}\left(75 \mathrm{MHz}, \mathrm{CD}_{3} \mathrm{OD}\right) \square 174.20,96.52$, 76.20, 61.23, 56.19, 52.53, 36.47; FT-IR (KBr) 3089, 2993, 2966, 2830, 2565, 2446, 1609, 1478, 1449, 1390, 1327, 1226, 1208, 1151, 1092, 1070, 1027, 954, 917, 840, 821, 796, 740, 693, 613, 578, 495, $456 \mathrm{~cm}^{-1}$; HRFAB calcd. for $\mathrm{C}_{7} \mathrm{H}_{13} \mathrm{NO}_{4} \mathrm{Li}(\mathrm{M}+\mathrm{Li})^{+}$ 182.1005, found 182.0999 .

Fmoc- $N-{ }^{c}$ Hyp $(O M O M)-O H($ S10 $)$<smiles>COCO[C@H]1CC(C(=O)OCc2ccccc2)N(F)C1</smiles>

The procedure used was identical with that used for the preparation of S5. Yield $63.4 \%$ as a white solid. The NMR spectra are reported for a mixture of two rotamers: ${ }^{1} \mathrm{H}$ NMR (300 MHz, $\left.\mathrm{CD}_{3} \mathrm{OD}\right) \square 7.78-7.64(\mathrm{~m}, 2 \mathrm{H}), 7.61-7.52(\mathrm{~m}, 2 \mathrm{H}), 7.39-7.18(\mathrm{~m}, 4 \mathrm{H}), 5.05$ (s, $1 \mathrm{H}), 4.65-4.50(\mathrm{~m}, 2 \mathrm{H}), 4.40-4.02(\mathrm{~m}, 5 \mathrm{H}), 3.66-3.42(\mathrm{~m}, 2 \mathrm{H}), 3.30(\mathrm{~s}, 1.5 \mathrm{H}), 3.28(\mathrm{~s}$, 1.5H), 2.42-2.17 (m, 2H); ${ }^{13} \mathrm{C}\{\mathrm{H}\}$ NMR (75 MHz, $\left.\mathrm{CD}_{3} \mathrm{OD}\right) \square 175.11,174.88,156.41$, $156.30,145.21,145.18,144.96,144.93,142.45,142.39,142.31,128.74,128.09,126.12$, 
$126.06,120.92,120.87,96.74,96.62,79.49,76.92,75.95,69.00,68.71,68.09,59.07$, 58.92, 55.98, 55.94, 53.99, 53.66, 48.42, 48.34, 37.84, 36.90; FT-IR (KBr) 2949, 1707, $1420,1355,1102,1035,917,759,740,621,547,427 \mathrm{~cm}^{-1} ; \mathrm{R}_{f}(1: 19$ methyl alcoholdichloromethane) 0.21; HRFAB calcd. for $\mathrm{C}_{22} \mathrm{H}_{22} \mathrm{NO}_{6} \mathrm{Li}_{2}(\mathrm{M}+2 \mathrm{Li}-\mathrm{H})^{+} 410.1767$, found 410.1767.

\section{Fmoc- $N$ - ${ }^{t} \mathrm{Hyp}-\mathrm{OBn}(\mathbf{S 1 1})$}

$\mathrm{HO}$<smiles>O=C(O[C@@H](c1ccccc1)C1CCCN1P)c1ccccc1</smiles>

trans-L-Hydroxyproline benzyl ester tosylate salt (3.934 g, $10.00 \mathrm{mmol})$ and $\mathrm{NaHCO}_{3}$ $(2.100 \mathrm{~g}, 25.00 \mathrm{mmol})$ were dissolved in water $(15.0 \mathrm{~mL})$ and $5 \mathrm{~min}$ later acetone $(15.0$ $\mathrm{mL}$ ) was added followed by FmocOSu $(3.373 \mathrm{~g}, 10.00 \mathrm{mmol})$. The resulting slurry was stirred overnight at room temperature. The reaction mixture was quenched by the addition of $4 \% \mathrm{HCl}(250 \mathrm{~mL})$ and was extracted with ethyl acetate $(2 \times 150 \mathrm{~mL})$. The combined organic extracts were washed with $5 \%$ aqueous $\mathrm{NaHCO}_{3}(150 \mathrm{~mL})$ and $5 \%$ aqueous $\mathrm{NaCl}(100 \mathrm{~mL})$, dried over $\mathrm{Na}_{2} \mathrm{SO}_{4}$, filtered, and concentrated on a rotary evaporator. The residue was purified by flash chromatography (1:1 ethyl acetate-hexane) to give the title compound (4.060 g, 91.5\% yield) as a foamy solid. The NMR spectra are reported for a mixture of two rotamers: ${ }^{1} \mathrm{H} \mathrm{NMR}\left(300 \mathrm{MHz}, \mathrm{CDCl}_{3}\right) \square 7.80-7.71(\mathrm{~m}, 2 \mathrm{H})$, 7.63-7.48 (m, 2H), 7.45-7.20 (m, 9H), $5.23(\mathrm{~d}, J=12.4 \mathrm{~Hz}, 0.5 \mathrm{H}), 5.15(\mathrm{~d}, J=12.4 \mathrm{~Hz}$, $0.5 \mathrm{H}), 5.13(\mathrm{~d}, J=12.1 \mathrm{~Hz}, 0.5 \mathrm{H}), 5.05(\mathrm{~d}, J=12.1 \mathrm{~Hz}, 0.5 \mathrm{H}), 4.64-4.19(\mathrm{~m}, 4.5 \mathrm{H})$, 4.02-3.93 (m, 0.5H), 3.78-3.60 (m, 1.5H), 3.58-3.50 (m, 0.5H), 2.43-2.25 (m, 1H), 2.16$2.05(\mathrm{~m}, 1 \mathrm{H}), 1.97-1.85(\mathrm{~m}, 1 \mathrm{H}) ;{ }^{13} \mathrm{C}\{\mathrm{H}\}$ NMR $\left(75 \mathrm{MHz}, \mathrm{CDCl}_{3}\right) \square$ 172.31, 172.24, 
$154.97,154.66,144.11,144.00,143.76,143.50,141.26,141.14,135.47,135.28,128.53$, $128.39,128.28,128.10,127.67,127.60,127.05,125.18,125.10,124.94,119.94,119.89$, $70.15,69.34,67.71,67.54,66.99,66.90,57.98,57.69,55.29,54.61,47.14,47.05,39.30$, 38.33; FT-IR (KBr) 3447, 3064, 3035, 2949, 1750, 1701, 1420, 1353, 1166, 1124, 1084, $1002,758,740,698,621,594,570,544,427 \mathrm{~cm}^{-1} ; \mathrm{R}_{f}(1: 1$ ethyl acetate-hexane) 0.27 ; HRFAB calcd. for $\mathrm{C}_{27} \mathrm{H}_{25} \mathrm{NO}_{5} \mathrm{Li}(\mathrm{M}+\mathrm{Li})^{+} 450.1893$, found 450.1908 .

\section{Fmoc- $N-{ }^{t} \mathrm{Hyp}(O \mathrm{BSi})-\mathrm{OBn}(\mathbf{S 1 2})$}

t-BuMe $2 \mathrm{SiO}$,<smiles>O=C(OCc1ccccc1)C1CCCN1F</smiles>

Fmoc- $N$ - ${ }^{t}$ Hyp-OBn (S11) (850.0 mg, $\left.1.917 \mathrm{mmol}\right)$, tert-BuMe ${ }_{2} \mathrm{SiCl}(1.444 \mathrm{~g}, 9.583$ mmol) and 1-methylimidazole $(1.528 \mathrm{~mL}, 19.17 \mathrm{mmol})$ were dissolved in DMF $(10 \mathrm{~mL})$ and stirred overnight at room temperature. The solvent was removed in vacuo and ethyl acetate was added $(200 \mathrm{~mL})$. The organic layer was washed with water $(100 \mathrm{~mL})$, dried over $\mathrm{Na}_{2} \mathrm{SO}_{4}$, filtered and evaporated. The residue was purified by flash chromatography (1:5 ethyl acetate-hexane) to afford the product $(930.1 \mathrm{mg}, 87.0 \%$ yield) as a colorless oil. The NMR spectra are reported for a mixture of two rotamers: ${ }^{1} \mathrm{H}$ NMR $(300 \mathrm{MHz}$, $\left.\mathrm{CDCl}_{3}\right) \square 7.80-7.70(\mathrm{~m}, 2 \mathrm{H}), 7.63-7.49(\mathrm{~m}, 2 \mathrm{H}), 7.44-7.20(\mathrm{~m}, 9 \mathrm{H}), 5.23(\mathrm{~d}, J=12.4 \mathrm{~Hz}$, $0.5 \mathrm{H}), 5.16(\mathrm{~d}, J=12.4 \mathrm{~Hz}, 0.5 \mathrm{H}), 5.13(\mathrm{~d}, J=12.1 \mathrm{~Hz}, 0.5 \mathrm{H}), 5.07(\mathrm{~d}, J=12.1 \mathrm{~Hz}$, $0.5 \mathrm{H}), 4.60-4.48(\mathrm{~m}, 1 \mathrm{H}), 4.48-4.40(\mathrm{~m}, 0.5 \mathrm{H}), 4.40-4.35(\mathrm{~m}, 1.5 \mathrm{H}), 4.32-4.4 .23(\mathrm{~m}$, 1.5H), 4.15-3.96 (m, 0.5H), 3.77-3.62 (m, 1H), 3.57-3.41 (m, 1H), 2.35-2.16 (m, 1H), 2.15-1.98 (m, 1H), $0.88(\mathrm{~s}, 5 \mathrm{H}), 0.86(\mathrm{~s}, 4 \mathrm{H}), 0.05-0.01(\mathrm{~m}, 6 \mathrm{H}) ;{ }^{13} \mathrm{C}\{\mathrm{H}\} \mathrm{NMR}(75 \mathrm{MHz}$, $\left.\mathrm{CDCl}_{3}\right) \square 172.42,172.38,154.95,154.45,144.16,144.02,143.84,143.63,141.23$, 
$135.58,135.38,128.50,128.35,128.26,128.10,127.60,127.54,127.00,125.10,125.03$, $124.93,119.92,119.85,70.38,69.52,67.54,66.87,66.78,58.10,57.84,55.09,54.78$, $47.08,39.89,38.83,25.67,17.93,-4.85,-4.92 ;{ }^{29} \mathrm{Si}\{\mathrm{H}\}$ INEPT NMR $\left(60 \mathrm{MHz}, \mathrm{CDCl}_{3}\right) \square$ 19.86, 19.80; FT-IR (thin film) 3066, 3037, 2954, 2930, 2885, 2857, 2250, 1748, 1710, $1498,1452,1418,1351,1257,1187,1163,1118,1094,1022,1007,910,837,777,758$, 739, 698, 648, 622, $426 \mathrm{~cm}^{-1} ; \mathrm{R}_{f}$ (1:5 ethyl acetate-hexane) 0.37; HRFAB calcd. for $\mathrm{C}_{33} \mathrm{H}_{40} \mathrm{NO}_{5} \mathrm{Si}(\mathrm{M}+\mathrm{H})^{+} 558.2676$, found 558.2658.

Fmoc- $N-{ }^{t} \mathrm{Hyp}(\mathrm{OBSi})-\mathrm{OH}(\mathbf{S 1 3})$

$t$-BuMe $\mathrm{SiO}$

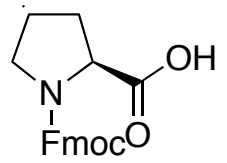

To a solution of Fmoc- $N{ }^{t} \mathrm{Hyp}(\mathrm{OBSi})-\mathrm{OBn}(\mathbf{S 1 2})(1.158 \mathrm{~g}, 2.077 \mathrm{mmol})$ in methyl alcohol (100 mL), palladium on activated carbon (463.1 mg, $10 \mathrm{wt}$ \%, water $\sim 50 \%)$ was added. The reaction was stirred under an atmosphere of hydrogen for $5 \mathrm{~min}$. The reaction contents were then filtered through Celite, and the filtrate was concentrated in vacuo. The resultant foamy oil was purified by flash chromatography (using eluent gradient chloroform to 10:90 methyl alcohol-chloroform) to furnish the acid as a white foam (586.7 $\mathrm{mg}, 60.4 \%$ yield). The NMR spectra are reported for a mixture of two rotamers: ${ }^{1} \mathrm{H}$ NMR (300 MHz, $\left.\mathrm{CDCl}_{3}\right) \square 10.34(\mathrm{~s}, 1 \mathrm{H}), 7.79(\mathrm{~d}, J=7.3 \mathrm{~Hz}, 1.4 \mathrm{H}), 7.73(\mathrm{~d}, J=7.3$ $\mathrm{Hz}, 0.6 \mathrm{H})$, 7.82-7.69 (m, 2H), 7.65-7.65 (m, 2H), 7.47-7.24 (m, 4H), 4.60-4.14 (m, 5H), 3.72-3.60 (m, 1H), 3.60-3.44 (m, 1H), 2.38-2.07 (m, 1H), $0.92(\mathrm{~s}, 6 \mathrm{H}), 0.90(\mathrm{~s}, 3 \mathrm{H}), 0.12$ $(\mathrm{s}, 2 \mathrm{H}), 0.11(\mathrm{~s}, 2 \mathrm{H}), 0.10(\mathrm{~s}, 1 \mathrm{H}), 0.09(\mathrm{~s}, 1 \mathrm{H}) ;{ }^{13} \mathrm{C}\{\mathrm{H}\}$ NMR $\left(75 \mathrm{MHz}, \mathrm{CDCl}_{3}\right)$ $178.00,176.44,155.85,154.58,143.97,143.77,143.68,141.24,127.69,127.56,127.03$, 
$125.03,124.96,124.88,119.95,119.84,70.21,69.54,67.91,67.65,58.09,57.48,55.17$, $54.85,47.05,39.89,38.41,25.67,17.92,-4.82,-4.92 ;{ }^{29} \mathrm{Si}\{\mathrm{H}\}$ INEPT NMR $(60 \mathrm{MHz}$, $\left.\mathrm{CDCl}_{3}\right) \square 20.07,19.95$; FT-IR (KBr) 3066, 2953, 2886, 2856, 1708, 1420, 1356, 1254, $1169,1119,1022,837,777,758,739,694,670,544,473,426 \mathrm{~cm}^{-1}$; Rf (methyl alcoholdichloromethane) 0.39; HRFAB calcd. for $\mathrm{C}_{26} \mathrm{H}_{32} \mathrm{NO}_{5} \mathrm{SiLi}_{2}(\mathrm{M}+2 \mathrm{Li}-\mathrm{H})^{+} 480.2370$, found 480.2388 .

\section{Fmoc- $N-{ }^{c} \mathrm{Hyp}-\mathrm{OBn}(\mathbf{S 1 4})$}

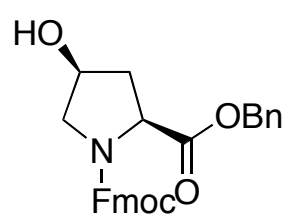

The procedure used was identical with that used for the preparation of S11. Yield 88.2\% as a viscous oil. The NMR spectra are reported for a mixture of two rotamers: ${ }^{1} \mathrm{H}$ NMR (300 MHz, $\left.\mathrm{CDCl}_{3}\right) \square 7.79-7.68(\mathrm{~m}, 2 \mathrm{H}), 7.61-7.45(\mathrm{~m}, 2 \mathrm{H}), 7.43-7.15(\mathrm{~m}, 9 \mathrm{H}), 5.26(\mathrm{~d}, J$ $=12.4 \mathrm{~Hz}, 0.5 \mathrm{H}), 5.17(\mathrm{~d}, J=12.4 \mathrm{~Hz}, 0.5 \mathrm{H}), 5.14(\mathrm{~d}, J=12.1 \mathrm{~Hz}, 0.5 \mathrm{H}), 5.07(\mathrm{~d}, J=$ $12.1 \mathrm{~Hz}, 0.5 \mathrm{H}), 4.54-4.18(\mathrm{~m}, 4.5 \mathrm{H}), 3.99(\mathrm{t}, J=6.6 \mathrm{~Hz}, 0.5 \mathrm{H}), 3.71(\mathrm{~d}, J=11.5 \mathrm{~Hz}, 1 \mathrm{H})$, $3.61(\mathrm{dd}, J=11.8,4.4 \mathrm{~Hz}, 1 \mathrm{H}), 3.35(\mathrm{~d}, J=8.8 \mathrm{~Hz}, 0.5 \mathrm{H}), 3.14(\mathrm{~d}, J=8.2 \mathrm{~Hz}, 0.5 \mathrm{H})$, 2.40-2.22 (m, 1H), $2.14(\mathrm{t}, J=11.0 \mathrm{~Hz}, 1 \mathrm{H}) ;{ }^{13} \mathrm{C}\{\mathrm{H}\} \mathrm{NMR}\left(75 \mathrm{MHz}, \mathrm{CDCl}_{3}\right) \square$ 174.08, $173.70,154.85,154.35,144.02,143.84,143.62,143.42,141.22,141.16,141.09,135.07$, $134.91,128.49,128.45,128.40,128.31,128.29,128.09,127.63,127.55,126.97,126.91$, $125.02,124.97,124.91,124.78,119.90,119.84,70.96,69.86,67.58,67.44,67.35,58.17$, 57.76, 55.92, 55.54, 47.03, 38.80, 37.69; FT-IR (abrasive pad) 3440, 1682, 1416, 1345, $1189,1083,739 \mathrm{~cm}^{-1} ; \operatorname{Rf}\left(1: 1\right.$ ethyl acetate-hexane) 0.29 ; HRFAB calcd. for $\mathrm{C}_{27} \mathrm{H}_{26} \mathrm{NO}_{5}$ $(\mathrm{M}+\mathrm{H})^{+}$444.1811, found 444.1812. 
Fmoc- $N-{ }^{c} \operatorname{Hyp}(O B S i)-O B n($ S15)

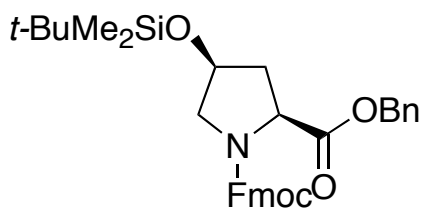

The procedure used was identical with that used for the preparation of S12. Yield $88.5 \%$ as a clear oil. The NMR spectra are reported for a mixture of two rotamers: ${ }^{1} \mathrm{H}$ NMR $\left(300 \mathrm{MHz}, \mathrm{CDCl}_{3}\right) \square 7.79(\mathrm{t}, J=7.6 \mathrm{~Hz}, 2 \mathrm{H}), 7.68-7.60(\mathrm{~m}, 1 \mathrm{H}), 7.58-7.52(\mathrm{~m}, 1 \mathrm{H})$, 7.48-7.23 (m, 9H), $5.24(\mathrm{~d}, \mathrm{~J}=12.5 \mathrm{~Hz}, 0.5 \mathrm{H}), 5.18(\mathrm{~d}, J=12.5 \mathrm{~Hz}, 0.5 \mathrm{H}), 5.16(\mathrm{~d}, J=$ $12.5 \mathrm{~Hz}, 0.5 \mathrm{H}), 5.08(\mathrm{~d}, J=12.5 \mathrm{~Hz}, 0.5 \mathrm{H}), 4.63-4.54(\mathrm{~m}, 1 \mathrm{H}), 4.53-4.24(\mathrm{~m}, 3.5 \mathrm{H}), 4.07$ $(\mathrm{t}, J=6.8 \mathrm{~Hz}, 0.5 \mathrm{H}), 3.78-3.68(\mathrm{~m}, 1 \mathrm{H}), 3.56-3.48(\mathrm{~m}, 1 \mathrm{H}), 2.45-2.30(\mathrm{~m}, 1 \mathrm{H}), 2.30-2.20$ $(\mathrm{m}, 1 \mathrm{H}), 0.96(\mathrm{~d}, J=0.7 \mathrm{~Hz}, 1 \mathrm{H}), 0.91(\mathrm{~d}, J=9.8 \mathrm{~Hz}, 8 \mathrm{H}), 0.15-0.04(\mathrm{~m}, 6 \mathrm{H}) ;{ }^{13} \mathrm{C}\{\mathrm{H}\}$ NMR (75 MHz, $\left.\mathrm{CDCl}_{3}\right) \square 171.38,171.20,154.72,154.46,144.18,143.71,143.64$, $141.26,141.22,141.17,141.10,135.60,135.46,128.40,127.91,127.54,126.93,125.22$, $124.98,124.91,119.82,70.68,69.75,69.64,67.37,66.80,66.74,57.98,57.80,57.65$, $55.14,54.80,47.09,39.73,38.65,25.64,25.51,17.87,-4.99 ;{ }^{29} \mathrm{Si}\{\mathrm{H}\}$ INEPT NMR $\left(60 \mathrm{MHz}, \mathrm{CDCl}_{3}\right) \square 19.82$; FT-IR (KBr) 3032, 2955, 2851, 1957, 1758, 1702, 1421, 1330, $1248,1205,1156,1123,1092,1028,930,836,762,738,696,604,548,471,430 \mathrm{~cm}^{-1} ; \mathrm{R}_{f}$ (1:5 ethyl acetate-hexane) 0.33; HRFAB calcd. for $\mathrm{C}_{33} \mathrm{H}_{39} \mathrm{NO}_{5} \mathrm{SiLi}(\mathrm{M}+\mathrm{Li})^{+}$564.2758, found 564.2733.

Fmoc- $N{ }^{-}{ }^{c} \mathrm{Hyp}(O B S i)-\mathrm{OH}(\mathbf{S 1 6})$ 
$t-\mathrm{BuMe}_{2} \mathrm{SiO}_{\mathrm{Fmoc}}$

The procedure used was identical with that used for the preparation of S13. Yield 37.1\% as a white solid: ${ }^{1} \mathrm{H}$ NMR $\left(300 \mathrm{MHz}, \mathrm{CDCl}_{3}\right) \square 10.15(\mathrm{~s}, 1 \mathrm{H}), 7.82-7.67(\mathrm{~m}, 2 \mathrm{H}), 7.67-$ $7.50(\mathrm{~m}, 2 \mathrm{H}), 7.50-7.22(\mathrm{~m}, 4 \mathrm{H}), 4.63-4.10(\mathrm{~m}, 5 \mathrm{H}), 3.75-3.58(\mathrm{~m}, 1 \mathrm{H}), 3.53-3.36(\mathrm{~m}$, 1H), 2.45-2.12 (m, 2H), $0.89(\mathrm{~s}, 9 \mathrm{H}), 0.07(\mathrm{~s}, 6 \mathrm{H}) ;{ }^{13} \mathrm{C}\{\mathrm{H}\}$ NMR $\left(75 \mathrm{MHz}, \mathrm{CDCl}_{3}\right) \square$ $176.39,175.84,155.13,154.49,143.83,143.55,141.12,127.54,126.93,126.88,125.07$, $124.90,124.80,119.83,70.48,69.80,67.69,57.90,57.60,55.13,54.81,47.12,39.47$, 38.28, 25.62, 17.91, -4.86; ${ }^{29} \mathrm{Si}\{\mathrm{H}\}$ INEPT NMR (60MHz, $\left.\mathrm{CDCl}_{3}\right) \square 20.93,20.34$; FT-IR (KBr) 3066, 2952, 2886, 2856, 1709, 1420, 1356, 1253, 1217, 1095, 1023, 1006, 920, $898,837,776,758,740,675,621,547,425 \mathrm{~cm}^{-1} ; \mathrm{R}_{f}(1: 19$ methyl alcoholdichloromethane) 0.39; HRFAB calcd. for $\mathrm{C}_{26} \mathrm{H}_{32} \mathrm{NO}_{5} \mathrm{SiLi}_{2}(\mathrm{M}+2 \mathrm{Li}-\mathrm{H})^{+} 480.2370$, found 480.2379 .

(S)-2-Hydroxy-3-methylbutiric acid benzyl ester (16)<smiles>CC(C)C(O)C(=O)OCc1ccccc1</smiles>

A round-bottomed flask equipped with a magnetic stirrer and Dean-Stark receiver was charged with (S)-(+)-2-hydroxy-3-methylbutiric acid (575.0 mg, $4.868 \mathrm{mmol})$, TsOH:H $\mathrm{H}_{2} \mathrm{O}$ (catalytic amount), benzyl alcohol $(15.0 \mathrm{~mL})$ and benzene $(50 \mathrm{~mL})$. The mixture was refluxed overnight, cooled to room temperature, and poured into EtOAc /5\% aqueous $\mathrm{NaHCO}_{3}(150 \mathrm{~mL}: 100 \mathrm{~mL})$. The organic layer was separated, washed with $5 \%$ aqueous 
$\mathrm{NaCl}$ (100 mL), and dried over $\mathrm{MgSO}_{4}$. After purification by flash chromatography (1:9 ethyl acetate-hexane; the product goes right above of benzyl alcohol) the desired product was obtained as a clear oil (882.1 mg, $87.1 \%$ yield): ${ }^{1} \mathrm{H}$ NMR (300 MHz, $\left.\mathrm{CDCl}_{3}\right) \square 7.40-$ $7.24(\mathrm{~m}, 5 \mathrm{H}), 5.24(\mathrm{~d}, J=12.1 \mathrm{~Hz}, 1 \mathrm{H}), 5.18(\mathrm{~d}, J=12.1 \mathrm{~Hz}, 1 \mathrm{H}), 4.08(\mathrm{dd}, J=6.3,3.6$ $\mathrm{Hz}, 1 \mathrm{H}), 2.85(\mathrm{~d}, J=6.3 \mathrm{~Hz}, 1 \mathrm{H}), 2.09$ (septet of doubles, $J=6.9,3.6 \mathrm{~Hz}, 1 \mathrm{H}), 1.00(\mathrm{~d}, J$ $=7.1 \mathrm{~Hz}, 3 \mathrm{H}), 0.83(\mathrm{~d}, J=6.9 \mathrm{~Hz}, 3 \mathrm{H}) ;{ }^{13} \mathrm{C}\{\mathrm{H}\} \mathrm{NMR}\left(75 \mathrm{MHz}, \mathrm{CDCl}_{3}\right) \square$ 174.72, $135.14,128.54,128.45,128.33,74.94,67.14,32.08,18.70,15.81$; FT-IR (thin film) $3510,3067,3035,2964,2934,2876,1735,1498,1456,1388,1370,1261,1214,1178$, $1138,1106,1070,1030,974,914,831,751,698,601 \mathrm{~cm}^{-1} ; \mathrm{R}_{f}(1: 5$ ethyl acetate-hexane) 0.48; HRFAB calcd. for $\mathrm{C}_{12} \mathrm{H}_{17} \mathrm{O}_{3}(\mathrm{M}+\mathrm{H})^{+} 209.1178$, found 209.1169.

Fmoc- $N$-Pro-OCH $\left(S-{ }^{i} \mathrm{Pr}\right) \mathrm{CO}_{2} \mathrm{Bn}(\mathbf{S 1 7})$<smiles>CC(C)C(OC(=O)C1CCCN1F)C(=O)OCc1ccccc1</smiles>

Fmoc- $N$-Pro-OH (1.008 g, $2.987 \mathrm{mmol})$ was added to a solution of L- $\mathrm{C}$ hydroxyisovaleric acid benzyl ester $(622.1 \mathrm{mg}, 2.987 \mathrm{mmol})$ in $\mathrm{CH}_{2} \mathrm{Cl}_{2}(7.0 \mathrm{~mL})$. 4(Dimethylamino)pyridine (72.99 mg, $597.3 \square \mathrm{mol}$ ) was added, followed by DIC (465.9 $\square \mathrm{L}, 2.987 \mathrm{mmol}$ ), and the solution was stirred at room temperature for $24 \mathrm{~h}$. The solution turned yellow and cloudy 2-3 min after DIC addition. Next day $\mathrm{CH}_{2} \mathrm{Cl}_{2}$ was removed, and EtOAc $(3.0 \mathrm{~mL})$ was added. The resulting suspension was subjected to flash chromatography (using eluent gradient 1:4 ethyl acetate-hexane to 1:2 ethyl acetatehexane) to give $1.127 \mathrm{~g}$ (71.5\% yield) of the title compound as an colorless oil. The NMR spectra are reported for a mixture of two rotamers: ${ }^{1} \mathrm{H}$ NMR $\left(300 \mathrm{MHz}, \mathrm{CDCl}_{3}\right) \square 7.80$ - 
$7.74(\mathrm{~m}, 2 \mathrm{H}), 7.67-7.54(\mathrm{~m}, 2 \mathrm{H}), 7.44-7.27(\mathrm{~m}, 9 \mathrm{H}), 5.24(\mathrm{~d}, J=12.1 \mathrm{~Hz}, 0.6 \mathrm{H}), 5.21(\mathrm{~d}$, $J=12.1 \mathrm{~Hz}, 0.4 \mathrm{H}), 5.13(\mathrm{~d}, J=12.4 \mathrm{~Hz}, 0.6 \mathrm{H}), 5.11(\mathrm{~d}, J=12.1,0.4 \mathrm{H}), 5.02(\mathrm{~d}, J=4.1$ $\mathrm{Hz}, 0.6 \mathrm{H}), 4.96(\mathrm{~d}, J=4.1 \mathrm{~Hz}, 0.4 \mathrm{H}), 4.56-4.17(\mathrm{~m}, 4 \mathrm{H}), 3.75-3.62(\mathrm{~m}, 1 \mathrm{H}), 3.57-3.45$ (m, 1H), 2.36-2.15 (m, 3H), 2.02-1.81 (m, 2H), $1.04(\mathrm{~d}, J=6.9,2 \mathrm{H}), 0.98(\mathrm{~d}, J=7.1 \mathrm{~Hz}$, $2 \mathrm{H}), 0.95(\mathrm{~d}, J=6.9 \mathrm{~Hz}, 1 \mathrm{H}), 0.93(\mathrm{~d}, J=6.9 \mathrm{~Hz}, 1 \mathrm{H}) ;{ }^{13} \mathrm{C}\{\mathrm{H}\}$ NMR $\left(75 \mathrm{MHz}, \mathrm{CDCl}_{3}\right) \square$ $172.21,172.08,169.33,169.03,154.81,154.34,144.30,144.05,143.80,143.62,141.21$, $141.18,141.09,135.13,135.04,128.50,128.43,128.36,128.34,127.59,127.52,126.97$, $126.94,126.89,125.20,125.15,125.02,124.94,119.87,119.82,76.88,67.60,67.38$, $66.95,66.86,58.69,58.41,47.14,47.10,46.87,46.39,30.67,30.00,29.93,29.45,24.05$, 23.09, 18.60, 17.01; FT-IR (thin film) 3066, 3037, 2968, 2879, 2251, 1747, 1705, 1451, $1417,1351,1271,1174,1127,1090,1020,990,912,759,739,699,648,622,588,542$ $\mathrm{cm}^{-1} ; \mathrm{R}_{f}\left(1: 2\right.$ ethyl acetate-hexane) 0.34; HRFAB calcd. for $\mathrm{C}_{32} \mathrm{H}_{34} \mathrm{NO}_{6}(\mathrm{M}+\mathrm{H})^{+}$528.2386, found 528.2408.

Fmoc- $N$-Pro-OCH $\left(S-{ }^{i} \mathrm{Pr}\right) \mathrm{CO}_{2} \mathrm{H}(\mathbf{1 9})$<smiles>CC(C)C(OC(=O)C1CCCN1P)C(=O)O</smiles>

The procedure used was identical with that used for the preparation of S13. The crude product was purified by flash chromatography (1:19 methyl alcohol-dichloromethane) to afford the product $\left(82.1 \%\right.$ yield) as a white foam : ${ }^{1} \mathrm{H}$ NMR NMR (300 $\left.\mathrm{MHz}, \mathrm{CDCl}_{3}\right) \square$ $10.38(\mathrm{~s}, 1 \mathrm{H}), 7.79-7.73(\mathrm{~m}, 2 \mathrm{H}), 7.65-7.53(\mathrm{~m}, 2 \mathrm{H}), 7.44-7.24(\mathrm{~m}, 4 \mathrm{H}), 4.98(\mathrm{dd}, J=$ 23.4, 3.9 Hz, 1H), 4.57-4.16 (m, 4H), 3.74-3.64 (m, 1H), 3.57-3.44 (m, 1H), 2.37-2.15 (m, 3H), 2.15-1.79 (m, 2H), 1.20-0.80 (m, 6H); ${ }^{13} \mathrm{C}\{\mathrm{H}\}$ NMR $\left(75 \mathrm{MHz}, \mathrm{CDCl}_{3}\right)$ 
173.82, 173.71, 171.87, 171.65, 155.04, 154.47, 144.00, 143.76, 143.54, 143.33, 141.06, 141.03, 140.95, 127. 50, 127.44, 126.86, 126.79, 125.08, 124.99, 124.90, 124.82, 119.77, $119.73,76.58,67.78,67.64,58.87,58.52,47.10,47.06,46.95,46.49,30.73,29.99,29.87$, 29.59, 24.18, 23.18, 18.74, 18.70, 17.06, 17.01; FT-IR (KBr) 2968, 2880, 1750, 1707, $1670,1450,1355,1177,1127,1090,1017,985,759,740,621,543,426 \mathrm{~cm}^{-1} ; \mathrm{R}_{f}(1: 19$ methyl alcohol-dichloromethane) 0.36; HRFAB calcd. for $\mathrm{C}_{25} \mathrm{H}_{27} \mathrm{NO}_{6} \mathrm{Li}(\mathrm{M}+\mathrm{Li})^{+}$ 444.1998, found 444.2001.

Fmoc- $N$-Pro-Glyco-OBn (S18)<smiles>O=C(COC(=O)C1CCCN1F)OCc1ccccc1</smiles>

The procedure used was identical with that used for the preparation of S17. Yield 75.9\% as a white solid. The NMR spectra are reported for a mixture of two rotamers: ${ }^{1} \mathrm{H}$ NMR $\left(300 \mathrm{MHz}, \mathrm{CDCl}_{3}\right) \square 7.74(\mathrm{t}, J=7.1 \mathrm{~Hz}, 2 \mathrm{H}), 7.60(\mathrm{t}, J=8.0 \mathrm{~Hz}, 1 \mathrm{H}), 7.54(\mathrm{t}, J=8.0 \mathrm{~Hz}$, 1H), 7.45-7.22 (m, 9H), $5.14(\mathrm{dd}, J=11.8,3.0 \mathrm{~Hz}, 2 \mathrm{H}), 4.85(\mathrm{~d}, J=15.9 \mathrm{~Hz}, 0.5 \mathrm{H}), 4.64$ $(\mathrm{d}, J=15.9 \mathrm{~Hz}, 0.5 \mathrm{H}), 4.58(\mathrm{~d}, J=15.9 \mathrm{~Hz}, 0.5 \mathrm{H}), 4.53-4.10(\mathrm{~m}, 4.5 \mathrm{H}), 3.72-3.54(\mathrm{~m}$, $1 \mathrm{H}), 3.54-3.38(\mathrm{~m}, 1 \mathrm{H}), 2.25-2.08(\mathrm{~m}, 2 \mathrm{H}), 2.08-1.74(\mathrm{~m}, 2 \mathrm{H}) ;{ }^{13} \mathrm{C}\{\mathrm{H}\}$ NMR $(75 \mathrm{MHz}$, $\left.\mathrm{CDCl}_{3}\right) \square 171.84,171.79,167.38,167.16,154.74,154.20,144.08,143.98,143.77$, $143.70,141.19,134.82,134.74,128.53,128.48,128.38,127.55,127.52,127.46,126.91$, $126.85,125.06,124.97,124.83,124.69,119.85,119.80,67.36,67.09,67.06,60.77$, $60.68,58.87,58.35,47.09,46.81,46.38,30.74,29.63,24.11,23.07$; FT-IR (KBr) 3502, 3467, 3394, 3090, 3062, 3031, 2986, 2965, 2949, 2891, 1963, 1924, 1816, 1762, 1741, $1706,1479,1450,1420,1355,1337,1278,1260,1163,1133,1092,994,912,762,742$, 
695, 611, 548, 465, $430 \mathrm{~cm}^{-1} ; \mathrm{R}_{f}$ (1:2 ethyl acetate-hexane) 0.27 ; HRFAB calcd. for $\mathrm{C}_{29} \mathrm{H}_{27} \mathrm{NO}_{6} \mathrm{Li}(\mathrm{M}+\mathrm{Li})^{+} 492.1998$, found 492.1975.

Fmoc- $N$-Pro-Glyco-OH (17)<smiles>O=C(O)COC(=O)C1CCCN1CO</smiles>

The procedure used was identical with that used for the preparation of S13. The crude product was purified by flash chromatography (1:39 methyl alcohol-dichloromethane) to afford the product (74.1\% yield) as a white foam. The NMR spectra are reported for a mixture of two rotamers: ${ }^{1} \mathrm{H}$ NMR $\left(300 \mathrm{MHz}, \mathrm{CDCl}_{3}\right) \square 7.76(\mathrm{t}, J=7.1 \mathrm{~Hz}, 2 \mathrm{H}), 7.63-$ 7.49 (m, 2H), 7.44-7.35 (m, 2H), 7.35-7.27 (m, 2H), $7.14(\mathrm{~s}, 1 \mathrm{H}), 4.81(\mathrm{~d}, J=16.5 \mathrm{~Hz}$, $0.5 \mathrm{H}), 4.61(\mathrm{~d}, J=16.5 \mathrm{~Hz}, 0.5 \mathrm{H}), 4.65-4.08(\mathrm{~m}, 5 \mathrm{H}), 3.70-3.56(\mathrm{~m}, 1 \mathrm{H}), 3.56-3.42(\mathrm{~m}$, $1 \mathrm{H}), 2.32-2.10(\mathrm{~m}, 2 \mathrm{H}), 2.10-1.82(\mathrm{~m}, 2 \mathrm{H}) ;{ }^{13} \mathrm{C}\{\mathrm{H}\}$ NMR (75 MHz, $\left.\mathrm{CDCl}_{3}\right) \square$ 171.68, $171.59,171.24,155.26,154.55,144.04,143.87,143.69,141.28,127.69,127.64,127.57$, $127.03,126.95,125.10,125.02,124.90,124.75,119.96,119.90,67.74,67.31,60.58$, 60.31, 59.03, 58.45, 47.09, 46.92, 46.57, 30.81, 29.75, 24.28, 23.18; FT-IR (KBr) 2956, $1751,1702,1424,1354,1167,1129,1091,759,741,621,426 \mathrm{~cm}^{-1} ; \mathrm{R}_{f}(1: 19$ methyl alcohol-dichloromethane) 0.36; HRFAB calcd. for $\mathrm{C}_{22} \mathrm{H}_{21} \mathrm{NO}_{6} \mathrm{Li}(\mathrm{M}+\mathrm{Li})^{+} 402.1529$, found 402.1538 .

Fmoc- $N$-Pro-Lac-OBn (S19)<smiles>CC(Cc1ccccc1)C(=O)OCC(=O)C1CCCN1F</smiles> 
The procedure used was identical with that used for the preparation of S17. Yield 79.2\% as a clear oil: ${ }^{1} \mathrm{H}$ NMR $\left(300 \mathrm{MHz}, \mathrm{CDCl}_{3}\right) \square 7.79-7.70(\mathrm{~m}, 2 \mathrm{H}), 7.65-7.50(\mathrm{~m}, 2 \mathrm{H})$, 7.43$7.22(\mathrm{~m}, 9 \mathrm{H}), 5.27-5.04(\mathrm{~m}, 3 \mathrm{H}), 4.56-4.12(\mathrm{~m}, 4 \mathrm{H}), 3.72-3.57(\mathrm{~m}, 1 \mathrm{H}), 3.56(\mathrm{~m}, 1 \mathrm{H})$, 2.28-2.10 (m, 2H), 2.01-1.77 (m, 2H), $1.53(\mathrm{~d}, J=7.1 \mathrm{~Hz}, 1 \mathrm{H}), 1.48(\mathrm{~d}, J=7.1 \mathrm{~Hz}, 1 \mathrm{H})$, $1.42(\mathrm{~d}, J=6.9 \mathrm{~Hz}, 1 \mathrm{H}) ;{ }^{13} \mathrm{C}\{\mathrm{H}\}$ NMR $\left(75 \mathrm{MHz}, \mathrm{CDCl}_{3}\right) \square 171.80,170.43,170.17$, $154.82,154.27,144.24,144.07,143.80,143.63,141.22,141.19,141.14,135.16,135.09$, $135.01,128.56,128.53,128.43,128.39,128.20,128.17,128.13,127.58,127.51,126.97$, $126.94,126.86,125.13,125.01,124.79,119.86,119.82,119.78,68.81,67.42,67.16$, $67.08,67.01,66.74,58.73,58.27,47.23,47.12,46.88,46.42,30.54,29.41,24.07,23.06$, 20.30, 16.77, 16.69; FT-IR (thin film) 3482, 3066, 3036, 2983, 2956, 2883, 2251, 1748, $1705,1498,1478,1452,1418,1352,1269,1173,1130,1090,1046,988,958,912,759$, $740,699,622,426 \mathrm{~cm}^{-1} ; \mathrm{R}_{f}\left(1: 2\right.$ ethyl acetate-hexane) 0.32; HRFAB calcd. for $\mathrm{C}_{30} \mathrm{H}_{30} \mathrm{NO}_{6}$ $(\mathrm{M}+\mathrm{H})^{+}$500.2073, found 500.2082.

Fmoc- $N$-Pro-Lac-OH (18)<smiles>O=C(O)COC(=O)C1CCCN1CCO</smiles>

The procedure used was identical with that used for the preparation of S13. The crude product was purified by flash chromatography (1:39 methyl alcohol-dichloromethane) to afford the product (73.6\% yield) as a white foam. The NMR spectra are reported for a mixture of two rotamers: ${ }^{1} \mathrm{H}$ NMR $\left(300 \mathrm{MHz}, \mathrm{CDCl}_{3}\right) \square 9.41(\mathrm{~s}, 1 \mathrm{H}), 7.80-7.72(\mathrm{~m}, 2 \mathrm{H})$, 7.64-7.50 (m, 2H), 7.44-7.25 (m, 4H), 5.27-5.15 (m, 0.5H), 5.09-4.97 (m, 0.5H), 4.55$4.12(\mathrm{~m}, 4 \mathrm{H}), 3.72-3.57(\mathrm{~m}, 1 \mathrm{H}), 3.57-3.43(\mathrm{~m}, 1 \mathrm{H}), 2.31-2.15(\mathrm{~m}, 2 \mathrm{H}), 2.05-1.84(\mathrm{~m}$, 
$2 \mathrm{H}), 1.55(\mathrm{~d}, J=7.1 \mathrm{~Hz}, 1.5 \mathrm{H}), 1.50(\mathrm{~d}, J=6.5 \mathrm{~Hz}, 1.5 \mathrm{H}) ;{ }^{13} \mathrm{C}\{\mathrm{H}\} \mathrm{NMR}(75 \mathrm{MHz}$, $\left.\mathrm{CDCl}_{3}\right) \square 174.88,174.63,171.49,155.00,154.45,143.92,143.77,143.52,143.33$, $141.05,141.02,127.50,127.43,126.85,126.77,124.99,124.89,124.65,119.78,119.72$ $119.68,68.54,68.46,67.63,67.37,58.83,58.35,47.16,47.06,46.95,46.52,30.60,29.54$, 24.17, 23.16, 16.77, 16.73; FT-IR (KBr) 2984, 2886, 1752, 1707, 1450, 1354, 1176, 1130, 1091, 1043, 986, 759, 741, $424 \mathrm{~cm}^{-1} ; \mathrm{R}_{f}(1: 19$ methyl alcohol-dichloromethane) 0.39; HRFAB calcd. for $\mathrm{C}_{23} \mathrm{H}_{23} \mathrm{NO}_{6} \mathrm{Li}(\mathrm{M}+\mathrm{Li})^{+} 416.1685$, found 416.1683 .

\section{Resolution of racemic nipecotic acid with enantiomerically pure camphorsulfonic acid.}

(1S)-(+)-10-Camphorsulfonic acid (44.96 g, $193.56 \mathrm{mmol})$ was added to a stirred solution of racemic nipecotic acid $(25.00 \mathrm{~g}, 193.56 \mathrm{mmol})$ in acetone $(400 \mathrm{~mL})$. The solution was heated to reflux, and $\mathrm{H}_{2} \mathrm{O}$ was added until all solids dissolved. The solution was cooled to room temperature and allowed to stir overnight. The precipitate was isolated by filtration and dried in vacuo. The same procedure was repeated twice to afford $10.59 \mathrm{~g}(15 \%$ yield $)$ of the desired product as a white solid.

\section{HPLC analysis of enantiomeric purity of nipecotic acid (method A).}

In this method, HPLC was performed on the 2-naphthylmethyl ester of Boc-Nip.

The procedure of Boc-protection is as follows. $1 \mathrm{~N} \mathrm{NaOH}(5 \mathrm{~mL})$ was added to a $0{ }^{\circ} \mathrm{C}$ solution of (S)-nipecotic acid (1S)-(+)-10-camphorsulfonic acid salt (0.90 g, $2.50 \mathrm{mmol})$ in dioxane $/ \mathrm{H}_{2} \mathrm{O}(1 / 1, \mathrm{v} / \mathrm{v})$ mixture $(8 \mathrm{~mL})$. (Boc $)_{2} \mathrm{O}(0.60 \mathrm{~g}, 2.75 \mathrm{mmol})$ was added slowly (approximately $5 \mathrm{~min}$ ) to the mixture, which was then warmed to room 
temperature. After stirring $1 \mathrm{~h}$, the solution was concentrated under reduced pressure. The remaining aqueous mixture was acidified to $\mathrm{pH} 2-3$ (using $1 \mathrm{~N} \mathrm{HCl}$ ) and extracted with ethyl acetate. The organic layer was washed with brine and dried over $\mathrm{MgSO}_{4}$. Concentration and drying under vacuum to afford the desired product $(0.47 \mathrm{~g}, 82 \%)$ as a white solid. Compound data was already reported. ${ }^{8}$

Boc-Nip-OH was converted to the corresponding 2-naphthylmethyl ester as follows. Boc-Nip-OH(0.25 g, $1.10 \mathrm{mmol})$ was dissolved in N,N-dimethylformamide (DMF) (5 $\mathrm{mL}), \mathrm{Cs}_{2} \mathrm{CO}_{3}(0.36 \mathrm{~g}, 1.10 \mathrm{mmol})$ and 2-(bromomethyl)naphthalene $(0.27 \mathrm{~g}, 1.2 \mathrm{mmol})$ were added, and the solution was stirred at room temperature for $24 \mathrm{~h}$. The solution was then concentrated, and the residue was dissolved in $\mathrm{H}_{2} \mathrm{O}$. The aqueous solution was extracted with $\mathrm{CH}_{2} \mathrm{Cl}_{2}$. The organic layer was dried over $\mathrm{MgSO}_{4}$ and concentrated to give oil. The crude product was purified by silica gel column chromatography $(50 \% \mathrm{AcOEt}$ in Hexane, $\mathrm{Rf}=0.43)$ to afford $0.29 \mathrm{~g}(70 \%$ yield $)$ of the desired product as a white solid. Compound data was already reported. ${ }^{8}$

HPLC conditions for checking enantiomeric purity of the 2-naphtylmethyl ester of Boc-Nip are as follows: column; Daicel OD flow rate ; $1.0 \mathrm{ml} / \mathrm{min} \mathrm{UV} \mathrm{;} 254 \mathrm{~nm}$, solvent system ; $5 \% i$-PrOH in Hexane column temp. ; $20{ }^{\circ} \mathrm{C}, \mathrm{Rt}=10.7 \mathrm{~min}$ for (S)-isomer and $11.4 \min$ for (R)-isomer.

\section{HPLC analysis of enantiomeric purity (method B).}

In this method, the enantiomeric purity of Fmoc-Nip-OH can be checked directly. HPLC conditions for checking enantiomeric purity of Fmoc-Nip-OH are as follows: column ; 
Daicel OD flow rate ; $0.8 \mathrm{ml} / \mathrm{min} \mathrm{UV} ; 204 \mathrm{~nm}$, solvent system; $10 \% i$-PrOH in Hexane column temp; $25^{\circ} \mathrm{C}, \mathrm{Rt}=7.6 \mathrm{~min}$ for $(\mathrm{S})$-isomer and $8.9 \mathrm{~min}$ for $(\mathrm{R})$-isomer.

Fmoc-Nip-OH (S20)<smiles>O=C(O)[C@@H]1CCCN(P)C1</smiles>

(S)-Nipecotic acid (1S)-(+)-10-camphorsulfonic acid salt (6.00 g, $16.60 \mathrm{mmol})$ was dissolved in $9 \% \mathrm{NaHCO}_{3}$ solution $(78.20 \mathrm{~g}, 66.40 \mathrm{mmol})$ and cooled to $0{ }^{\circ} \mathrm{C}$. A solution of Fmoc-OSU $(4.76 \mathrm{~g}, 14.11 \mathrm{mmol})$ in dioxane $(44 \mathrm{~mL})$ was added in one portion at $0{ }^{\circ} \mathrm{C}$, and the reaction mixture was warmed to room temperature. After TLC showed that all Fmoc-OSU disappeared (ca. 10 min), the reaction mixture was diluted with $\mathrm{H}_{2} \mathrm{O}$ (440 $\mathrm{mL}$ ), extracted with ether (one time) and ethyl acetate (twice). The remaining aqueous phase is cooled to $0{ }^{\circ} \mathrm{C}$ and acidified to $\mathrm{pH} 2$ with conc. $\mathrm{HCl}$. The aqueous phase and white precipitate was extracted with ethyl acetate four times. The extract is washed with brine, $\mathrm{H}_{2} \mathrm{O}$, dried over $\mathrm{MgSO}_{4}$, and concentrated to give a white solid. The crude product was purified by recrystallization from EtOAc/Hexane mixture to afford $4.06 \mathrm{~g}(82 \%$ yield) of the desired product as a white solid. ${ }^{4} \mathrm{H}$ NMR $\left(300 \mathrm{MHz}, \mathrm{CDCl}_{3}\right) \square 7.78-7.74$ (m, 2H), 7.59-7.56 (m, 2H), 7.42-7.25 (m, 4H), $4.44(\mathrm{~d}, \mathrm{~J}=6.59 \mathrm{~Hz}, 2 \mathrm{H}), 4.24(\mathrm{t}, \mathrm{J}=6.59$, $1 \mathrm{H}), 4.18-4.08(\mathrm{~m}, 1 \mathrm{H}), 3.89-3.80(\mathrm{~m}, 1 \mathrm{H}), 3.20-3.00(\mathrm{~m}, 1 \mathrm{H}), 2.96-2.88(\mathrm{~m}, 1 \mathrm{H}), 2.58-$ $2.30(\mathrm{~m}, 1 \mathrm{H}), 2.15-2.04(\mathrm{~m}, 1 \mathrm{H}), 1.78-1.60(\mathrm{~m}, 2 \mathrm{H}), 1.58-1.30(\mathrm{~m}, 1 \mathrm{H}) .{ }^{13} \mathrm{C}$ NMR $(75$ $\left.\mathrm{MHz}, \mathrm{CDCl}_{3}\right) \square 178.97,155.49,144.30,141.61,127.95,127.33,125.26,120.26,67.72$, 47.59, 45.82, 44.49, 41.26, 27.27, 24.34. LRFAB m/z (\% rel. intensity) $352\left(\mathrm{MH}^{+}, 60\right)$, 
246 (18), 179 (100), 165 (24), 154 (88), 137 (80), 107 (28). HRFAB calcd for $\mathrm{C}_{21} \mathrm{H}_{22} \mathrm{O}_{4} \mathrm{~N}$

$\left(\mathrm{MH}_{+}\right) 352.1549$, found 352.1554 .

Ac-Ala-Pps(S)-(R)-Nip-(S)-Nip-Pps(S)-Ala-NH 2 (21)

Rink amide MBHA resin was swollen with DMF for 20 min. Fmoc deprotection consisted of addition of $25 \%$ piperidine in DMF and then shaking the reaction vessel for 25 min. The resin was washed with DMF (X 3), MeOH (X 3), DMF (X 4). Peptide coupling steps were performed by standard Fmoc protocol. PyBOP/HOBt method was used for (R)-Nip-(S)-Nip coupling and (R)-Nip-Pps(S) coupling, and DIC/HOBt method was used for all other coupling reactions. Fmoc-Ala-OH was used 5 equiv. but FmocNip-OH and Fmoc-Pps(s)-OH were used 3 equiv. for coupling reaction. Terminal acetylation was performed using excess $\mathrm{Ac}_{2} \mathrm{O}$ in the presence of $\mathrm{Et}_{3} \mathrm{~N}\left(\mathrm{DMF} / \mathrm{Ac}_{2} \mathrm{O} / \mathrm{Et}_{3} \mathrm{~N}\right.$ $=20 / 5 / 1, \mathrm{v} / \mathrm{v} / \mathrm{v})$. After acetylation, the peptide was cleaved by treatment with trifluoroacetic acid (TFA/TSI (triisopropylsilane) $/ \mathrm{H}_{2} \mathrm{O}=95 / 2.5 / 2.5, \mathrm{v} / \mathrm{v} / \mathrm{v}$ ) for $3 \mathrm{~h}$. The liquid was then filtered and the resin washed twice with TFA. The combined filtrates were concentrated on rotavap and added 8-10 fold volume of cold ether. The appeared white precipitate was isolated by filtration under a light vacuum or by using a centrifuge and dried in vacuo. The crude peptide was analyzed and purified by HPLC. Analytical HPLC conditions: column; $250 \mathrm{~mm}$ x $4.6 \mathrm{~mm}$ Ultrasphere C8 5u from Alltech flow rate; $0.5 \mathrm{ml} / \mathrm{mini}$. UV; $204 \mathrm{~nm}$ column temp.; $20{ }^{\circ} \mathrm{C}$ solvent system; $\mathrm{CH}_{3} \mathrm{CN} / \mathrm{H}_{2} \mathrm{O}=1 / 1$ (v/v). Preparative HPLC conditions: column; $250 \mathrm{~mm}$ x $22 \mathrm{~mm}$ Econosil C18 10u from Alltech, flow rate; $6.0 \mathrm{ml} / \mathrm{mini}$. UV; $204 \mathrm{~nm}$ column temp. ; $25^{\circ} \mathrm{C}$, solvent system; $\mathrm{CH}_{3} \mathrm{CN} / \mathrm{H}_{2} \mathrm{O}=$ $1 / 1(\mathrm{v} / \mathrm{v})$ 
(4S)-4-Benzyl-3-[(2E)-3-phenylprop-2-enoyl]-1,3-oxazolidin-2-one (S22)<smiles>O=C(/C=C/c1ccccc1)N1C(=O)OC[C@H]1Cc1ccccc1</smiles>

$\mathrm{MeMgCl}$ (3.0M in THF, $10.6 \mathrm{~mL}, 31.79 \mathrm{mmol})$ was added to a solution of (S)-(-)4-benzyl-2-oxazolidinone (5.522 $\mathrm{g}, 31.17 \mathrm{mmol})$ in $\mathrm{THF}(100 \mathrm{~mL})$ at $0^{\circ} \mathrm{C}$. The mixture was stirred in an ice bath for $30 \mathrm{~min}$, and a solution of cinnamoyl chloride $(5.711 \mathrm{~g}, 34.28$ mmol) in THF (20 mL) was added. The reaction was stirred in the ice bath for 15 min and at room temperature overnight. $2.0 \mathrm{M}$ aqueous $\mathrm{NH}_{4} \mathrm{Cl}(150 \mathrm{~mL})$ was added, and $\mathrm{THF}$ was removed under reduced pressure. The product was extracted with EtOAc $(250 \mathrm{~mL})$. The organic layer was washed with saturated $\mathrm{NaHCO}_{3}(150 \mathrm{~mL}), 2.0 \mathrm{M} \mathrm{NH} \mathrm{NCl}_{4}(150 \mathrm{~mL})$, dried over $\mathrm{Na}_{2} \mathrm{SO}_{4}$, filtered and concentrated in vacuo to afford $9.531 \mathrm{~g}$ (99.5\% yield) of the crude product as a yellow solid: ${ }^{1} \mathrm{H}$ NMR $\left(300 \mathrm{MHz}, \mathrm{CDCl}_{3}\right) \square 7.96$ (s, 2H), 7.75-7.60 (m, 2H), 7.50-7.20 (m, 8H), 4.90-4.72 (m, 1H), 4.32-4.13 (m, 2H), $3.40(\mathrm{dd}, J=13.4,3.2$ $\mathrm{Hz}, 1 \mathrm{H}), 2.88(\mathrm{dd}, J=13.4,9.5 \mathrm{~Hz}, 1 \mathrm{H}) ;{ }^{13} \mathrm{C}\{\mathrm{H}\}$ NMR $\left(75 \mathrm{MHz}, \mathrm{CDCl}_{3}\right) \square 165.09$, $153.45,146.33,135.27,134.43,130.65,129.39,128.87,128.82,128.59,127.24,116.90$, 66.07, 55.30, 37.80; FT-IR (KBr) 3516, 3338, 3285, 3095, 3085, 3062, 3027, 2973, 2962, $1958,1780,1758,1673,1619,1577,1498,1475,1450,1392,1350,1287,1215,1122$, $1082,1065,1043,1014,982,869,764,750,714,695,682,644,575,496,483 \mathrm{~cm}^{-1}$; HRFAB calcd. for $\mathrm{C}_{19} \mathrm{H}_{17} \mathrm{NO}_{3} \mathrm{Li}(\mathrm{M}+\mathrm{Li})^{+} 314.1368$, found 314.1358 . 
(4S)-4-Benzyl-3-[(3S)-3-(diphenylphosphorothioyl)-3-phenylpropanoyl]-1,3-oxazolidin2-one (S23)<smiles>O=C(C[C@H](c1ccccc1)P(=S)(c1ccccc1)c1ccccc1)N1C(=O)OC[C@H]1Cc1ccccc1</smiles>

(4S)-4-Benzyl-3-[(3R)-3-(diphenylphosphorothioyl)-3-phenylpropanoyl]-1,3-oxazolidin2-one (S24)<smiles>O=C(C[C@H](c1ccccc1)P(=O)(c1ccccc1)c1ccccc1)N1C(=O)OC[C@H]1Cc1ccccc1</smiles>

A solution of $\mathrm{Ph}_{2} \mathrm{PSH}(6.126 \mathrm{~g}, 28.06 \mathrm{mmol})$ in THF $(150 \mathrm{~mL})$ was cooled in an acetone/dry ice bath, and $\mathrm{BuLi}(1.8 \mathrm{M}$ in hexane, $15.6 \mathrm{~mL}, 28.06 \mathrm{mmol})$ was added. The mixture was stirred at $-78^{\circ} \mathrm{C}$ for $10 \mathrm{~min}$, and a solution of $(4 S)-4-B e n z y l-3-[(2 E)-3-$ phenylprop-2-enoyl]-1,3-oxazolidin-2-one (8.623 g, $28.06 \mathrm{mmol})$ in THF (50 $\mathrm{mL})$ was added via canula. The cooling bath was removed, and the reaction was allowed to warm to room temperature over $15-20$ min. $2.0 \mathrm{M}$ aqueous $\mathrm{NH}_{4} \mathrm{Cl}(150 \mathrm{~mL})$ was added followed by EtOAc $(350 \mathrm{~mL})$. The organic layer was separated, dried over $\mathrm{Na}_{2} \mathrm{SO}_{4}$ and concentrated in vacuo. The residue was checked by ${ }^{31} \mathrm{P}$ NMR $\left(120 \mathrm{MHz}, \mathrm{CDCl}_{3}\right)$, and two peaks of approximately equal intensity were observed at $\square 51.59$ and 51.10 . The diastereomers were separated by flash chromatography (1:3 ethyl acetate-hexane). S24: 
$5.313 \mathrm{~g}\left(36.0 \%\right.$ yield) was obtained as a white crystalline solid: ${ }^{1} \mathrm{H}$ NMR $(300 \mathrm{MHz}$, $\left.\mathrm{CDCl}_{3}\right) \square 8.30-8.14(\mathrm{~m}, 2 \mathrm{H}), 7.62-7.43(\mathrm{~m}, 5 \mathrm{H}), 7.39-7.09(\mathrm{~m}, 11 \mathrm{H}), 7.09-6.98(\mathrm{~m}, 2 \mathrm{H})$, $4.81(\mathrm{td}, J=10.7,3.6 \mathrm{~Hz}, 1 \mathrm{H}), 4.48-4.37(\mathrm{~m}, 1 \mathrm{H}), 4.13-3.95(\mathrm{~m}, 3 \mathrm{H}), 3.36(\mathrm{ddd}, J=17.3$, 9.3, 3.6 Hz, 1H), $2.90(\mathrm{dd}, J=16.8,13.5 \mathrm{~Hz}, 1 \mathrm{H}), 2.43(\mathrm{dd}, J=13.5,9.6 \mathrm{~Hz}, 1 \mathrm{H}) ;{ }^{13} \mathrm{C}$ $\{\mathrm{H}\}$ NMR $\left(75 \mathrm{MHz}, \mathrm{CDCl}_{3}\right) \square 170.34,170.10,152.99,134.89,134.16,134.10,132.17$, $132.05,131.83,131.79,131.55,131.42,131.17,131.13,130.80,130.46,130.08,130.01$, $129.79,129.12,128.78,128.62,127.93,127.77,127.71,127.68,127.51,127.47,127.18$, $66.15,54.87,42.63,41.94,37.20,36.78,36.72 ;{ }^{31} \mathrm{P}\{\mathrm{H}\}$ NMR $\left(120 \mathrm{MHz}, \mathrm{CDCl}_{3}\right)$ प51.62; FT-IR (KBr) 3550, 3372, 3054, 3024, 2999, 2973, 1952, 1891, 1797, 1775, $1696,1603,1584,1492,1453,1435,1391,1354,1331,1265,1202,1168,1109,1095$, $1052,1027,999,821,781,740,712,696,622,607,528,508,485,441,428 \mathrm{~cm}^{-1} ; \mathrm{R}_{f}(1: 2$ ethyl acetate-hexane) 0.32; HRFAB calcd. for $\mathrm{C}_{31} \mathrm{H}_{28} \mathrm{NO}_{3} \mathrm{PSLi}(\mathrm{M}+\mathrm{Li})^{+} 532.1688$, found 532.1675. $6.578 \mathrm{~g}$ (44.6\% yield) was obtained as a white foam: ${ }^{1} \mathrm{H}$ NMR $(300 \mathrm{MHz}$, $\left.\mathrm{CDCl}_{3}\right) \square 8.21-8.10(\mathrm{~m}, 2 \mathrm{H}), 7.58-7.48(\mathrm{~m}, 4 \mathrm{H}), 7.38-7.12(\mathrm{~m}, 12 \mathrm{H}), 6.92-6.85(\mathrm{~m}, 2 \mathrm{H})$, $4.73(\mathrm{dt}, J=10.7,3.6 \mathrm{~Hz}, 1 \mathrm{H}), 4.48-4.37(\mathrm{~m}, 1 \mathrm{H}), 4.20(\mathrm{ddd}, J=17.3,10.7,8.0 \mathrm{~Hz}, 1 \mathrm{H})$, 4.10-4.00 (m, 2H), $3.25(\mathrm{ddd}, J=17.5,9.9,3.6 \mathrm{~Hz}, 1 \mathrm{H}), 2.83(\mathrm{dd}, J=13.5,3.0 \mathrm{~Hz}, 1 \mathrm{H})$, $2.51(\mathrm{dd}, J=13.7,8.8 \mathrm{~Hz}, 1 \mathrm{H}) ;{ }^{13} \mathrm{C}\{\mathrm{H}\} \mathrm{NMR}\left(75 \mathrm{MHz}, \mathrm{CDCl}_{3}\right) \square$ 170.76, 170.53, $152.89,134.55,134.39,134.33,132.13,132.00,131.76,131.72,131.64,131.51,131.44$, $131.22,131.18,130.99,130.36,130.03,129.96,129.22,128.74,128.60,127.97,127.81$, $127.77,127.74,127.53,127.49,127.14,65.82,54.86,43.17,42.47,37.04,36.25,36.18$; ${ }^{31} \mathrm{P}\{\mathrm{H}\}$ NMR $\left(120 \mathrm{MHz}, \mathrm{CDCl}_{3}\right) \square 51.11$; FT-IR (KBr) 3650, 3538, 3372, 3058, 3028, 2920, 1962, 1892, 1780, 1696, 1601, 1584, 1494, 1480, 1437, 1375, 1257, 1215, 1102, 
$986,837,752,698,626,613,516,488 \mathrm{~cm}^{-1} ; \mathrm{R}_{f}(1: 2$ ethyl acetate-hexane) 0.23 ; HRFAB calcd. for $\mathrm{C}_{31} \mathrm{H}_{28} \mathrm{NO}_{3} \mathrm{PSLi}(\mathrm{M}+\mathrm{Li})^{+} 532.1688$, found 532.1665 .

(4S)-4-Benzyl-3-[(2R, 3R)-2-azido-3-(diphenylphosphorothioyl)-3-phenylpropanoyl]-1,3oxazolidin-2-one (S25)<smiles>NC(C(=O)N1CCOC1=O)[C@H](c1ccccc1)P(=S)(c1ccccc1)c1ccccc1</smiles>

A solution of $\mathbf{S 2 3}(2.383 \mathrm{~g}, 4.534 \mathrm{mmol})$ in THF $(15.0 \mathrm{~mL})$ was added to a solution of $\mathrm{KN}\left(\mathrm{SiMe}_{3}\right)_{2}(11.08 \mathrm{~mL}, 0.45 \mathrm{M}$ in toluene, $4.987 \mathrm{mmol})$ in $\mathrm{THF}(15.0 \mathrm{~mL})$ cooled to $-78^{\circ} \mathrm{C}$. The mixture was stirred at that temperature for $60 \mathrm{~min}$. A solution of 2,4,6-triisopropylbenzenesulfonyl azide $(1.683 \mathrm{~g}, 5.441 \mathrm{mmol})$ in THF $(15.0 \mathrm{~mL})$ was added followed by addition of acetic acid $(1.20 \mathrm{~mL}, 20.86 \mathrm{mmol})$ in THF $(5.0 \mathrm{~mL}) 2 \mathrm{~min}$ later. The cooling bath was removed, and the reaction was stirred overnight at room temperature. Next day it was neutralized with $5 \%$ aqueous $\mathrm{NaHCO}_{3}(150 \mathrm{~mL})$ and extracted with EtOAc $(250 \mathrm{~mL})$. The organic layer was washed with $5 \%$ aqueous $\mathrm{NaCl}$ $(100 \mathrm{~mL})$, dried over $\mathrm{Na}_{2} \mathrm{SO}_{4}$, filtered and concentrated in vacuo. The residue was purified by flash chromatography (1:2 ethyl acetate-hexane) to give $1.239 \mathrm{~g}(52.0 \%$ recovered yield) of the starting material and $844.2 \mathrm{mg}$ ( $32.9 \%$ yield) of the product as a white foam: ${ }^{1} \mathrm{H}$ NMR (300 MHz, $\mathrm{CDCl}_{3}$ ) $\square 8.26-8.14$ (m, 2H), 7.64-7.46 (m, 5H), 7.35$7.04(\mathrm{~m}, 13 \mathrm{H}), 6.31(\mathrm{dd}, J=9.3,6.9 \mathrm{~Hz}, 1 \mathrm{H}), 5.02(\mathrm{dd}, J=11.0,9.3 \mathrm{~Hz}, 1 \mathrm{H}), 4.53-4.42$ (m, 1H), 4.18-4.07 (m, 2H), $2.77(\mathrm{dd}, J=13.5,3.3 \mathrm{~Hz}, 1 \mathrm{H}), 2.31(\mathrm{dd}, J=13.5,10.7 \mathrm{~Hz}$, 
$1 \mathrm{H}) ;{ }^{13} \mathrm{C}\{\mathrm{H}\} \mathrm{NMR}\left(75 \mathrm{MHz}, \mathrm{CDCl}_{3}\right) \square 166.97,166.92,152.49,135.18,132.52,132.46$, $132.00,131.87,131.75,131.62,131.51,131.47,130.88,130.85,130.81,130.69,130.24$, $130.17,129.61,129.00,128.69,128.31,128.15,128.10,127.86,127.82,127.56,127.40$, $126.97,66.43,62.21,62.12,55.27,48.29,47.66,37.11 ;{ }^{31} \mathrm{P}\{\mathrm{H}\} \mathrm{NMR}\left(120 \mathrm{MHz}, \mathrm{CDCl}_{3}\right)$ C 46.85; FT-IR (KBr) 3330, 3058, 3028, 2106, 1782, 1702, 1602, 1584, 1494, 1479, $1454,1437,1390,1264,1211,1098,996,751,697,628,611,526,517,485 \mathrm{~cm}^{-1} ; \mathrm{R}_{f}(1: 2$ ethyl acetate-hexane) 0.41; HRFAB calcd. for $\mathrm{C}_{31} \mathrm{H}_{27} \mathrm{~N}_{4} \mathrm{O}_{3} \mathrm{PSLi}(\mathrm{M}+\mathrm{Li})^{+} 573.1702$, found 573.1680.

(4S)-4-Benzyl-3-[(2R, 3S)-2-azido-3-(diphenylphosphorothioyl)-3-phenylpropanoyl]-1,3oxazolidin-2-one (S26)<smiles>NC(C(=O)N1C(=O)OC[C@H]1Cc1ccccc1)C(c1ccccc1)P(=O)(c1ccccc1)c1ccccc1</smiles>

The procedure used was identical with that used for the preparation of S25. Yield 51.7\% as a white foam: ${ }^{1} \mathrm{H}$ NMR (300 MHz, $\left.\mathrm{CDCl}_{3}\right) \square 8.21-8.10(\mathrm{~m}, 2 \mathrm{H}), 7.63-7.47$ (m, 5H), 7.35-7.07 (m, 13H), $6.17(\mathrm{dd}, J=10.7,8.0 \mathrm{~Hz}, 1 \mathrm{H}), 4.92(\mathrm{t}, J=10.4 \mathrm{~Hz}, 1 \mathrm{H}), 4.17-$ $4.06(\mathrm{~m}, 2 \mathrm{H}), 3.93-3.83(\mathrm{~m}, 1 \mathrm{H}), 3.12(\mathrm{dd}, J=13.7,3.3 \mathrm{~Hz}, 1 \mathrm{H}), 2.75(\mathrm{dd}, J=13.5,9.3$ $\mathrm{Hz}, 1 \mathrm{H}) ;{ }^{13} \mathrm{C}\{\mathrm{H}\}$ NMR $\left(75 \mathrm{MHz}, \mathrm{CDCl}_{3}\right) \square 168.01,152.62,134.71,132.45,132.39$, 132.30, 132.18, 132.07, 131.94, 131.81, 131.74, 131.70, 131.21, 131.17, 130.79, 130.40, $130.33,130.26,129.26,128.82,128.37,128.21,127.95,127.91,127.80,127.63,127.29$, $66.36,59.98,59 . .85,55.41,48.90,48.27,37.38 ;{ }^{31} \mathrm{P}\{\mathrm{H}\}$ NMR $\left(120 \mathrm{MHz}, \mathrm{CDCl}_{3}\right)$ 
प46.53; FT-IR (KBr) 3280, 3058, 3028, 2961, 2926, 2109, 1781, 1706, 1601, 1494, $1454,1437,1389,1212,1097,997,750,699,630,612,518,486 \mathrm{~cm}^{-1} ; \mathrm{R}_{f}(1: 2$ ethyl acetate-hexane) 0.32; HRFAB calcd. for $\mathrm{C}_{31} \mathrm{H}_{27} \mathrm{~N}_{4} \mathrm{O}_{3} \mathrm{PSLi}(\mathrm{M}+\mathrm{Li})^{+}$573.1702, found 573.1655.

(2R, 3R)-2-azido-3-(diphenylphosphorothioyl)-3-phenylpropanoic acid (S27)<smiles>N[C@H](C(=O)O)[C@H](c1ccccc1)P(=S)(c1ccccc1)c1ccccc1</smiles>

A precooled $0.2 \mathrm{M}$ solution of $\mathrm{LiOH}$ in water $(11.0 \mathrm{~mL}, 2.205 \mathrm{mmol})$ was added to a solution of $\mathbf{S 2 5}(624.9 \mathrm{mg}, 1.103 \mathrm{mmol})$ in $\mathrm{THF}(33.1 \mathrm{~mL})$ at $0^{\circ} \mathrm{C}$. After stirring for $15 \mathrm{~min}$ at $0^{\circ} \mathrm{C}$ the reaction was quenched with $5 \%$ aqueous $\mathrm{HCl}(100 \mathrm{~mL})$, and THF was removed in vacuo. The aqueous layer was extracted with EtOAc $(3 \times 100 \mathrm{~mL})$. The combined organic extracts were dried over $\mathrm{Na}_{2} \mathrm{SO}_{4}$, filtered and concentrated in vacuo. The residue was purified by flash chromatography (1:30:70 acetic acid-ethyl acetatehexane) to give $251.8 \mathrm{mg}$ (56.0\% yield) of the product as a white foam: ${ }^{1} \mathrm{H}$ NMR (300 $\left.\mathrm{MHz}, \mathrm{CDCl}_{3}\right) \square 9.03(\mathrm{~s}, 1 \mathrm{H}), 8.04-7.92(\mathrm{~m}, 2 \mathrm{H}), 7.58-7.32(\mathrm{~m}, 6 \mathrm{H})$, 7.30-7.07 (m, 7H), $5.19(\mathrm{dd}, J=8.8,6.0 \mathrm{~Hz}, 1 \mathrm{H}), 4.43(\mathrm{dd}, J=12.9,6.0 \mathrm{~Hz}, 1 \mathrm{H}) ;{ }^{13} \mathrm{C}\{\mathrm{H}\} \mathrm{NMR}(75 \mathrm{MHz}$, $\left.\mathrm{CDCl}_{3}\right) \square 174.55,174.42,132.51,132.38,132.13,132.01,131.61,131.57,131.42$, $131.36,130.90,130.77,130.70,129.85,129.69,128.64,128.61,128.48,128.32,128.29$, $128.12,128.09,127.85,127.68,62.61,62.56,49.53,48.88 ;{ }^{31} \mathrm{P}\{\mathrm{H}\} \mathrm{NMR}(120 \mathrm{MHz}$, $\left.\mathrm{CDCl}_{3}\right) \square 47.23$; FT-IR (KBr) 3650, 3057, 2581, 2117, 1962, 1896, 1719, 1600, 1585, 
$1494,1481,1453,1437,1270,1097,1080,1028,999,895,811,750,695,627,609,521$, $485 \mathrm{~cm}^{-1} ; \mathrm{R}_{f}$ (1:50:50 acetic acid-ethyl acetate-hexane) 0.54; HRFAB calcd. for $\mathrm{C}_{21} \mathrm{H}_{18} \mathrm{~N}_{3} \mathrm{O}_{2} \mathrm{PSLi}(\mathrm{M}+\mathrm{Li})^{+}$414.1017, found 414.1015.

(2R, 3S)-2-azido-3-(diphenylphosphorothioyl)-3-phenylpropanoic acid (S28)<smiles></smiles>

The procedure used was identical with that used for the preparation of S27. Yield 61.9\% as a white foam: ${ }^{1} \mathrm{H}$ NMR $\left(300 \mathrm{MHz} \mathrm{CDCl}_{3}\right) \square 9.46(\mathrm{~s}, 1 \mathrm{H}), 8.04-7.92(\mathrm{~m}, 2 \mathrm{H})$, 7.58-7.32 (m, 6H), 7.32-7.06 (m, 7H), $5.20(\mathrm{dd}, J=8.5,6.1 \mathrm{~Hz}, 1 \mathrm{H}), 4.43(\mathrm{dd}, J=12.9$, $6.0 \mathrm{~Hz}, 1 \mathrm{H}) ;{ }^{13} \mathrm{C}\{\mathrm{H}\}$ NMR $\left(75 \mathrm{MHz}, \mathrm{CDCl}_{3}\right) \square 174.40,174.27,132.51,132.38,132.13$, $132.01,131.60,131.56,131.41,131.35,130.89,130.76,130.69,129.84,129.68,128.62$, $128.47,128.31,128.11,127.84,127.67,62.52,62.47,49.53,48.87 ;{ }^{31} \mathrm{P}\{\mathrm{H}\}$ NMR $(120$ $\mathrm{MHz}, \mathrm{CDCl}_{3}$ ) $\square$ 47.24; FT-IR (KBr) 3650, 3058, 2117, 1718, 1494, 1437, 1272, 1097 , 751, 696, 522, $486 \mathrm{~cm}^{-1} ; \mathrm{R}_{f}(1: 50: 50$ acetic acid-ethyl acetate-hexane) 0.54; HRFAB calcd. for $\mathrm{C}_{21} \mathrm{H}_{18} \mathrm{~N}_{3} \mathrm{O}_{2}$ PSLi (M+Li) ${ }^{+}$414.1017, found 414.0998.

Fmoc- $N$-Pps(PS, $\square-R$-Ph)-OH (S29) 


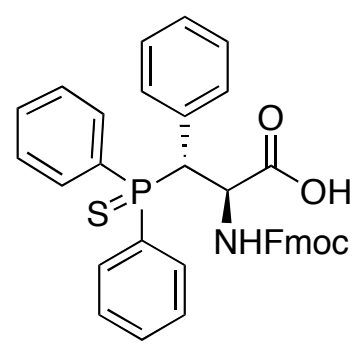

$\mathrm{SnCl}_{2}(1.012 \mathrm{~g}, 5.340 \mathrm{mmol})$ was added to a solution of $\mathbf{S 2 7}(435.2 \mathrm{mg}, 1.068$ $\mathrm{mmol})$ in methyl alcohol $(30.0 \mathrm{~mL})$. The mixture was stirred for $3 \mathrm{~h}$ at room temperature and a solution of $\mathrm{KFH}_{2} \mathrm{O}(1.207 \mathrm{~g}, 12.82 \mathrm{mmol})$ in $\mathrm{MeOH}(10.0 \mathrm{~mL})$ was added followed by addition of $\mathrm{CH}_{2} \mathrm{Cl}_{2}(50.0 \mathrm{~mL})$. The resulting suspension was filtered through a glass filter and the filtrate was concentrated in vacuo. Water $(10.0 \mathrm{~mL})$ and $\mathrm{NaCO}_{3}(336.3 \mathrm{mg}$, $4.003 \mathrm{mmol})$ were added followed by addition of acetone $(10.0 \mathrm{~mL})$ and FmocOSu (360.2 $\mathrm{mg}, 1.068 \mathrm{mmol}$ ). The reaction was stirred overnight and quenched by $4 \% \mathrm{HCl}$ $(150 \mathrm{~mL})$. The aqueous layer was extracted with ethyl acetate $(2 \times 125 \mathrm{~mL})$. The organic extracts were washed with $5 \% \mathrm{NaCl}$ and dried over $\mathrm{Na}_{2} \mathrm{SO}_{4}$. The product was purified by flash chromatography (1:30:70 acetic acid-ethyl acetate-hexane) to give $443.8 \mathrm{mg}$ of $\mathbf{S 2 9}$ (74.9\% yield) as a foam: ${ }^{1} \mathrm{H}$ NMR $\left(300 \mathrm{MHz} \mathrm{CDCl}_{3}\right) \square 8.99$ (s, 1H), 8.25-8.08 (m, 2H), $7.78(\mathrm{~d}, J=7.7 . \mathrm{Hz}, 2 \mathrm{H}), 7.71-7.10(\mathrm{~m}, 19 \mathrm{H}), 6.08(\mathrm{~d}, J=7.7 \mathrm{~Hz}, 1 \mathrm{H}), 5.05-4.93(\mathrm{~m}, 1 \mathrm{H})$, $4.66(\mathrm{dd}, J=12.4,4.1 \mathrm{~Hz}, 1 \mathrm{H}), 4.42-4.28(\mathrm{~m}, 1 \mathrm{H}), 4.28-4.13(\mathrm{~m}, 2 \mathrm{H}) ;{ }^{13} \mathrm{C}\{\mathrm{H}\} \mathrm{NMR}(75$ $\left.\mathrm{MHz}, \mathrm{CDCl}_{3}\right) \square 174.72,174.56,155.83,143.76,143.68,141.14,132.11,131.99,131.87$, $131.49,131.37,130.59,130.51,130.40,129.36,128.91,128.75,128.53,128.44,128.19$ $128.02,127.65,127.09,127.03,125.40,119.86,67.58,54.39,46.88,46.14,45.45 ;{ }^{31} \mathrm{P}$ $\{\mathrm{H}\}$ NMR (120 MHz, $\left.\mathrm{CDCl}_{3}\right) \square$ 46.06; FT-IR (KBr) 3432, 3059, 2581, 1960, 1911, 1724, $1515,1450,1437,1247,1098,1052,909,740,695,517,488 \mathrm{~cm}^{-1} ; \mathrm{R}_{f}(1: 50: 50$ acetic 
acid-ethyl acetate-hexane) 0.36; HRFAB calcd. for $\mathrm{C}_{36} \mathrm{H}_{31} \mathrm{NO}_{4} \mathrm{PS}(\mathrm{M}+\mathrm{H})^{+}$604.1711, found 604.1686 .

Fmoc- $N$-Pps $\left(P S,{ }_{-}-S\right.$-Ph)-OH (S30)<smiles></smiles>

The procedure used was identical with that used for the preparation of S29. Yield 68.8\% as a foam: ${ }^{1} \mathrm{H}$ NMR $\left(300 \mathrm{MHz}, \mathrm{CDCl}_{3}\right) \square 8.56(\mathrm{~s}, 1 \mathrm{H}), 8.24-8.10(\mathrm{~m}, 2 \mathrm{H}), 7.78(\mathrm{~d}$, $J=7.4 \mathrm{~Hz}, 2 \mathrm{H}), 7.71-7.12(\mathrm{~m}, 19 \mathrm{H}), 6.06(\mathrm{~d}, J=7.7 \mathrm{~Hz}, 1 \mathrm{H}), 5.05-4.94(\mathrm{~m}, 1 \mathrm{H}), 4.66$ $(\mathrm{dd}, J=12.1,3.9 \mathrm{~Hz}, 1 \mathrm{H}), 4.42-4.28(\mathrm{~m}, 1 \mathrm{H}), 4.28-4.14(\mathrm{~m}, 2 \mathrm{H}) ;{ }^{13} \mathrm{C}\{\mathrm{H}\}$ NMR $(75$ $\left.\mathrm{MHz}, \mathrm{CDCl}_{3}\right) \square 174.68,174.51,155.82,149.86,143.77,143.69,141.15,132.15,132.00$, $131.88,131.50,131.37,130.60,130.52,130.42,129.39,128.92,128.76,128.54,128.20$, $128.04,127.65,127.10,127.04,125.40,119.86,67.59,54.39,46.90,46.17,45.48 ;{ }^{31} \mathrm{P}$ $\{\mathrm{H}\}$ NMR (120 MHz, $\left.\mathrm{CDCl}_{3}\right) \square$ 46.05; FT-IR (KBr) 3637, 3431, 3059, 1959, 1912, 1727 , $1514,1450,1437,1325,1246,1098,1052,998,741,695,517,488 \mathrm{~cm}^{-1} ; \mathrm{R}_{f}(1: 50: 50$ acetic acid-ethyl acetate-hexane) 0.36; HRFAB calcd. for $\mathrm{C}_{36} \mathrm{H}_{29} \mathrm{NO}_{4} \mathrm{PSLi}_{2}(\mathrm{M}+2 \mathrm{Li}-\mathrm{H})^{+}$ 616.1875, found 616.1885.

\section{Spectral data for Boc-phosphine sulfide-Methyl esters:}




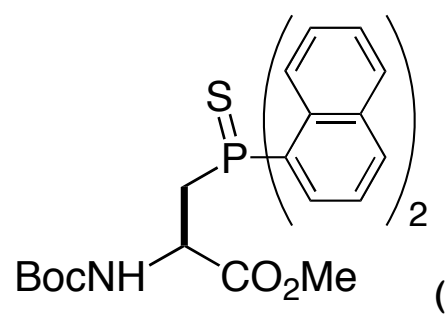

(S31)

${ }^{1} \mathrm{H}$ NMR $\left(300 \mathrm{MHz}, \mathrm{CDCl}_{3}\right) \square 8.56(\mathrm{dd}, J=6.6,17.6 \mathrm{~Hz}, 1 \mathrm{H}), 8.39(\mathrm{dd}, J=7.1,17.0 \mathrm{~Hz}$, 1H), $8.03(\mathrm{dd}, J=8.2,30 \mathrm{~Hz}, 2 \mathrm{H}), 7.93(\mathrm{~d}, J=7.7 \mathrm{~Hz}, 2 \mathrm{H}), 7.77(\mathrm{br}-\mathrm{s}, 2 \mathrm{H}), 7.54(\mathrm{q} J=$ $9.1 \mathrm{~Hz}, 2 \mathrm{H}), 7.31(\mathrm{t}, J=7.1 \mathrm{~Hz}, 2 \mathrm{H}), 7.21(\mathrm{t}, J=7.2 \mathrm{~Hz}, 2 \mathrm{H}), 5.41(\mathrm{~d}, J=7.4 \mathrm{~Hz}, 1 \mathrm{H})$, $4.76(\mathrm{ddt}, J=20.2,7.4,13.7, \mathrm{~Hz}, 1 \mathrm{H}), 3.63(\mathrm{dd}, J=6.0,9.9 \mathrm{~Hz}, 2 \mathrm{H}), 3.52(\mathrm{~s}, 3 \mathrm{H}), 1.20$ (s, 9H). ${ }^{13} \mathrm{C} \mathrm{NMR}\left(100 \mathrm{MHz}, \mathrm{CDCl}_{3}\right) \square 171.8\left(\mathrm{~d}, J_{\mathrm{CP}}=11.7 \mathrm{~Hz}\right), 154.96(\mathrm{~s}), 134.21\left(\mathrm{~d}, J_{\mathrm{CP}}\right.$ = 8.6 Hz), $133.69\left(\mathrm{~d}, J_{\mathrm{CP}}=2.8 \mathrm{~Hz}\right), 132.00\left(\mathrm{~d}, J_{\mathrm{CP}}=8.6 \mathrm{~Hz}\right), 129.67(\mathrm{~s}), 127.27(\mathrm{~s})$, $126.53\left(\mathrm{~d}, J_{\mathrm{CP}}=6.9 \mathrm{~Hz}\right), 125.75\left(\mathrm{~d}, J_{\mathrm{CP}}=6.5 \mathrm{~Hz}\right), 125.58\left(\mathrm{~d}, J_{\mathrm{CP}}=5.7 \mathrm{~Hz}\right), 125.28\left(\mathrm{~d}, J_{\mathrm{CP}}\right.$ $=14.3 \mathrm{~Hz}), 125.15\left(\mathrm{~d}, J_{\mathrm{CP}}=14.3 \mathrm{~Hz}\right), 79.95(\mathrm{~s}), 52.76(\mathrm{~s}), 50.47(\mathrm{~s}), 33.18\left(\mathrm{~d}, J_{\mathrm{CP}}=58.1\right.$ $\mathrm{Hz}), 28.30$ (s). ${ }^{31} \mathrm{P}$ NMR (120 MHz, $\left.\mathrm{CDCl}_{3}\right) \mathrm{3}$ 37.04. IR ( $\left.\mathrm{KBr}, \mathrm{cm}^{-1}\right)$ 3364, 3056, 2977, 1742, 1717, 1507, 1366, 1217, 1165, 1049, 1026, 801, 772. FAB-MS; [M + Li] calcd. 526.1793, obsd. 526.1797. $\mathrm{R} f=0.2$ (30\% EtOAc in hexane)

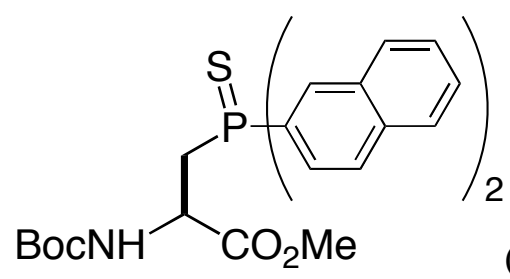

(S32)

${ }^{1} \mathrm{H}$ NMR $\left(300 \mathrm{MHz}, \mathrm{CDCl}_{3}\right) \square 8.56(\mathrm{dd}, J=7.4,15.7 \mathrm{~Hz}, 2 \mathrm{H}), 7.7-8.0(\mathrm{~m}, 8 \mathrm{H}), 7.5-7.6$ (m, 4H), $5.44(\mathrm{~d}, J=7.4 \mathrm{~Hz}, 1 \mathrm{H}), 4.7-4.9(\mathrm{~m}, 1 \mathrm{H}), 3.65(\mathrm{~s}, 3 \mathrm{H}), 3.25-3.60(\mathrm{~m}, 2 \mathrm{H}), 1.04$ (s, 9H). ${ }^{13} \mathrm{C}$ NMR (100 MHz, $\left.\mathrm{CDCl}_{3}\right) \square 171.75\left(\mathrm{~d}, J_{\mathrm{CP}}=10.6 \mathrm{~Hz}\right), 154.93(\mathrm{~s}), 134.65(\mathrm{~s})$, $133.40\left(\mathrm{~d}, J_{\mathrm{CP}}=10.5 \mathrm{~Hz}\right), 133.10\left(\mathrm{~d}, J_{\mathrm{CP}}=10.3 \mathrm{~Hz}\right), 132.75\left(\mathrm{~d}, J_{\mathrm{CP}}=13.7 \mathrm{~Hz}\right), 129.27(\mathrm{~d}$, 
$\left.J_{\mathrm{CP}}=2.9 \mathrm{~Hz}\right), 128.91\left(\mathrm{~d}, J_{\mathrm{CP}}=24.0 \mathrm{~Hz}\right), 128.74\left(\mathrm{~d}, J_{\mathrm{CP}}=24.0 \mathrm{~Hz}\right), 127.96(\mathrm{~s}), 127.34(\mathrm{~s})$, $126.00\left(\mathrm{~d}, J_{\mathrm{CP}}=10.9 \mathrm{~Hz}\right), 79.96(\mathrm{~s}), 52.92(\mathrm{~s}), 50.54(\mathrm{~s}), 33.16\left(\mathrm{~d}, J_{\mathrm{CP}}=58.7 \mathrm{~Hz}\right), 28.07$ (s). ${ }^{31} \mathrm{P}$ NMR (120 MHz, $\left.\mathrm{CDCl}_{3}\right) \square$ 38.84. IR $\left(\mathrm{KBr}, \mathrm{cm}^{-1}\right)$ 3362, 3053, 2976, 1743, 1711,1500,1366, 1341, 1251, 1165, 1080, 816, 747, 477. FAB-MS; [M + Li] calcd. 526.1793, obsd. 526.1772. $\mathrm{R} f=0.3$ (35\% EtOAc in hexane)

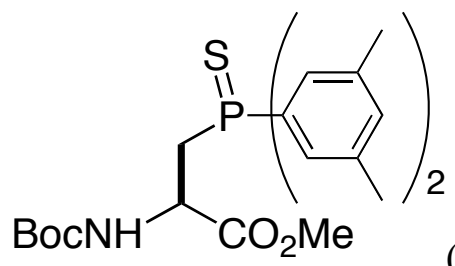

(S33)

${ }^{1} \mathrm{H}$ NMR (300 MHz, $\left.\mathrm{CDCl}_{3}\right) \square 7.39(\mathrm{~d}, J=13.7 \mathrm{~Hz}, 4 \mathrm{H}), 7.07$ (s, 2H), $5.51(\mathrm{~d}, J=7.4 \mathrm{~Hz}$, $1 \mathrm{H}), 4.59-4.72(\mathrm{~m}, 1 \mathrm{H}), 3.63(\mathrm{~s}, 3 \mathrm{H}), 3.02-3.23(\mathrm{~m}, 2 \mathrm{H}), 2.30(\mathrm{~s}, 12 \mathrm{H}), 1.25(\mathrm{~s}, 9 \mathrm{H}) .{ }^{13} \mathrm{C}$ $\operatorname{NMR}\left(100 \mathrm{MHz}, \mathrm{CDCl}_{3}\right) \square 171.85\left(\mathrm{~d}, J_{\mathrm{CP}}=10.9 \mathrm{~Hz}\right), 155.00(\mathrm{~s}), 138.63\left(\mathrm{~d}, J_{\mathrm{CP}}=9.4 \mathrm{~Hz}\right)$, $138.46\left(\mathrm{~d}, J_{\mathrm{CP}}=9.4 \mathrm{~Hz}\right), 133.56(\mathrm{~s}), 128.64\left(\mathrm{~d}, J_{\mathrm{CP}}=10.3 \mathrm{~Hz}\right), 79.92(\mathrm{~s}), 52.76(\mathrm{~s}), 50.51$ (s), $33.25\left(\mathrm{~d}, J_{\mathrm{CP}}=57.8 \mathrm{~Hz}\right), 28.32(\mathrm{~s}), 21.58(\mathrm{~s}) .{ }^{31} \mathrm{P} \mathrm{NMR}\left(120 \mathrm{MHz}, \mathrm{CDCl}_{3}\right) \square 38.35$. IR $\left(\mathrm{KBr}, \mathrm{cm}^{-1}\right) 3358,2977,2923,1718,1600,1500,1167,1049,1020,850,692,627$. FABMS; $[\mathrm{M}+\mathrm{Li}]$ calcd. 482.2106, obsd. 482.2111. $\mathrm{R} f=0.33$ (30\%EtOAc in hexane)

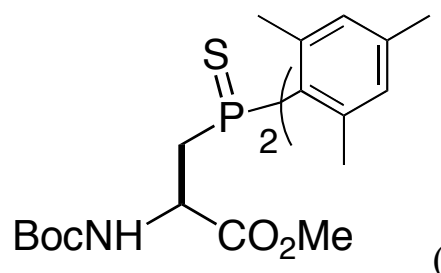

(S34)

${ }^{1} \mathrm{H}$ NMR (300 MHz, $\left.\mathrm{CDCl}_{3}\right) \square 6.75-6.84(\mathrm{~m}, 4 \mathrm{H}), 6.06$ (br-d, $\left.J=4.7 \mathrm{~Hz}, 1 \mathrm{H}\right), 3.92-4.09$ (m, 1H), 3.68 (s, 3H), 3.44-3.57 (m, 1H), 2.91-3.04 (m, 1H), $2.44(\mathrm{~s}, 6 \mathrm{H}), 2.32(\mathrm{~s}, 6 \mathrm{H})$, $2.23(\mathrm{~s}, 6 \mathrm{H}), 1.37(\mathrm{~s}, 9 \mathrm{H}) .{ }^{13} \mathrm{C} \mathrm{NMR}\left(100 \mathrm{MHz}, \mathrm{CDCl}_{3}\right) \square 172.47\left(\mathrm{~d}, J_{\mathrm{CP}}=16.4 \mathrm{~Hz}\right)$, $154.94(\mathrm{~s}), 141.62\left(\mathrm{~d}, J_{\mathrm{CP}}=10.0 \mathrm{~Hz}\right), 139.52\left(\mathrm{~d}, J_{\mathrm{CP}}=10.3 \mathrm{~Hz}\right), 132.47\left(\mathrm{~d}, J_{\mathrm{CP}}=11.2 \mathrm{~Hz}\right)$, $131.99\left(\mathrm{~d}, J_{\mathrm{CP}}=11.5 \mathrm{~Hz}\right), 80.00(\mathrm{~s}), 52.85(\mathrm{~s}), 51.88(\mathrm{~s}), 41.10\left(\mathrm{~d}, J_{\mathrm{CP}}=53.0 \mathrm{~Hz}\right), 28.47$ 
$(\mathrm{s}), 23.68\left(\mathrm{~d}, J_{\mathrm{CP}}=4.9 \mathrm{~Hz}\right), 21.04\left(\mathrm{~d}, J_{\mathrm{CP}}=5.2 \mathrm{~Hz}\right) .{ }^{31} \mathrm{P} \mathrm{NMR}\left(120 \mathrm{MHz}, \mathrm{CDCl}_{3}\right) \square 39.44$.

IR $\left(\mathrm{KBr}, \mathrm{cm}^{-1}\right) 3343,2974,2930,1717,1603,1501,1452,1366,1248,1219,1168,1046$, 1027, 855, 649. FAB-MS; [M + H] calcd. 504.2337, obsd. 504.2331. $\mathrm{R} f=0.3(30 \%$

EtOAc in hexane)

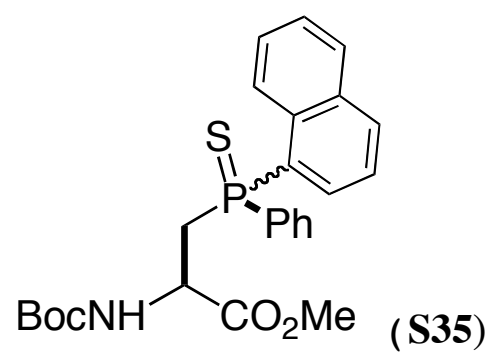

${ }^{1} \mathrm{H}$ NMR (300 MHz, $\left.\mathrm{CDCl}_{3}\right) \square 8.18(\mathrm{~d}, J=8.2 \mathrm{~Hz}, 1 \mathrm{H}), 8.01(\mathrm{~d}, J=8.3 \mathrm{~Hz}, 1 \mathrm{H}), 7.87(\mathrm{~d}$, $J=8.2 \mathrm{~Hz}, 1 \mathrm{H}), 7.74(\mathrm{dd}, J=6.6,13.5 \mathrm{~Hz}, 2 \mathrm{H}), 7.5-7.58(\mathrm{~m}, 1 \mathrm{H}), 7.35-7.45(\mathrm{~m}, 6 \mathrm{H})$, $5.54(\mathrm{~d}, J=6.9 \mathrm{~Hz}, 1 \mathrm{H}), 4.62-4.78(\mathrm{~m}, 1 \mathrm{H}), 3.62(\mathrm{~s}, 3 \mathrm{H}), 3.42-3.58(\mathrm{~m}, 1 \mathrm{H}), 3.23-3.38$ $(\mathrm{m}, 1 \mathrm{H}), 1.26(\mathrm{~s}, 9 \mathrm{H}) .{ }^{13} \mathrm{C}$ NMR $\left(100 \mathrm{MHz}, \mathrm{CDCl}_{3}\right) \square 171.72\left(\mathrm{~d}, J_{\mathrm{CP}}=10.3 \mathrm{~Hz}\right), 155.09$ $(\mathrm{s}), 134.40\left(\mathrm{~d}, J_{\mathrm{CP}}=8.8 \mathrm{~Hz}\right), 134.24(\mathrm{~s}), 133.72(\mathrm{~s}), 133.55(\mathrm{~s}), 133.15(\mathrm{~s}), 131.83\left(\mathrm{~d}, J_{\mathrm{CP}}=\right.$ $2.9 \mathrm{~Hz}), 131.00\left(\mathrm{~d}, J_{\mathrm{CP}}=10.6 \mathrm{~Hz}\right), 129.65(\mathrm{~s}), 129.20\left(\mathrm{~d}, J_{\mathrm{CP}}=12.6 \mathrm{~Hz}\right), 128.45(\mathrm{~s})$, $127.24(\mathrm{~s}), 126.55(\mathrm{~s}), 126.47(\mathrm{~s}), 124.85\left(\mathrm{~d}, J_{\mathrm{CP}}=14.1 \mathrm{~Hz}\right), 80.11(\mathrm{~s}), 52.83(\mathrm{~s}), 50.56$ $(\mathrm{s}), 33.30\left(\mathrm{~d}, J_{\mathrm{CP}}=57.8 \mathrm{~Hz}\right), 28.37(\mathrm{~s}) .{ }^{31} \mathrm{P}$ NMR $\left(120 \mathrm{MHz}, \mathrm{CDCl}_{3}\right)$ ]38.06. IR (KBr, $\left.\mathrm{cm}^{-1}\right) 3361,3055,2977,1743,1709,1508,1437,1366,1217,1165,1049,1026,829$, 801, 774, 748, 713, 693. FAB-MS; [M + Li] calcd. 476.1637, obsd. 476.1616. $\mathrm{R} f=0.2$ (30\% EtOAc in hexane) 


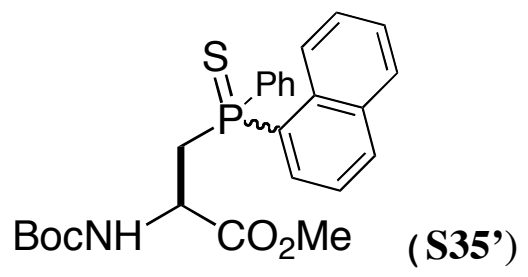

${ }^{1} \mathrm{H}$ NMR $\left(300 \mathrm{MHz}, \mathrm{CDCl}_{3}\right) \square 8.27(\mathrm{~d}, J=8.5 \mathrm{~Hz}, 1 \mathrm{H}), 8.09(\mathrm{dd}, J=6.9,16.2 \mathrm{~Hz}, 1 \mathrm{H})$, $8.00(\mathrm{~d}, J=8.2 \mathrm{~Hz}, 1 \mathrm{H}), 7.85(\mathrm{~d}, J=8.0 \mathrm{~Hz}, 1 \mathrm{H}), 7.77(\mathrm{dd}, J=6.6,20.3 \mathrm{~Hz}, 2 \mathrm{H}), 7.48-$ $7.57(\mathrm{~m}, 1 \mathrm{H}), 7.32-7.47(\mathrm{~m}, 5 \mathrm{H}), 5.44(\mathrm{~d}, J=7.7 \mathrm{~Hz}, 1 \mathrm{H}), 4.72-4.89(\mathrm{~m}, 1 \mathrm{H}), 3.64(\mathrm{~s}$, $3 \mathrm{H}), 3.30-3.48(\mathrm{~m}, 2 \mathrm{H}), 1.26(\mathrm{~s}, 9 \mathrm{H}) .{ }^{13} \mathrm{C} \mathrm{NMR}\left(100 \mathrm{MHz}, \mathrm{CDCl}_{3}\right) \square 171.91\left(\mathrm{~d}, J_{\mathrm{CP}}=11.8\right.$ $\mathrm{Hz}), 155.05(\mathrm{~s}), 134.50\left(\mathrm{~d}, J_{\mathrm{CP}}=9.2 \mathrm{~Hz}\right), 133.74\left(\mathrm{~d}, J_{\mathrm{CP}}=3.2 \mathrm{~Hz}\right), 132.45\left(\mathrm{~d}, J_{\mathrm{CP}}=9.7\right.$ $\mathrm{Hz}), 131.98\left(\mathrm{~d}, J_{\mathrm{CP}}=8.6 \mathrm{~Hz}\right), 131.72(\mathrm{~s}), 131.21\left(\mathrm{~d}, J_{\mathrm{CP}}=11.2 \mathrm{~Hz}\right), 129.63(\mathrm{~s}), 129.06(\mathrm{~d}$, $\left.J_{\mathrm{CP}}=12.6 \mathrm{~Hz}\right), 128.89(\mathrm{~s}), 127.82(\mathrm{~s}), 127.24(\mathrm{~s}), 126.62(\mathrm{~s}), 126.54(\mathrm{~s}), 124.70\left(\mathrm{~d}, J_{\mathrm{CP}}=\right.$ $13.7 \mathrm{~Hz}), 80.09(\mathrm{~s}), 52.91(\mathrm{~s}), 50.44(\mathrm{~s}), 33.48\left(\mathrm{~d}, J_{\mathrm{CP}}=58.4 \mathrm{~Hz}\right), 28.39(\mathrm{~s}) .{ }^{31} \mathrm{P}$ NMR (120 MHz, $\left.\mathrm{CDCl}_{3}\right) \square$ 37.57. IR (KBr, cm $\left.{ }^{-1}\right) 3361,3059,2983,2946,2932,1757,1690$, $1527,1436,1390,1365,1350,1284,1249,1211,1169,1052,1024,829,803,776,689$, 608. FAB-MS; $[\mathrm{M}+\mathrm{Li}]$ calcd. 476.1637, obsd. 476.1619. $\mathrm{R} f=0.2(30 \%$ EtOAc in hexane)

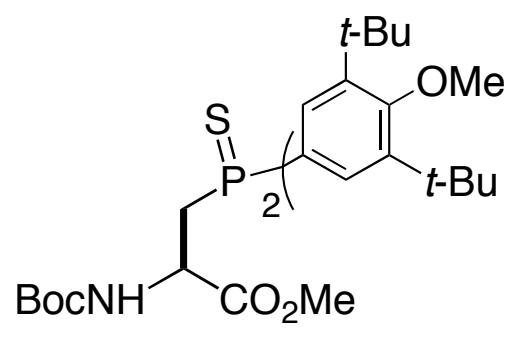

(S36)

${ }^{1} \mathrm{H}$ NMR $\left(300 \mathrm{MHz}, \mathrm{CDCl}_{3}\right) \square 7.67(\mathrm{dd}, J=14.3,14.3 \mathrm{~Hz}, 4 \mathrm{H}), 5.84(\mathrm{~d}, J=6.3 \mathrm{~Hz}, 1 \mathrm{H})$, 4.53-4.69 (m, 1H), $3.68(\mathrm{~d}, J=2.5 \mathrm{~Hz}, 6 \mathrm{H}), 3.57(\mathrm{~s}, 3 \mathrm{H}), 2.93-3.05(\mathrm{~m}, 1 \mathrm{H}), 1.39(\mathrm{~d}, J=$ $3.9 \mathrm{~Hz}, 36 \mathrm{H}), 1.32(\mathrm{~s}, 9 \mathrm{H}) .{ }^{13} \mathrm{C} \mathrm{NMR}\left(100 \mathrm{MHz}, \mathrm{CDCl}_{3}\right) \square 172.01\left(\mathrm{~d}, J_{\mathrm{CP}}=10.6 \mathrm{~Hz}\right)$, 
$162.88\left(\mathrm{~d}, J_{\mathrm{CP}}=12.8 \mathrm{~Hz}\right), 155.34(\mathrm{~s}), 144.50\left(\mathrm{~d}, J_{\mathrm{CP}}=12.3 \mathrm{~Hz}\right), 144.27(\mathrm{~s}), 130.14\left(\mathrm{~d}, J_{\mathrm{CP}}\right.$ $=12.1 \mathrm{~Hz}), 80.07(\mathrm{~s}), 64.66,64.63,52.60,50.83,36.35,36.33,35.26,34.50,32.11$, 28.48. ${ }^{31} \mathrm{P}$ NMR $\left(120 \mathrm{MHz}, \mathrm{CDCl}_{3}\right) \square$ 39.50. IR $\left(\mathrm{KBr}, \mathrm{cm}^{-1}\right) 3340,2963,2874,1748$, 1718, 1499, 1449, 1410, 1393, 1365, 1267, 1227, 1167, 1143, 1116, 1008, 880, 733. FAB-MS; $[\mathrm{M}+\mathrm{H}]$ calcd. 703.4035, obsd. 703.4021. $\mathrm{R} f=0.2(15 \%$ EtOAc in hexane)

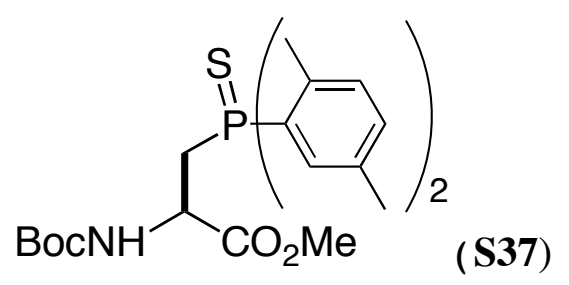

${ }^{1} \mathrm{H}$ NMR (300 MHz, $\left.\mathrm{CDCl}_{3}\right) \square 7.9(\mathrm{t}, J=15.7 \mathrm{~Hz}, 2 \mathrm{H}), 7.15-7.25(\mathrm{~m}, 2 \mathrm{H}), 7.01(\mathrm{dd}, J=$ 7.8, $13.2 \mathrm{~Hz}, 2 \mathrm{H}), 5.39(\mathrm{~d}, J=7.1 \mathrm{~Hz}, 1 \mathrm{H}), 4.44-4.60(\mathrm{~m}, 1 \mathrm{H}), 3.66(\mathrm{~s}, 3 \mathrm{H}), 3.22-3.37$ (m, 2H), $2.38(\mathrm{~s}, 6 \mathrm{H}), 1.98(\mathrm{~d}, J=7.7 \mathrm{~Hz}, 6 \mathrm{H}), 1.30(\mathrm{~s}, 9 \mathrm{H}) .{ }^{13} \mathrm{C} \mathrm{NMR}\left(100 \mathrm{MHz}, \mathrm{CDCl}_{3}\right)$ $\square 172.00\left(\mathrm{~d}, J_{\mathrm{CP}}=10.4 \mathrm{~Hz}\right), 155.07(\mathrm{~s}), 137.47\left(\mathrm{~d}, J_{\mathrm{CP}}=8.9 \mathrm{~Hz}\right), 137.15\left(\mathrm{~d}, J_{\mathrm{CP}}=9.5 \mathrm{~Hz}\right)$, $136.17\left(\mathrm{~d}, J_{\mathrm{CP}}=12.3 \mathrm{~Hz}\right), 133.17-132.25(\mathrm{~m}), 131.07\left(\mathrm{~d}, J_{\mathrm{CP}}=20.1 \mathrm{~Hz}\right), 130.01\left(\mathrm{~d}, J_{\mathrm{CP}}=\right.$ $21.2 \mathrm{~Hz}), 80.02(\mathrm{~s}), 52.84(\mathrm{~s}), 50.41(\mathrm{~s}), 31.91\left(\mathrm{~d}, J_{\mathrm{CP}}=58.1 \mathrm{~Hz}\right), 28.36(\mathrm{~s}), 21.06\left(\mathrm{~d}, J_{\mathrm{CP}}=\right.$ 24.0 Hz). ${ }^{31}$ P NMR (120 MHz, $\left.\mathrm{CDCl}_{3}\right) \square 36.81 . \mathrm{IR}\left(\mathrm{KBr}, \mathrm{cm}^{-1}\right)$ 3362, 2976, 2926, 1714, 1487, 1366, 1217, 1166, 1048, 911, 818, 620. FAB-MS; [M + Li] calcd. 482.2106, obsd. 482.2089. $\mathrm{R} f=0.17$ (20\% EtOAc in hexane)

\section{General procedure for preparation of Fmoc-phosphine sulfide-acids from iodoalanine:}

To a 0.4-0.5 M THF solution of the Boc-phosphine sulfide-Methyl ester at $0^{\circ}$ was added 2 equivalents of aqueous $\mathrm{LiOH}(0.2 \mathrm{M})$, at $0^{\circ}$, dropwise via cannula. Upon completion, as 
determined by TLC, the reaction was neutralized with conc. $\mathrm{HCl}$. The THF was removed under reduced pressure and the resulting material was extracted two times with DCM, dried with $\mathrm{Na}_{2} \mathrm{SO}_{4}$, filtered and concentrated to a white foam. The resulting Boc-acid was treated with 50\% TFA in DCM until complete removal of the Boc group as judged by TLC. The reaction mixture was then concentrated, dissolved in toluene and concentrated, dissolved in chloroform and concentrated and finally dissolved in DCM and concentrated before drying in-vacuo for 30 minutes. To the resulting unprotected amino acid, dissolved in a 1:1 acetone: water mixture, was added 2 equivalents of $\mathrm{NaHCO}_{3}$ and 1 equivalent of Fmoc-OSu. The reaction was allowed to stir overnight before neutralizing with conc. $\mathrm{HCl}$ and removal of the $\mathrm{MeOH}$ under reduced pressure. The resulting material was extracted twice with DCM, dried with $\mathrm{Na}_{2} \mathrm{SO}_{4}$, filtered, concentrated and chromatographed with a $\mathrm{MeOH} / \mathrm{DCM}$ solvent system.

\section{Spectral data for Fmoc-phosphine sulfide acids:}

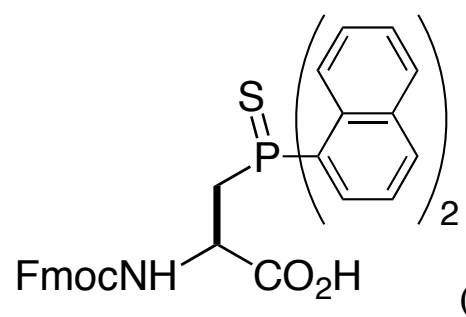

(S38)

${ }^{1} \mathrm{H}$ NMR (300 MHz, $\left.\mathrm{CDCl}_{3}\right) \square 11.2$ (br-s, 1H), 8.34-8.90 (m, 2H), $8.23(\mathrm{~d}, J=7.7 \mathrm{~Hz}$, $1 \mathrm{H}), 8.1(\mathrm{~d}, J=7.1 \mathrm{~Hz}, 1 \mathrm{H}), 7.93(\mathrm{~d}, J=7.7 \mathrm{~Hz}, 1 \mathrm{H}), 7.86(\mathrm{~d}, J=8.0 \mathrm{~Hz}, 1 \mathrm{H}), 7.75(\mathrm{~d}, J$ $=7.4 \mathrm{~Hz}, 2 \mathrm{H}), 7.68(\mathrm{~d}, J=7.1 \mathrm{~Hz}, 2 \mathrm{H}) 7.21-7.66(\mathrm{~m}, 12 \mathrm{H}), 5.95$ (br-s, 1H), 4.75-4.96 (br$\mathrm{m}, 1 \mathrm{H}), 3.67-4.15(\mathrm{~m}, 5 \mathrm{H}) .{ }^{13} \mathrm{C} \mathrm{NMR}\left(100 \mathrm{MHz}, \mathrm{CDCl}_{3}\right) \square 175.16\left(\mathrm{~d}, J_{\mathrm{CP}}=14.3 \mathrm{~Hz}\right)$, $155.75(\mathrm{~s}), 144.02\left(\mathrm{~d}, J_{\mathrm{CP}}=11.2 \mathrm{~Hz}\right), 143.81(\mathrm{~s}), 141.47(\mathrm{~s}), 141.43(\mathrm{~s}), 134.35\left(\mathrm{~d}, J_{\mathrm{CP}}=\right.$ $8.9 \mathrm{~Hz}), 134.12\left(\mathrm{~d}, J_{\mathrm{CP}}=6.8 \mathrm{~Hz}\right), 133.86(\mathrm{~s}), 132.13\left(\mathrm{~d}, J_{\mathrm{CP}}=8.3 \mathrm{~Hz}\right), 131.07\left(\mathrm{~d}, J_{\mathrm{CP}}=8.7\right.$ 
$\mathrm{Hz}), 129.72(\mathrm{~s}), 128.05(\mathrm{~s}), 127.44(\mathrm{~s}), 126.62\left(\mathrm{~d}, J_{\mathrm{CP}}=5.7 \mathrm{~Hz}\right), 125.70(\mathrm{~s}), 125.37\left(\mathrm{~d}, J_{\mathrm{CP}}\right.$ $=10.5 \mathrm{~Hz}), 120.24(\mathrm{~s}), 67.52(\mathrm{~s}), 50.60(\mathrm{~s}), 47.08(\mathrm{~s}), 33.07\left(\mathrm{~d}, J_{\mathrm{CP}}=58.1 \mathrm{~Hz}\right) \cdot{ }^{31} \mathrm{P} \mathrm{NMR}$ $\left(120 \mathrm{MHz}, \mathrm{CDCl}_{3}\right) \square$ 37.22. IR $\left(\mathrm{KBr}, \mathrm{cm}^{-1}\right)$ 3294, 3059, 2588, 1954, 1719, 1508, 1330, 1249, 1046, 801, 772, 759, 741. FAB-MS; [M + 2Li-H] calcd. 640.1875, obsd. 640.1848. $\mathrm{R} f=0.13(50 \%$ EtOAc in hexane)

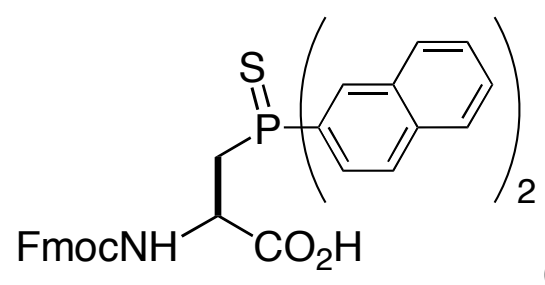

(S39)

${ }^{1} \mathrm{H}$ NMR (300 MHz, $\left.\mathrm{CDCl}_{3}\right) \square 10.4$ (br-s, 1H), 8.53 (dd, $\left.J=15.5,21.3 \mathrm{~Hz}, 2 \mathrm{H}\right), 7.75-7.95$ (m, 8H), $7.68(\mathrm{~d}, J=7.4 \mathrm{~Hz}, 2 \mathrm{H}), 7.4-7.6(\mathrm{~m}, 4 \mathrm{H}), 7.15-7.4(\mathrm{~m}, 6 \mathrm{H}), 6.02(\mathrm{~d}, J=7.4 \mathrm{~Hz}$, $1 \mathrm{H}), 4.75-4.95(\mathrm{~m}, 1 \mathrm{H}), 3.5-3.81(\mathrm{~m}, 4 \mathrm{H}), 3.26-3.45(\mathrm{~m}, 1 \mathrm{H}) .{ }^{13} \mathrm{C}$ NMR $(100 \mathrm{MHz}$, $\left.\mathrm{CDCl}_{3}\right) \square 175.51\left(\mathrm{~d}, J_{\mathrm{CP}}=12.3 \mathrm{~Hz}\right), 155.79(\mathrm{~s}), 143.83(\mathrm{~s}), 141.30\left(\mathrm{~d}, J_{\mathrm{CP}}=3.1 \mathrm{~Hz}\right)$, $134.69\left(\mathrm{~d}, J_{\mathrm{CP}}=6.3 \mathrm{~Hz}\right), 133.58\left(\mathrm{~d}, J_{\mathrm{CP}}=10.6 \mathrm{~Hz}\right), 132.97\left(\mathrm{~d}, J_{\mathrm{CP}}=10.5 \mathrm{~Hz}\right), 132.70(\mathrm{~d}$, $\left.J_{\mathrm{CP}}=13.7 \mathrm{~Hz}\right), 132.59\left(\mathrm{~d}, J_{\mathrm{CP}}=13.5 \mathrm{~Hz}\right), 129.22(\mathrm{~s}), 128.95\left(\mathrm{~d}, J_{\mathrm{CP}}=15.5 \mathrm{~Hz}\right), 128.66(\mathrm{~s})$, $127.93\left(\mathrm{~d}, J_{\mathrm{CP}}=10.9 \mathrm{~Hz}\right), 127.30\left(\mathrm{~d}, J_{\mathrm{CP}}=12.9 \mathrm{~Hz}\right), 126.10\left(\mathrm{~d}, J_{\mathrm{CP}}=13.1 \mathrm{~Hz}\right), 125.93(\mathrm{~d}$, $\left.J_{\mathrm{CP}}=12.2 \mathrm{~Hz}\right), 125.44\left(\mathrm{~d}, J_{\mathrm{CP}}=4.3 \mathrm{~Hz}\right), 120.04(\mathrm{~s}), 67.37(\mathrm{~s}), 50.81(\mathrm{~s}), 46.72(\mathrm{~s}), 32.44$ $\left(\mathrm{d}, J_{\mathrm{CP}}=59.8 \mathrm{~Hz}\right) \cdot{ }^{31} \mathrm{P} \mathrm{NMR}\left(120 \mathrm{MHz}, \mathrm{CDCl}_{3}\right) \square$ 39.32. IR $\left(\mathrm{KBr}, \mathrm{cm}^{-1}\right) 3305,3054$, 2605, 1719, 1508, 1251, 1080, 741. FAB-MS; [M + H] calcd. 628.1711, obsd. 628.1701. $\mathrm{R} f=0.27(3 \% \mathrm{MeOH}$ in $\mathrm{DCM})$ 


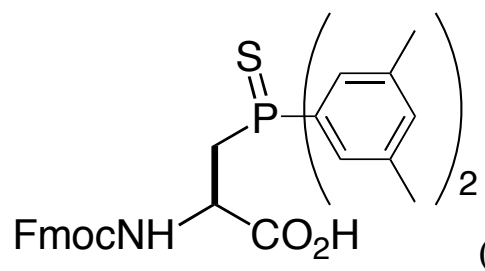

(S40)

${ }^{1} \mathrm{H}$ NMR $\left(300 \mathrm{MHz}, \mathrm{CDCl}_{3}\right) \square 7.74(\mathrm{~d}, J=7.4 \mathrm{~Hz}, 2 \mathrm{H}), 7.22-7.55,(\mathrm{~m}, 10 \mathrm{H}), 7.06(\mathrm{~d}, J=$ $15.4 \mathrm{~Hz}, 2 \mathrm{H}), 6.07(\mathrm{~d}, J=6.1 \mathrm{~Hz}, 1 \mathrm{H}), 4.60-4.72(\mathrm{~m}, 1 \mathrm{H}), 3.98-4.21(\mathrm{~m}, 3 \mathrm{H}), 3.05-3.35$ (m, 2H), 2.28 (s, 12H). ${ }^{13} \mathrm{C}$ NMR (100 MHz, $\left.\mathrm{CDCl}_{3}\right) \square 176.17$ (br-s), 156.19 (s), 144.00 $(\mathrm{s}), 141.35(\mathrm{~s}), 138.60\left(\mathrm{~d}, J_{\mathrm{CP}}=28.6 \mathrm{~Hz}\right), 138.64(\mathrm{~s}), 133.72(\mathrm{~s}), 128.80\left(\mathrm{~d}, J_{\mathrm{CP}}=22.9 \mathrm{~Hz}\right)$, $128.78(\mathrm{~s}), 127.62$ (d, $\left.J_{\mathrm{CP}}=38 \mathrm{~Hz}\right), 125.63$ (s), 120.08 (s), 67.63 (s), 51.10 (s), 47.08 (s), $32.60\left(\mathrm{~d}, J_{\mathrm{CP}}=55.6 \mathrm{~Hz}\right), 21.55(\mathrm{~s}) .{ }^{31} \mathrm{P} \mathrm{NMR}\left(120 \mathrm{MHz}, \mathrm{CDCl}_{3}\right) \square 39.21 . \mathrm{IR}\left(\mathrm{KBr}, \mathrm{cm}^{-1}\right)$ 3298, 3037, 2918, 1718, 1522, 1449, 1251, 1124, 1048, 851, 759, 740, 691. FAB-MS; [M $+\mathrm{Li}]$ calcd. 590.2106, obsd. 590.2092. $\mathrm{R} f=0.3(3 \% \mathrm{MeOH}$ in DCM)

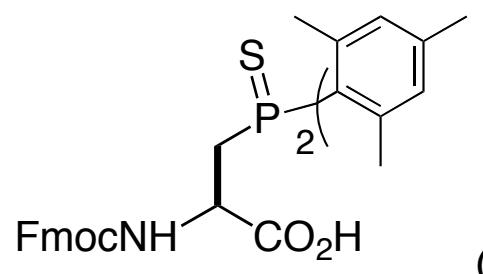

(S41)

${ }^{1} \mathrm{H}$ NMR $\left(300 \mathrm{MHz}, \mathrm{CDCl}_{3}\right) \square 7.76(\mathrm{~d}, J=7.4 \mathrm{~Hz}, 2 \mathrm{H}), 7.62(\mathrm{dd}, J=7.2,16.2 \mathrm{~Hz}, 2 \mathrm{H})$, 7.28-7.45 (m, 4H), 6.74-6.88 (m, 4H), 4.02-4.33 (m, 4H), 3.52-3.65 (m, 1H), 3.02-3.19 $(\mathrm{m}, 1 \mathrm{H}), 2.38(\mathrm{~d}, J=21.7 \mathrm{~Hz}, 12 \mathrm{H}), 2.19(\mathrm{~d}, J=10.7 \mathrm{~Hz}, 6 \mathrm{H}) .{ }^{13} \mathrm{C}$ NMR $(100 \mathrm{MHz}$, $\left.\mathrm{CDCl}_{3}\right) \square 176.36(\mathrm{~s}), 156.27(\mathrm{~s}), 144.00\left(\mathrm{~d}, J_{\mathrm{CP}}=17.8 \mathrm{~Hz}\right), 141.46\left(\mathrm{~d}, J_{\mathrm{CP}}=5.7 \mathrm{~Hz}\right)$, $140.88(\mathrm{~s}), 139.58\left(\mathrm{~d}, J_{\mathrm{CP}}=10 \mathrm{~Hz}\right), 132.63\left(\mathrm{~d}, J_{\mathrm{CP}}=10.3 \mathrm{~Hz}\right), 132.00\left(\mathrm{~d}, J_{\mathrm{CP}}=8.9 \mathrm{~Hz}\right)$, $127.97(\mathrm{~s}), 127.40(\mathrm{~s}), 125.80\left(\mathrm{~d}, J_{\mathrm{CP}}=20 \mathrm{~Hz}\right), 120.16(\mathrm{~s}), 67.84(\mathrm{~s}), 52.40(\mathrm{~s}), 47.20(\mathrm{~s})$, $40.40\left(\mathrm{~d}, J_{\mathrm{CP}} 51.8 \mathrm{~Hz}\right), 23.65\left(\mathrm{~d}, J_{\mathrm{CP}}=9.8 \mathrm{~Hz}\right), 21.05\left(\mathrm{~d}, J_{\mathrm{CP}}=5.7 \mathrm{~Hz}\right) .{ }^{31} \mathrm{P} \mathrm{NMR}(120$ $\left.\mathrm{MHz}, \mathrm{CDCl}_{3}\right) \square$ 39.83. IR (KBr, cm $\left.{ }^{-1}\right)$ 3294, 3025, 2967, 2924, 1725, 1604, 1517, 1450, 
1401, 1247, 1046, 910, 851, 759, 739, 648. FAB-MS; [M + H] calcd. 612.2337, obsd. 612.2331. $\mathrm{R} f=0.32(3 \% \mathrm{MeOH}$ in $\mathrm{DCM})$

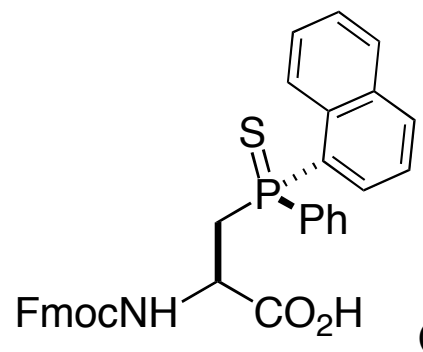

$(\mathbf{S 4 2})$

${ }^{1} \mathrm{H}$ NMR $\left(300 \mathrm{MHz}, \mathrm{CDCl}_{3}\right) \square 8.20(\mathrm{~d}, J=7.4 \mathrm{~Hz}, 1 \mathrm{H}), 8.14(\mathrm{~d}, J=6.3 \mathrm{~Hz}, 1 \mathrm{H}), 7.95(\mathrm{~d}$, $J=8.2 \mathrm{~Hz}, 1 \mathrm{H}), 7.78-7.87(\mathrm{~m}, 2 \mathrm{H}), 7.76(\mathrm{~d}, J=7.7 \mathrm{~Hz}, 3 \mathrm{H}), 7.46-7.54(\mathrm{~m}, 3 \mathrm{H}), 7.35-$ $7.54(\mathrm{~m}, 6 \mathrm{H}), 7.25-7.54(\mathrm{~m}, 3 \mathrm{H}), 6.03(\mathrm{~d}, J=6.6 \mathrm{~Hz}, 1 \mathrm{H}), 4.61-4.75(\mathrm{~m}, 1 \mathrm{H}), 3.92-4.10$ (m, 3H), 3.45-3.62 (m, 1H), 3.28-3.62 (m, 1H). ${ }^{13} \mathrm{C}$ NMR (100 MHz, $\left.\mathrm{CDCl}_{3}\right) \square 175.13(\mathrm{~d}$, $\left.J_{\mathrm{CP}}=12.8 \mathrm{~Hz}\right), 155.96(\mathrm{~s}), 143.92(\mathrm{~s}), 143.85(\mathrm{~s}), 141.44(\mathrm{~s}), 134.32\left(\mathrm{~d}, J_{\mathrm{CP}}=9.2 \mathrm{~Hz}\right)$ $133.97(\mathrm{~s}), 133.63\left(\mathrm{~d}, J_{\mathrm{CP}}=10.9 \mathrm{~Hz}\right), 133.24(\mathrm{~s}), 132.13(\mathrm{~s}), 131.80(\mathrm{~s}), 131.14\left(\mathrm{~d}, J_{\mathrm{CP}}=\right.$ $10.9 \mathrm{~Hz}), 129.66(\mathrm{~s}), 129.31\left(\mathrm{~d}, J_{\mathrm{CP}}=12.3 \mathrm{~Hz}\right), 127.98(\mathrm{~s}), 127.37(\mathrm{~s}), 126.64(\mathrm{~s}), 126.47$ (s), $125.61(\mathrm{~s}), 124.97(\mathrm{~s}), 124.78(\mathrm{~s}), 120.18(\mathrm{~s}), 67.68(\mathrm{~s}), 50.82(\mathrm{~s}), 47.06(\mathrm{~s}), 32.80(\mathrm{~d}$, $\left.J_{\mathrm{CP}}=58.1 \mathrm{~Hz}\right) .{ }^{31} \mathrm{P}$ NMR $\left.\left(120 \mathrm{MHz}, \mathrm{CDCl}_{3}\right)\right] 38.20 . \mathrm{IR}\left(\mathrm{KBr}, \mathrm{cm}^{-1}\right)$ 3300, 3059, 2588, 1719, 1508, 1449, 1437, 1332, 1250, 773, 760, 741. FAB-MS; [M + Li] calcd. 584.1637, obsd. 584.1625. $\mathrm{R} f=0.2(2 \% \mathrm{MeOH}$ in $\mathrm{DCM})$

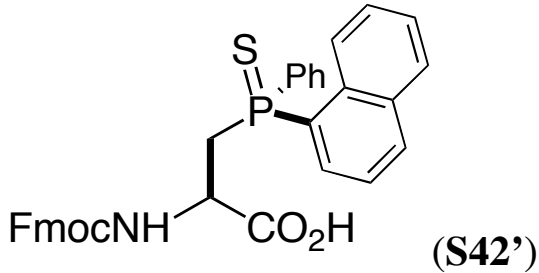


${ }^{1} \mathrm{H}$ NMR $\left(300 \mathrm{MHz}, \mathrm{CDCl}_{3}\right) \square 8.33(\mathrm{~d}, J=8.2 \mathrm{~Hz}, 1 \mathrm{H}), 8.06(\mathrm{dd}, J=7.2,16.2 \mathrm{~Hz}, 1 \mathrm{H})$, $7.97(\mathrm{~d}, J=8.2 \mathrm{~Hz}, 1 \mathrm{H}), 7.80-7.90(\mathrm{~m}, 2 \mathrm{H}), 7.74(\mathrm{~d}, J=8.1 \mathrm{~Hz}, 3 \mathrm{H}), 5.89(\mathrm{~d}, J=7.1 \mathrm{~Hz}$, $1 \mathrm{H}), 4.81-4.95(\mathrm{~m}, 1 \mathrm{H}), 3.83-4.17(\mathrm{~m}, 3 \mathrm{H}), 3.34-3.54(\mathrm{~m}, 2 \mathrm{H}) .{ }^{13} \mathrm{C}$ NMR $(100 \mathrm{MHz}$, $\left.\mathrm{CDCl}_{3}\right) \square 175.76(\mathrm{~s}), 155.88(\mathrm{~s}), 143.88(\mathrm{~s}), 141.42(\mathrm{~s}), 134.50\left(\mathrm{~d}, J_{\mathrm{CP}}=9.2 \mathrm{~Hz}\right), 133.91$ $(\mathrm{s}), 133.30(\mathrm{~s}), 132.42(\mathrm{~s}), 132.22(\mathrm{~s}), 132.04\left(\mathrm{~d}, J_{\mathrm{CP}}=8.9 \mathrm{~Hz}\right), 131.89(\mathrm{~s}), 131.34\left(\mathrm{~d}, J_{\mathrm{CP}}\right.$ $=11.1 \mathrm{~Hz}), 129.66(\mathrm{~s}), 128.97\left(\mathrm{~d}, J_{\mathrm{CP}}=12.9 \mathrm{~Hz}\right), 127.98(\mathrm{~s}), 127.35(\mathrm{~s}), 126.71(\mathrm{~s})$, $126.49\left(\mathrm{~d}, J_{\mathrm{CP}}=8.0 \mathrm{~Hz}\right), 125.63(\mathrm{~s}), 124.85(\mathrm{~s}), 124.67(\mathrm{~s}), 120.16(\mathrm{~s}), 67.61(\mathrm{~s}), 50.64$ (s), $47.03(\mathrm{~s}), 33.00\left(\mathrm{~d}, J_{\mathrm{CP}}=54.4 \mathrm{~Hz}\right) \cdot{ }^{31} \mathrm{P}$ NMR $\left(120 \mathrm{MHz}, \mathrm{CDCl}_{3}\right) \square$ 37.56. IR $(\mathrm{KBr}$, $\left.\mathrm{cm}^{-1}\right) 3305,3058,2588,1718,1508,1450,1437,1332,1251,1102,1048,908,798,773$, 760, 740. FAB-MS; $[\mathrm{M}+2 \mathrm{Li}-\mathrm{H}]$ calcd. 590.1719, obsd. 590.1710. $\mathrm{R} f=0.2(2 \% \mathrm{MeOH}$ in DCM)

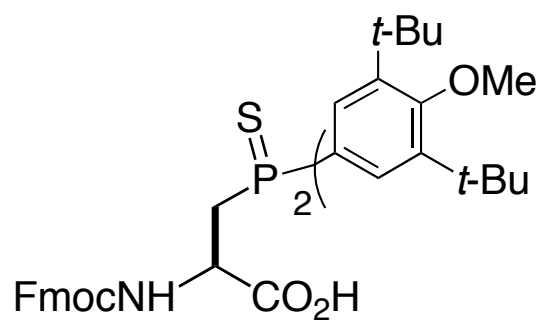

(S43)

${ }^{1} \mathrm{H}$ NMR (300 MHz, $\left.\mathrm{CDCl}_{3}\right)$ ] 7.69-7.82 (m, 6H), 7.55-7.62 (m, 2H), 7.23-7.40 (m, 4H), $6.48(\mathrm{br}-\mathrm{d}, J=4.7 \mathrm{~Hz}, 1 \mathrm{H}), 4.53-4.67(\mathrm{~m}, 1 \mathrm{H}), 4.1-4.26(\mathrm{~m}, 3 \mathrm{H}), 6.48(\mathrm{~d}, J=10.4 \mathrm{~Hz}$, $6 \mathrm{H}), 3.00-3.21(\mathrm{~m}, 2 \mathrm{H}), 1.41(\mathrm{~s}, 36 \mathrm{H}) .{ }^{13} \mathrm{C} \mathrm{NMR}\left(100 \mathrm{MHz}, \mathrm{CDCl}_{3}\right) \square 175.90\left(\mathrm{~d}, J_{\mathrm{CP}}=\right.$ $15.8 \mathrm{~Hz}), 162.98\left(\mathrm{~d}, J_{\mathrm{CP}}=12.0 \mathrm{~Hz}\right), 156.19(\mathrm{~s}), 144.73\left(\mathrm{~d}, J_{\mathrm{CP}}=12.3 \mathrm{~Hz}\right), 144.52\left(\mathrm{~d}, J_{\mathrm{CP}}=\right.$ $12.3 \mathrm{~Hz}), 143.90$ (s), 141.40 (s), 130.30 (s), 130.04 (s), 127.92 (s), 127.42 (s), 125.65 (s), $120.12(\mathrm{~s}), 67.63(\mathrm{~s}), 64.71(\mathrm{~s}), 51.43(\mathrm{~s}), 47.16(\mathrm{~s}), 36.38(\mathrm{~s}), 33.98\left(\mathrm{~d}, J_{\mathrm{CP}}=57.3 \mathrm{~Hz}\right)$, 32.13 (s). ${ }^{31}$ P NMR (120 MHz, $\left.\mathrm{CDCl}_{3}\right) \square$ 40.33. IR (KBr, cm $\left.{ }^{-1}\right)$ 3289, 2962, 1725, 1509, 
1450, 1410, 1362, 1262, 1228, 1142, 1116, 1006, 740. FAB-MS; $[\mathrm{M}+\mathrm{H}]$ calcd. 812.4114, obsd. 812.4100. $\mathrm{R} f=0.3(2 \% \mathrm{MeOH}$ in $\mathrm{DCM})$

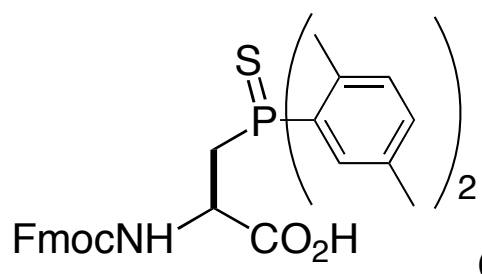

(S44)

${ }^{1} \mathrm{H}$ NMR (300 MHz, $\left.\mathrm{CDCl}_{3}\right) \square 10.01(\mathrm{br}-\mathrm{s}, 1 \mathrm{H}), 7.97$ (t, $\left.J=15.4 \mathrm{~Hz}, 2 \mathrm{H}\right), 7.76(\mathrm{~d}, J=7.2$ $\mathrm{Hz}, 2 \mathrm{H}), 7.61(\mathrm{dd}, J=7.2,15.4 \mathrm{~Hz}, 2 \mathrm{H}), 7.29-7.45(\mathrm{~m}, 4 \mathrm{H}), 7.12-7.25(\mathrm{~m}, 2 \mathrm{H}), 6.98-7.08$ (m, 2H), $6.32(\mathrm{~d}, J=6.6 \mathrm{~Hz}, 1 \mathrm{H}), 4.48-6.63(\mathrm{~m}, 1 \mathrm{H}), 4.08-4.24(\mathrm{~m}, 3 \mathrm{H}), 3.30-3.51(\mathrm{~m}$, $2 \mathrm{H}), 2.30(\mathrm{~d}, J=24.7 \mathrm{~Hz}, 6 \mathrm{H}), 2.06(\mathrm{~s}, 6 \mathrm{H}) .{ }^{13} \mathrm{C} \mathrm{NMR}\left(100 \mathrm{MHz}, \mathrm{CDCl}_{3}\right) \square 175.88(\mathrm{~d}$, $\left.J_{\mathrm{CP}}=14.1 \mathrm{~Hz}\right), 156.03(\mathrm{~s}), 143.85(\mathrm{~s}), 141.48(\mathrm{~s}), 137.45\left(\mathrm{~d}, J_{\mathrm{CP}}=11.5 \mathrm{~Hz}\right), 137.32\left(\mathrm{~d}, J_{\mathrm{CP}}\right.$ $=9.1 \mathrm{~Hz}), 136.40\left(\mathrm{~d}, J_{\mathrm{CP}}=12.6 \mathrm{~Hz}\right), 136.32\left(\mathrm{~d}, J_{\mathrm{CP}}=12.6 \mathrm{~Hz}\right), 133.09\left(\mathrm{~d}, J_{\mathrm{CP}}=6.6 \mathrm{~Hz}\right)$, $132.32\left(\mathrm{~d}, J_{\mathrm{CP}}=12.6 \mathrm{~Hz}\right), 128.03(\mathrm{~s}), 127.44\left(\mathrm{~d}, J_{\mathrm{CP}}=4.3 \mathrm{~Hz}\right), 125.70\left(\mathrm{~d}, J_{\mathrm{CP}}=16.3 \mathrm{~Hz}\right)$, $120.26(\mathrm{~s}), 67.75(\mathrm{~s}), 50.82(\mathrm{~s}), 47.12(\mathrm{~s}), 31.62\left(\mathrm{~d}, J_{\mathrm{CP}}=57.0 \mathrm{~Hz}\right), 21.30\left(\mathrm{~d}, J_{\mathrm{CP}}=10.0\right.$ $\mathrm{Hz}), 25.10\left(\mathrm{~d}, J_{\mathrm{CP}}=8.9 \mathrm{~Hz}\right) \cdot{ }^{31} \mathrm{P}$ NMR $\left(120 \mathrm{MHz}, \mathrm{CDCl}_{3}\right) \square$ 37.37. IR $\left(\mathrm{KBr}, \mathrm{cm}^{-1}\right) 3289$, $3037,2922,2599,1719,1517,1486,1450,1248,1046,909,816,740$. FAB-MS; [M + 2Li-H] calcd. 596.2188, obsd. 596.2179. $\mathrm{R} f=0.3(3 \% \mathrm{MeOH}$ in DCM)

\section{General method for solution phase peptide synthesis and phosphine deprotection:}

To a Boc-protected amino acid in DCM was added 1.5 equiv. of PyBOP and an ammonium salt of an amino ester. 3 equiv. of DIPEA were added and the reaction was allowed to stir for 30 minutes. The reaction mixture was then washed with $3 \mathrm{~N} \mathrm{HCl}$, sat. sodium bicarb., and brine. The DCM solution was dried with $\mathrm{Na}_{2} \mathrm{SO}_{4}$, filtered, 
concentrated and chromatographed on silica gel. The Boc-methyl ester protected dipeptide was then treated with a 50\% solution of TFA in DCM until complete removal of the Boc group as judged by TLC. The reaction mixture was then concentrated, dissolved in toluene and concentrated, dissolved in chloroform and concentrated and finally dissolved in DCM and concentrated before drying in-vacuo for 30 minutes. This coupling/deprotection sequence was repeated until the desired Boc-methyl ester protected six-mer. was attained.

$10 \square \mathrm{mol}$ of the bis-phosphine ligands were treated with $400 \mathrm{mg}$ of Raney-Ni* in MeCN (under $\mathrm{N}_{2}$ ) for 2 hours (6-membered ring) or until complete by TLC (5-membered ring). The Raney-Ni was allowed to settle and the solution was syringe filtered into a schlenk tube. The Raney-Ni was washed with MeCN 3 X $3 \mathrm{~mL}$ and syringe filtered into the schlenk tube and concentrated in-vacuo.

"Prior to deprotection, the Raney-Ni slurry was washed with $\mathrm{MeOH}$ until the $\mathrm{MeOH}$ was clear and then washed with $\mathrm{MeCN} 3 \mathrm{X}$.

\section{Spectral data of peptide ligands:}

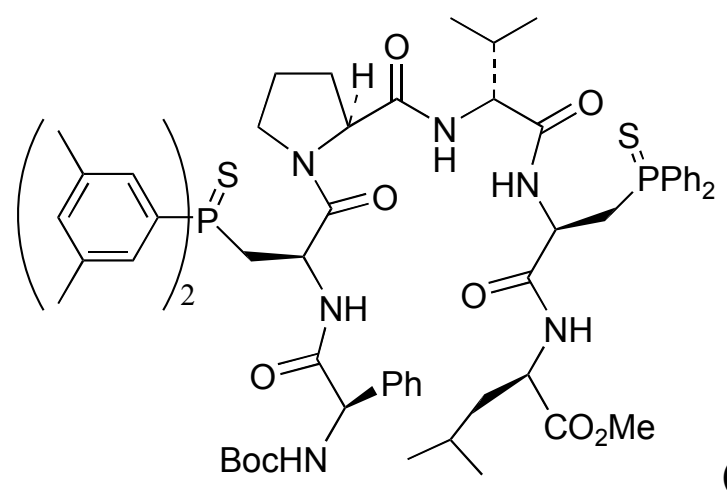

(83)

${ }^{1} \mathrm{H}$ NMR (600 MHz, $\left.\mathrm{CDCl}_{3}\right) \square 7.68-7.83$ (m, 3H), 7.20-7.50 (m, 20H), 7.08 (s, 2H), 5.57-

$5.62(\mathrm{~m}, 1 \mathrm{H}), 4.90-5.00(\mathrm{~m}, 1 \mathrm{H}), 4.70-4.80(\mathrm{~m}, 1 \mathrm{H}), 4.60-4.64(\mathrm{~m}, 1 \mathrm{H}), 4.35-4.42(\mathrm{~m}$, 
2H), 3.88-3.94 (m, 1H), 3.68 (s, 3H), 3.44-3.50 (br-s, 2H), 3.27-3.35 (m, 1H), 3.11-3.20 (m, 1H), 2.95-3.04 (m, 2H), $2.30(\mathrm{~s}, 6 \mathrm{H}), 2.27(\mathrm{~s}, 6 \mathrm{H}), 2.14-2.22(\mathrm{~m}, 1 \mathrm{H}), 1.95-2.40(\mathrm{~m}$, $2 \mathrm{H}), 1.80-1.86(\mathrm{~m}, 1 \mathrm{H}), 1.46-1.62(\mathrm{~m}, 4 \mathrm{H}), 1.37-1.44(\mathrm{~m}, 9 \mathrm{H}), 0.80-0.92(\mathrm{~m}, 12 \mathrm{H}) .{ }^{13} \mathrm{C}$ NMR $\left(100 \mathrm{MHz}, \mathrm{CDCl}_{3}\right) \square 173.05,171.81,170.98,170.67,170.51,170.28,170.11$, $170.02,155.07,138.53,138.49,138.44,138.41,133.68,133.60,132.65,132.13,131.93$, $131.66,131.55,131.40,131.20,131.12,131.04,128.77,128.69,128.64,128.56,128.50$, $128.44,128.37,128.14,127.86,127.80,127.17,79.97,60.91,58.75,58.28,52.12,51.09$, $49.46,48.39,47.50,40.57,33.31,32.93,28.86,28.22,24.96,24.56,22.59,22.00,21.79$, 21.24, 21.18, 19.77, 17.58. ${ }^{31} \mathrm{P}$ NMR (120 MHz, $\left.\mathrm{CDCl}_{3}\right) \square$ 43.67, 40.67. IR ( $\left.\mathrm{KBr}, \mathrm{cm}^{-1}\right)$ 3300, 3042, 2952, 2924, 2868, 1737, 1676, 1519, 1435, 1362, 1242, 1161, 848, 691. MALDI-MS; calcd. 1204.5, obsd. [M + Na] 1227.5.

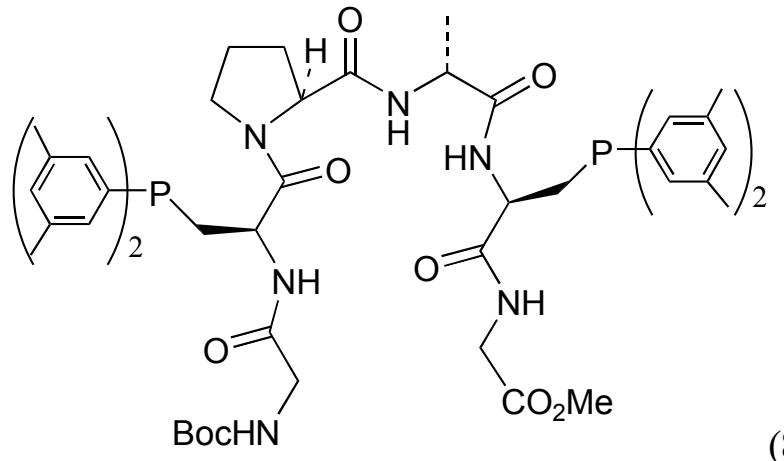

(84)

${ }^{1} \mathrm{H}$ NMR (300 MHz, $\left.\mathrm{CDCl}_{3}\right) \square 7.38-7.63$ (m, 10H), 7.05-7.15 (m, 4H), 6.84 (br-d, $J=5.8$ Hz, 1H), 6.70 (br-d, $J=7.4 \mathrm{~Hz}, 1 \mathrm{H}), 5.20-5.30$ (m, 1H), 4.60-4.79 (m, 2H), 4.19-4.25 (m, 1H), 3.89-4.09 (m, 2H), 3.68-3.83 (m, 4H), $3.57(\mathrm{~s}, 3 \mathrm{H}), 3.22-3.51(\mathrm{~m}, 3 \mathrm{H}), 3.09-3.22$ (m, 2H), 2.85-3.01 (m, 1H), 2.27-2.37 (m, 24H), 1.80-2.15 (m, 4H), $1.42(\mathrm{~s}, 9 \mathrm{H}), 1.11(\mathrm{~d}$ $J=7.1 \mathrm{~Hz}, 3 \mathrm{H}) .{ }^{13} \mathrm{C}$ NMR $\left(150 \mathrm{MHz}, \mathrm{CDCl}_{3}\right) \square 172.34,171.82,171.00,170.92,170.62$, $170.53,169.97,168.43,155.43,138.57,138.53,138.48,138.45,138.37,138.22,138.14$, $133.53,133.46,133.21,132.43,131.89,131.58,131.06,128.96,128.89,128.77,128.69$, 
$128.63,128.57,128.35,128.28,128.06,79.82,61.11,52.02,50.24,50.09,47.74,46.86$,

$43.45,41.07,34.63,34.27,32.50,32.12,28.44,28.23,25.05,21.23,21.21,16.02 .{ }^{31} \mathrm{P}$

NMR (120 MHz, $\left.\mathrm{CDCl}_{3}\right) \square 40.65$, 39.57. IR (KBr, cm $\left.{ }^{-1}\right)$ 3294, 3025, 2975, 2919, 2241,

$1748,1715,1667,1525,1441,1362,1239,1208,1166,1122,1041,848,727,691,632$.

MALDI-MS; calcd. 1100.4434, obsd. [M + Na] 1123.67.

\section{References}

(1) Papaioannou, D.; Stavropoulos, G.; Karagiannis, K.; Francis, G. W.;

Brekke, T.; Aksnes, D. W. Acta Chemica Scandinavica 1990, 44, 243-247.

(2) Peters, G. J. Am. Chem. Soc. 1960, 82, 4751-4752.

(3) Greenfield, S. J.; Gilbertson, S. R. Synthesis 2001, 2337-2340.

(4) Gilbertson, S. R.; Chen, G.; McLoughlin, M. J. Am. Chem. Soc. 1994, $116,4481-4482$.

(5) Henderson, W. A.; Buckler, S. A.; Day, N. E.; Grayson, M. J. Org. Chem. 1961, 26, 4770-4771.

(6) Casalnuovo, A. L.; RajanBabu, T. V.; Ayers, T. A.; Warren, T. H. J. Am. Chem. Soc. 1994, 116, 9869.

(7) Teunissen, H. T.; Hansen, C. B.; Bickelhaupt, F. Phosphorus, Sulfur and Silicon, 1996, 118, 309.

(8) Chung, Y. J.; Huck, B. R.; Christianson, L. A.; Stanger, H. E.;

Krauthauser, S.; Powell, D. R.; Gillman, S. H. J. Am. Chem. Soc. 2000, 122, 3995-4004. 